\title{
Using theoretical perspectives to predict the size of addressable markets for mobile payment systems
}

By

\section{Verónica Giggey}

\begin{abstract}
A thesis submitted to the Faculty of Graduate Studies and Research in partial fulfillment of the requirements for the degree of Master of Applied Science in Technology Innovation Management
\end{abstract}

Department of Systems and Computer Engineering,

Carleton University

Ottawa, Ontario

CANADA

July 2006

Copyright @ July 2006, Verónica Giggey 


$\begin{array}{ll}\begin{array}{l}\text { Library and } \\ \text { Archives Canada }\end{array} & \begin{array}{l}\text { Bibliothèque et } \\ \text { Archives Canada }\end{array} \\ \begin{array}{l}\text { Published Heritage } \\ \text { Branch }\end{array} & \begin{array}{l}\text { Direction du } \\ \text { Patrimoine de l'édition }\end{array} \\ \begin{array}{l}\text { 395 Wellington Street } \\ \text { Ottawa ON K1A ON4 }\end{array} & \begin{array}{l}\text { 395, rue Wellington } \\ \text { Ottawa ON K1A ON4 } \\ \text { Canada }\end{array}\end{array}$

Your file Votre référence ISBN: 978-0-494-18314-4 Our file Notre référence ISBN: 978-0-494-18314-4

NOTICE:

The author has granted a nonexclusive license allowing Library and Archives Canada to reproduce, publish, archive, preserve, conserve, communicate to the public by telecommunication or on the Internet, loan, distribute and sell theses worldwide, for commercial or noncommercial purposes, in microform, paper, electronic and/or any other formats.

The author retains copyright ownership and moral rights in this thesis. Neither the thesis nor substantial extracts from it may be printed or otherwise reproduced without the author's permission.
AVIS:

L'auteur a accordé une licence non exclusive permettant à la Bibliothèque et Archives Canada de reproduire, publier, archiver, sauvegarder, conserver, transmettre au public par télécommunication ou par l'Internet, prêter, distribuer et vendre des thèses partout dans le monde, à des fins commerciales ou autres, sur support microforme, papier, électronique et/ou autres formats.

L'auteur conserve la propriété du droit d'auteur et des droits moraux qui protège cette thèse. $\mathrm{Ni}$ la thèse ni des extraits substantiels de celle-ci ne doivent être imprimés ou autrement reproduits sans son autorisation.
In compliance with the Canadian

Privacy Act some supporting forms may have been removed from this thesis.

While these forms may be included in the document page count, their removal does not represent any loss of content from the thesis.
Conformément à la loi canadienne sur la protection de la vie privée, quelques formulaires secondaires ont été enlevés de cette thèse.

Bien que ces formulaires aient inclus dans la pagination, il n'y aura aucun contenu manquant.

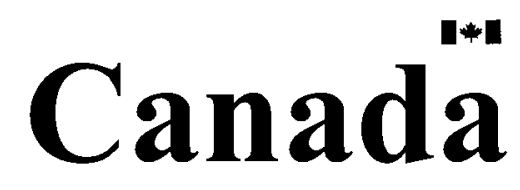




\section{Abstract}

The objective of this research is to develop a method to estimate the size of emerging markets, for which abundant and convincing data are not available. The adoption of mobile payment services in South America is modeled using a stochastic analysis tool, staged estimation procedure and historical data. Adoption curves are estimated using dimensions traditionally used in the literature and construct dimensions derived using three complementary theoretical perspectives. The proposed method is first tested using adoption data for regions for which mobile payments exist. The method is then applied to South America, a region in which mobile payments have not been deployed. The results and lessons learned from the application of the method are used to propose modifications to the method. 


\section{Acknowledgements}

First and foremost, I would like to thank my thesis supervisor, Professor Tony Bailetti. I have learned an invaluable amount from him, and these are lessons I can carry with me and apply beyond my studies. His support and dedication are greatly appreciated and without his vision, this project would have never begun. I would also like to acknowledge Professor John Callahan, who was always available and kept me on track so I would conduct good research.

I would also like to thank the team at Nortel Networks that contributed significantly to this research, especially Thomas Chmara, Jennie McCloskey and Bruce Wallace. Their feedback and insights continuously shaped this project and without their contribution we would not have obtained the same results. Nortel's financial support for the development of this thesis is also gratefully acknowledged.

I would also like to thank my mother, who has always supported me in everything that I do and who is a continuous inspiration in my life. My family has always set high standards for themselves and has showed me the value of education and research.

This effort is as much mine as it is my husband's, Robert. Thank your for everything, including editing every draft and presentation for the past two years. Finally, to my son Alejandro, for simply being him. 


\section{Table of Contents}

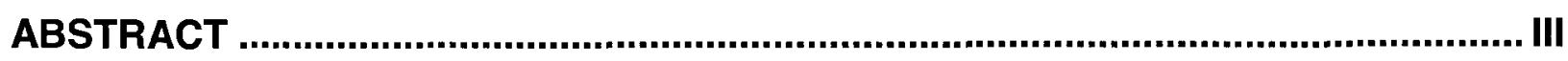

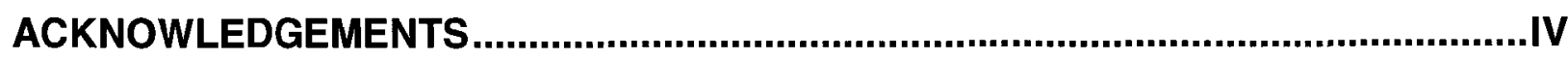

LIST OF TABLES .....................................................................................................

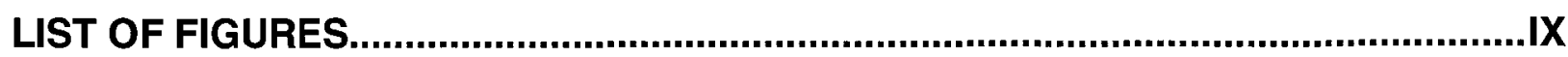

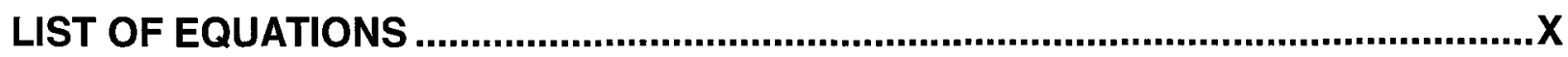

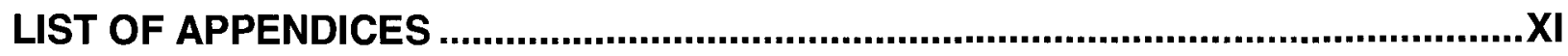

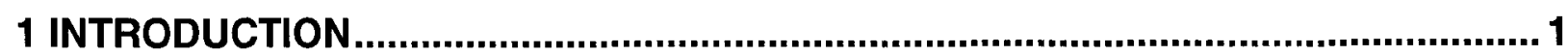

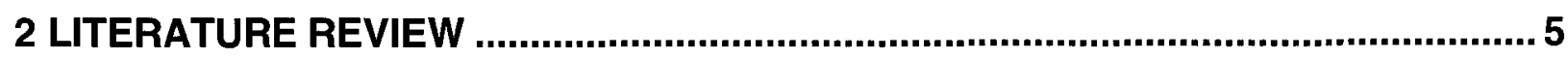

2.1 Successful Innovation in High-Technology Service Development .................. 5

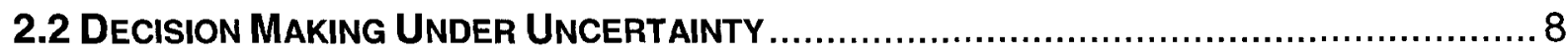

2.2.1 The Four Levels of Uncertainty ........................................................ 11

2.3 GLobal Diffusion ReSEARCH AND ModelS ................................................. 14

2.3.1 Existing Generalizations in Global Diffusion ...................................... 15

2.3.2 Existing Biases in Global Diffusion .................................................... 16

2.3.3 Diffusion Model Considerations ................................................... 17

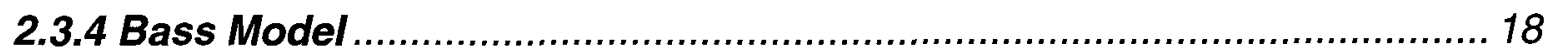

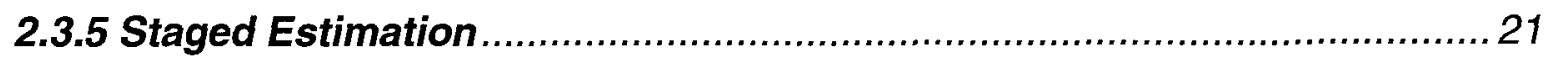

2.3.6 Other Diffusion Models Considerations............................................. 25

2.4 LESSONS LEARNED FROM THE LITERATURE REVIEW.........................................27

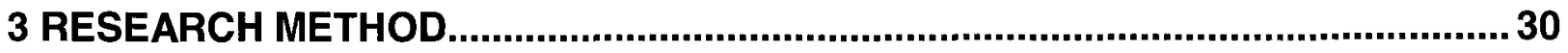

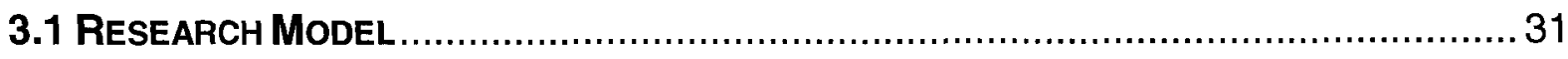

3.2 Selecting Theoretical Perspectives and Cases .......................................... 33 


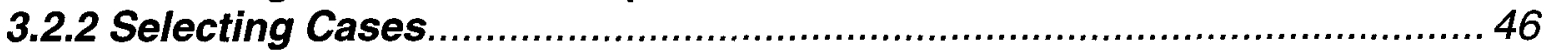

3.3 Identify Traditional Literature, Construct and Control Dimensions ............50

3.3.1 Dimensions from the Literature ......................................................5

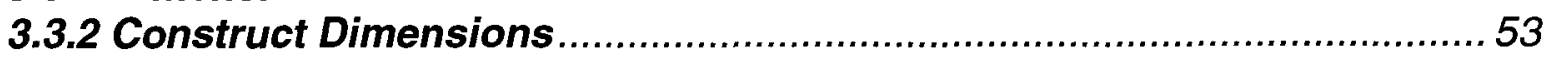

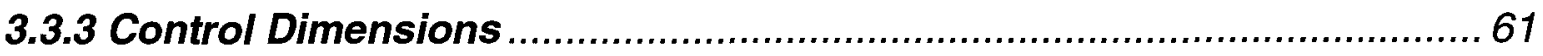

3.4 IDENTIFY AND OPERATIONALIZE RegIONS to Be AdDRESSED..................................6 63

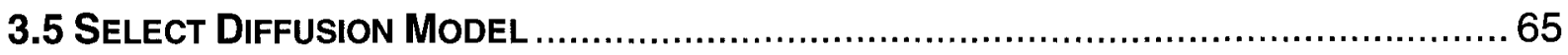

3.6 Use Theoretical Perspectives and Dimensions to Define the InPUTS OF the

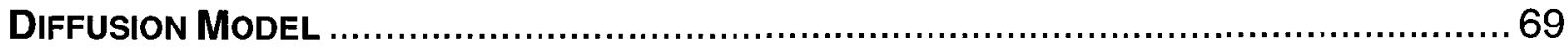

3.7 Use Historical Data and Theoretical Insights to Estimate the Parameters of THE DIFFUSION MODEL.............................................................................. 76

3.7.1 The Case of the Japanese Operators .................................................. 79

3.7.2 The Case of the South Korean Operators ............................................ 87

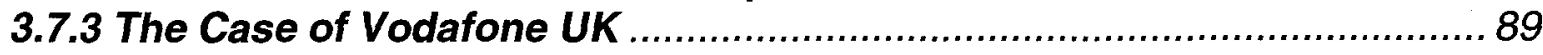

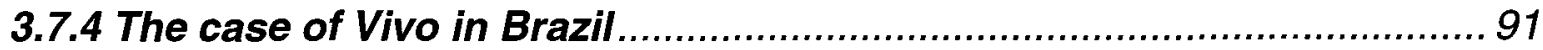

3.8 Use Estimated Parameters and Model to Predict Size of Addressable

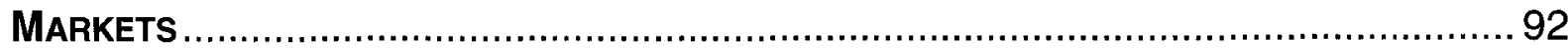

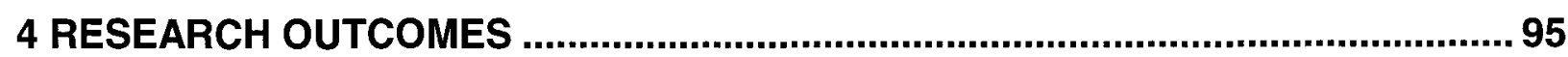

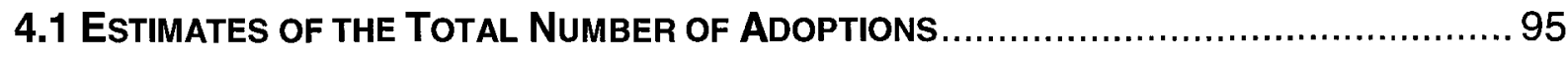

4.2 Method to Incorporate Theoretical Constructs ..................................... 110

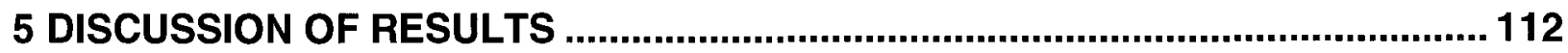

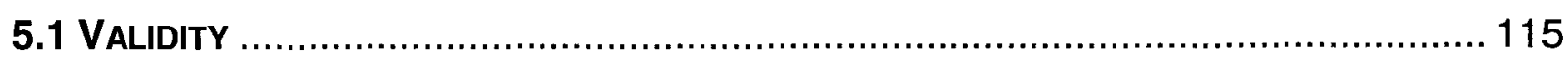

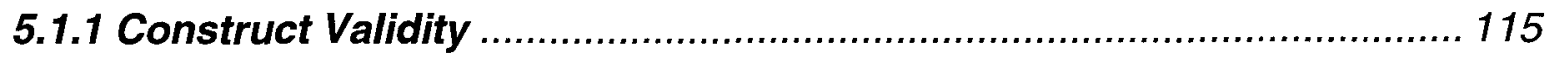

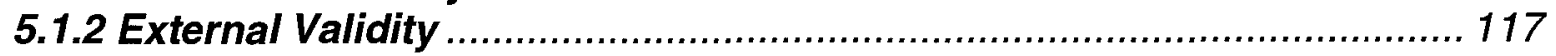

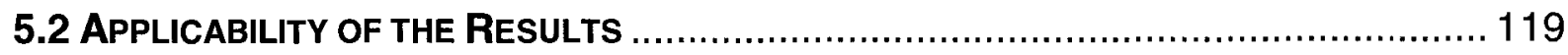

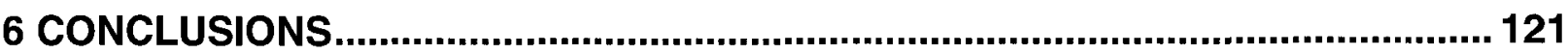

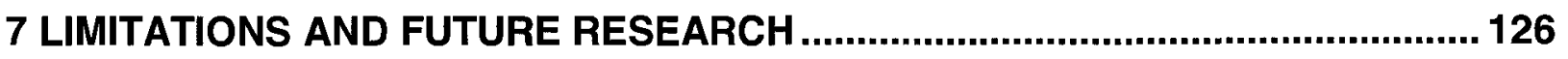




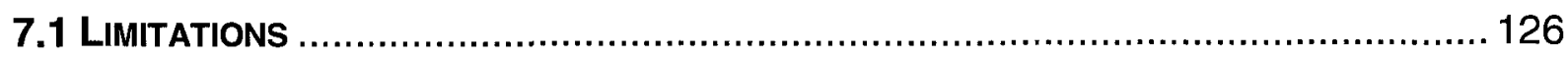

7.2 Proposed Changes to the Method ..................................................... 127

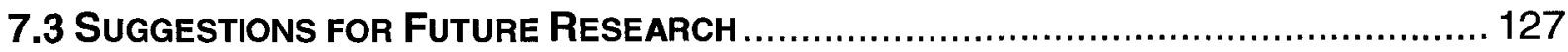

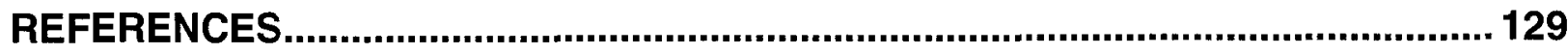




\section{List of Tables}

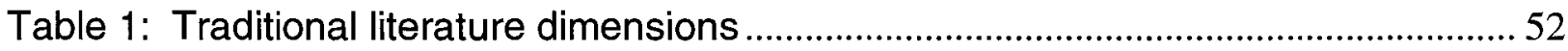

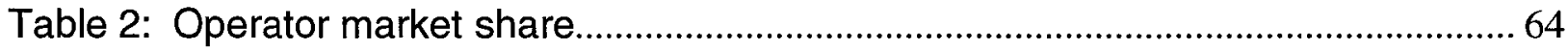

Table 3: Definition of social system and ceiling for developed nations ............................. 72

Table 4: Definition of social system and ceiling for developing nations .......................... 75

Table 5: Difference between forecast and actual adoptions for the case of..................... 82

Table 6: i-mode forecast with two years of adoption data ................................................. 83

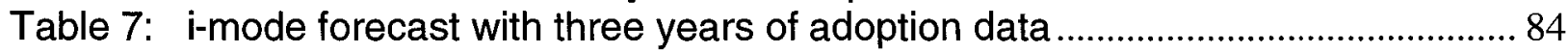

Table 8: i-mode forecast with four years of adoption data .............................................. 85

Table 9: i-mode forecast with five years of adoption data ................................................. 85

Table 10: i-mode forecast with six years of sales data ..................................................... 86

Table 11: Difference between forecast and actual adoptions for the case of Magic @...89

Table 12: Difference between forecast and actual adoptions for the case of Vivo.......... 92

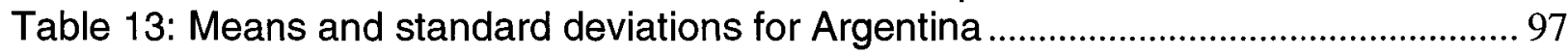

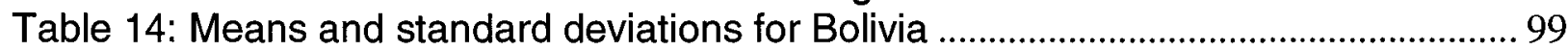

Table 15: Means and standard deviations for Brazil .................................................... 100

Table 16: Means and standard deviations for Chile ....................................................... 102

Table 17: Means and standard deviations for Colombia ................................................ 103

Table 18: Means and standard deviations for Ecuador .................................................... 104

Table 19: Means and standard deviations for Paraguay ................................................. 106

Table 20: Means and standard deviations for Peru........................................................ 107

Table 21: Means and standard deviations for Uruguay ................................................... 108

Table 22: Means and standard deviations for Venezuela .............................................. 109

Table 23: Summary of the results for available cases ................................................... 113

Table 24: Summary of results for Latin American forecast ................................................ 115 


\section{List of Figures}

Figure 1: Idea development time line........................................................................ 2

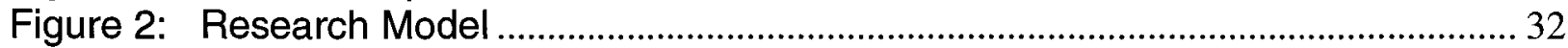

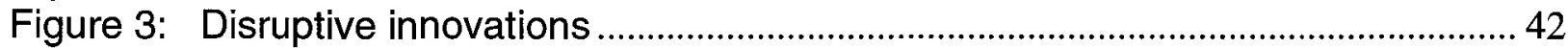

Figure 4: Mobile Internet - a disruptive innovation ................................................... 43

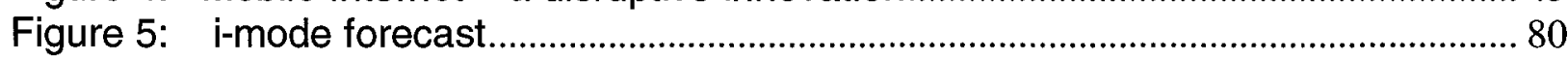

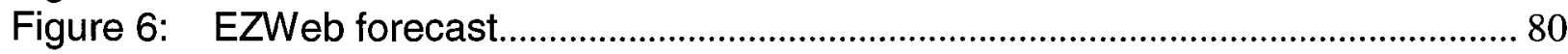

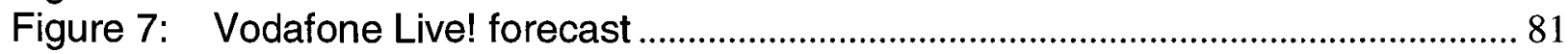

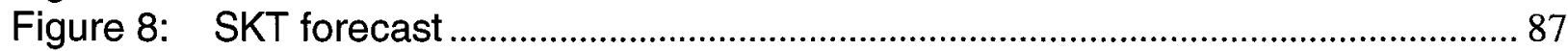

Figure 9: Magic @ forecast ........................................................................................ 89

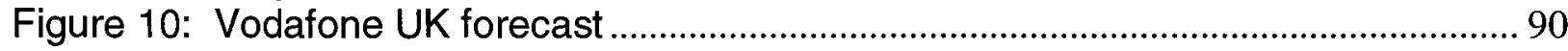

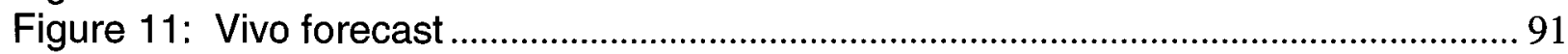

Figure 12: Assumption 1- Time origin intercept, A .................................................... 93

Figure 13: Argentina forecast (mean values from 1000 trials) ..................................... 96

Figure 14: Bolivia forecast (mean values from 1000 trials) ............................................ 98

Figure 15: Brazil forecast (mean values from 1000 trials) .......................................... 99

Figure 16: Chile forecast (mean values from 1000 trials) ............................................ 101

Figure 17: Colombia forecast (mean values from 1000 trials) ...................................... 102

Figure 18: Ecuador forecast (mean values from 1000 trials) ...................................... 103

Figure 19: Paraguay forecast (mean values from 1000 trials) ...................................... 105

Figure 20: Peru forecast (mean values from 1000 trials) ............................................. 106

Figure 21: Uruguay forecast (mean values from 1000 trials)....................................... 108

Figure 22: Venezuela forecast (mean values from 1000 trials) .................................... 109 


\section{List of Equations}

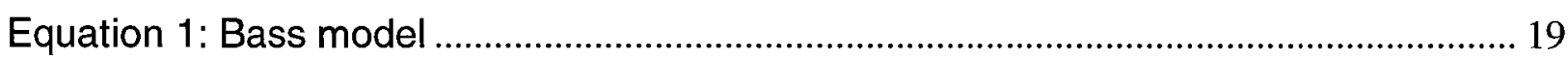

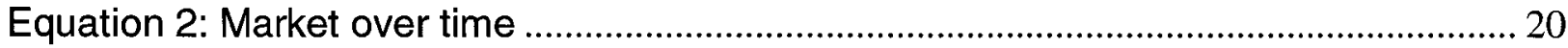

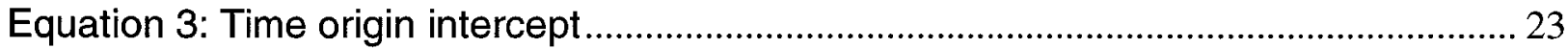

Equation 4: Staged estimation model .......................................................................... 24

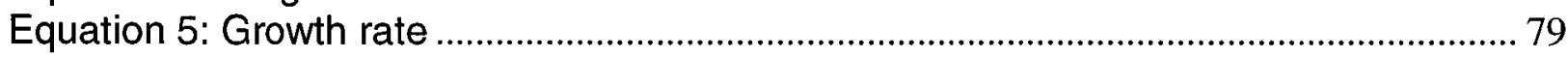




\section{List of Appendices}

Appendix A: Growth Rate Distributions ........................................................................ 134

Appendix B: Example of Crystal Ball Results ............................................................. 135 


\section{Introduction}

Global diffusion model research has focused on: (i) a single market or region; (ii) the diffusion of products, specifically consumer durables; and (iii) developed nations (Dekimpe, Parker and Sarvary, 2000c). This research examines the diffusion of innovative services in South America. It is an attempt to fill the gaps in the existing literature.

The objective of this research is to develop a method to estimate the size of emerging markets, for which abundant and convincing data are not available. The method is first tested in areas for which adoption data is available, then used to estimate the addressable market for mobile payments in South America. The lessons learned from applying the method are used to improve it.

Figure 1 shows that when the idea for a market opportunity is first introduced there are no market metrics available to base decisions on. By the time there is enough market information available a lot of time and money could have been spent on an unprofitable opportunity or a profitable opportunity could be overlooked for fear of a bad investment. The method developed in this research is designed to lead to better decisions, cost savings and first mover advantages. 
Figure 1: Idea development time line

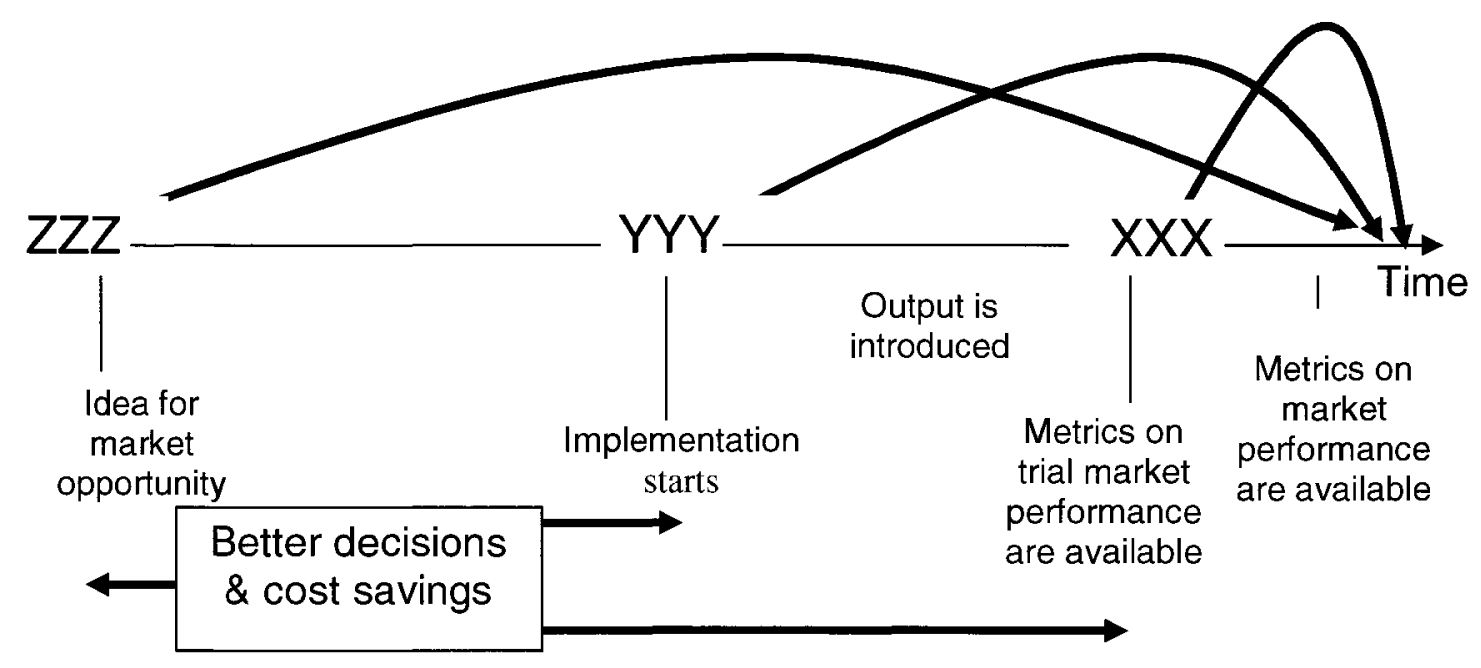

This research builds on the research conducted by Ashraf (2005). His research generated a set of construct dimensions thought to increase the probability of adoption of mobile payments. These construct dimensions were incorporated into a diffusion model's parameters and used to estimate the adoption of mobile payments for South America. Adoptions were also estimated using dimensions that have been extracted from the literature.

This research will be relevant to academics interested in predicting the diffusion of new operator services in developing nations. Top management teams of established network operators, new entrants, equipment suppliers and venture capitalist; will be able to apply the proposed method to assess the attractiveness of new or emerging markets and make better decisions early on, when little or no data are available. 
The outcomes of this research are:

1. Estimates of the sales curves at time period $t$ for each of the countries in South America using; (i) traditional literature dimensions; and (ii) construct dimensions.

2. A method to incorporate theoretically based insights into the parameters of diffusion models.

This research will contribute to the existing literature by providing a method to estimate market size for innovative services in markets for which there is a lack of abundant or convincing data. The use of theoretical perspectives and analogies can also be used, in a more general level, to address problems in situations where there is no abundant and reliable data.

The intent is also to operationalize a set of constructs that can be used to provide inputs to analytical tools. This can help managers make decisions by performing simulations on spreadsheet models. A method is only as good as it is applicable, in order for it to be useful it needs to be intuitive and compatible with what is currently in use by executives and analysts. 
This research also contributes by creating a link between a theoretical construct and a diffusion model dimension, which can be used to derisk situations in which there is a lack of data.

The rest of this paper is organized as follows:

- Section 2 is a review of the existing literature.

- Section 3 explains the research model and the research method.

- Section 4 contains the research outcomes.

- Section 5 is a discussion of the results, research validity and managerial implications.

- Section 6 outlines the major conclusions

- Section 7 contains the limitations and future areas of research. 


\section{Literature Review}

This chapter is organized into four sections. The first section reviews the literature on successful innovation in high-technology service development. The role of information gathering and how it relates to innovation success is examined. The second section is an overview of the decision making process under conditions of uncertainty. This covers the major issues that executives face as well as current tools available. The third section is an overview of the global diffusion literature. Existing generalizations and biases are outlined as well as an overview of the Bass Model and improvements on its parameter estimations. The final section is a summary of the most important lessons learned from the literature review.

\subsection{Successful Innovation in High-Technology Service Development}

High-technology services have been defined as services that involve the use of information and communication technology, ICT (van Riel, Lemmink and Ouwersloot, 2004). Due to the fast pace of technological developments and market globalization, most high-technology service providers currently experience hyper competition and exceptional turbulence in their market places (Bogner and Barr, 2000; D'Aveni, 1994, 1995). These issues have turned hightechnology service innovation into a risky matter. Substantial investments are needed for the development of services and failure rates are high. It is crucial to increase innovation success rates (van Riel et al., 2004). 
De Brentani and Ragot (1996) use a SWOT analysis to distinguish between external and internal innovation success factors. External factors are benefits of the new service as seen by customers (i.e., how well a new service addresses opportunities and threats in the market environment or how well it complements or supplements existing products and services). Internal success factors are associated with the firm's competencies and they affect consumer benefit only indirectly (Storey and Easingwood, 1993). Things such as the competence to innovate, the organization of the firm's new service development process, appropriate organizational structure and decision architecture have all been found to contribute substantially to innovation success (van Riel et al., 2004). Other internal innovation success factors are the amount and quality of the conducted market research, development speed, technological advantage and a synergy between the new service and the organization (van Riel et al., 2004). Rapid technological change and turbulence in the market place increase the importance of these internal success factors (Barney, 1991).

Available research has focused on the external success factors (Edvardsson, Haglund, and Mattsson, 1995). One of the most important, but highly under researched, internal success factors is organizational decision making (March, 1991). The intangibility of the end product and generally high levels of uncertainty complicate decision making for high-technology service innovation (van Riel et al., 2004). How well organizations succeed in reducing the uncertainty which surrounds innovation managers affects their decision-making 
effectiveness (Galbraith, 1973, 1974). Better decision-making in new service development projects therefore will improve project success (Shapira, 1997; Simon, 1997) and innovation success rates (Cooper and Edgett, 1996).

Information plays an important role in the reduction of managerial uncertainty in high-technology service innovation processes (Lievens and Moenaert, 2000). Factors dealing with the role of information are how well the companies gather and diffuse information, as well as how well managers process this information into decisions (van Riel et al., 2004).

The structured acquisition of information with respect to the technology and customer requirements can make a substantial difference in the success of innovations (van Riel et al., 2004).

van Riel et al., (2004) showed that there is a positive relationship between the type of information gathered and the likelihood of high-technology service innovation success. Their results indicate that companies need to focus on gathering technological and customer information, as opposed to gathering information on competitors, which was actually shown to have a negative effect. The authors believe this may be due to the intangible nature of high-technology services, and while they might seem easy to copy, it is very difficult to reverse engineer them. They also suggest that the experience nature of services inhibits customers from comparing new offers with similar existing and competing 
services. van Riel et al., (2004) also found that promoting an innovative climate which fosters informal communication positively affects the likelihood of success. Others conclude that services that are not unique and not evidently superior to competitive offerings are prone to become failures (Dutta, Narasimhan, Rajiv, 1999).

\subsection{Decision Making Under Uncertainty}

All too often executives have a binary view when it comes to decision making under uncertainty (Courtney, Kirkland and Viguerie, 1999). Uncertainty is either underestimated in order to come up with rigid forecasts or it is overestimated, in which case all analysis is abandoned and managers are left to rely on their gut feel and experience. At best, an inaccurate forecast can be of no use in the decision making process and at worse it can be highly misleading and down right dangerous. Relying solely on experience can also prove to be dangerous due to the turbulence in the macro environment of the organization, which may make acquired experience and knowledge lose its value rapidly (van Riel et al., 2004).

Executives deal with uncertainty in different ways (Courtney et al., 1999). Some executives decide that the best thing is to shape their own future by making high stake bets. An example of this is the millions of dollars that Kodak invested in digital photography in hopes to reshape the way people created, stored and viewed images. While this investment served the company well, most companies lack the industry position or assets to be able to follow this approach. 
A second and less risky approach is to make limited investments in emerging markets. Companies can achieve this by forming operational or distributional alliances. It is difficult to say if these kinds of investments reserve the right to play or simply the right to lose (Courtney et al., 1999).

A third approach is for executives to focus on building flexibility into their processes in order to allow the companies to adapt as the market evolves (Courtney et al., 1999). One problem with this approach is that waiting and seeing until the market becomes clear can create a window for competitors. At the same time, focusing on competitive information may lead companies to focus less on customer requirements and end up performing worse in the innovation process (van Riel et al., 2004).

The standard practice for strategic planning is to lay out a vision of future events and then use a tool such as a discounted-cash-flow (DCF) analysis in order to aid the decision making process (Courtney et al., 1999). DCF is a valuation method that is used to measure the attractiveness of an investment opportunity ${ }^{1}$. DCF analysis uses future free cash flow projections and discounts them to arrive at a net present value (NPV), which is then used to evaluate the potential for investment. If the NPV is lower than the current cost of the investment, the opportunity may be seen as a good one. This may be a very powerful tool, but it does have its weaknesses. First of all it is simply a mechanical valuation tool,

\footnotetext{
${ }^{1}$ DCF summary is under Copyright @2000, Investopedia.com - Owned and Operated by Investopedia Inc.
} 
and therefore subject to the axiom "garbage in, garbage out". Another issue is that it assumes that all investments are irreversible, which is not the case in reality. Managers usually have the option to abandon an investment if the results are poor. The goal of DCF analysis is to find the most likely outcome and create a strategy based on it. This may work well in a stable market, but under uncertainty this is marginally helpful at best (Courtney et al., 1999).

Option pricing theory offers managerial flexibility relative to the DCF method (Charnes and Cobb, 2003). Managerial options on real investment projects can be compared to options on financial assets, such as stocks. An option is the right to buy or sell an asset within a given time period for a given price. The option itself becomes an asset with an associated value that can be measured. Black and Scholes (1973) provided an analytical solution to the value of an option on a financial asset with a single exercise date. Merton (1973) adapted the model to include options on dividend paying stocks. Numerical approaches were developed soon thereafter as alternatives to the Black Scholes approach (Schwartz, 1977; Parkinson, 1977). The Black Scholes approach and its generalizations employ partial differential equations, which often have closedform solutions that lead to simple pricing formulas. In some cases, the differential equations need to be solved numerically using techniques such as the Monte Carlo method ${ }^{2}$ (Charnes and Cobb, 2003). Boyle (1977) offered Monte Carlo simulation as an alternative to numerical integration and finite difference approach methods for valuing options on financial assets (Charnes and Cobb,

\footnotetext{
${ }^{2}$ Some of the tools used in this research will use Monte Carlo simulation.
} 
2003). To obtain an estimate of the option value, a number of sample values are randomly selected from a previously defined distribution which describes the terminal values of the option. In turn, these terminal values are discounted and averaged over the number of trials (Charnes and Cobb, 2003). It is key to this approach to select the appropriate distribution that best fits the data. Other option pricing alternatives include a binomial lattice method (Cox, Ross and Rubinstein, 1979), a simulation using least squares regression (Broadie and Glasserman, 1997), stochastic dynamic programming and stochastic differential equations.

The following section will introduce some additional tools that aid managers in the decision making process. It is important to keep in mind that while some of the tools can be very powerful, they are only as useful as the information that is entered into them. It is the manager's responsibility to provide the tool with the best data possible.

\subsubsection{The Four Levels of Uncertainty}

Courtney, Kirkland and Viguerie (1999) propose a framework for managers to avoid making decisions in a binary way. The framework is based on the fact that even in the most uncertain environments it is possible to gather strategically relevant information. It is possible to identify things such as market demographics, performance attributes of current technologies, elasticities of demand for certain stable product categories and competitor's capacity 
expansion plans. The uncertainty that remains after the best possible analysis has been conducted is referred to as the residual uncertainty. This residual uncertainty has been found to fall under one of four levels (Courtney et al., 1999):

\section{Level 1: Clear Enough Future}

At this level it is possible to create a forecast that is precise enough for strategy development. While the forecast might be inexact, it will be sufficiently narrow to allow for a single strategy. The residual uncertainty is irrelevant.

\section{Level 2: Alternate Futures}

The future may be described as one of a few alternate outcomes or discrete scenarios. It is not possible to determine through analysis which outcome will occur, although some of the probabilities may be known. The most important characteristic of this level is that strategy will change from one outcome to the next. A common situation at this level is when strategic choices depend on those of competitors, and competitor choices have either not been observed or can not be predicted.

\section{Level 3: A Range of Futures}

A range of potential futures can be identified. This range is defined by a limited number of key variables, but the actual outcome may lie anywhere in the range. There are no natural discrete scenarios. Similar to level two, 
some or all aspects of the strategy will change depending on the outcome. Companies in emerging industries or entering new geographic locations may face level three uncertainties.

\section{Level 4: True Ambiguity}

Multiple dimensions of uncertainty interact to create an environment that is virtually impossible to predict. Unlike level three, there is no range of potential outcomes that can be identified; it might not even be possible to predict all the potential variables that will influence each outcome.

Executives that treat uncertainty in a binary manner classify all conditions as either Level 1 or Level 4 . Research shows that most of all strategy problems fall into Levels 2 and 3 (Courtney et al., 1999). The right analysis tool depends on the level of uncertainty. At Level 1 the 'traditional strategy toolkit' may be used. These are the tools like DCF analysis, value chain analysis, Porter's 5-forces and market research. At Level 2 it is important to identify what the possible outcomes are and assign probabilities to each one. Tools such as option valuation models (Dixit and Pindyck, 1995; Luerhman, 1997) and game theory (Dixit and Nalebuff, 1991; Brandenburger and Nalebuff, 1995) may then be used to study the possible outcomes. At Level 3 it is necessary to reduce the range of possible outcomes and identify a limited number of scenarios. It is important that these scenarios are not redundant and that you focus on what is probable, not just possible. Entering an emergent market falls into this level of uncertainty. Tools 
such as latent demand research and technology forecasting will aid in strategy planning. Finally, at Level 4 , it is important not to rely simply on gut feel. It should be possible to identify some of the relevant variables that will determine how the market will evolve over time. It is also possible to identify favorable and unfavorable indicators and adapt strategy as information becomes available. Analogous markets can be studied in order to determine the key attributes of the winners and losers as well as identify the strategies that lead to those outcomes. Tools such as pattern recognition and nonlinear dynamic models (Senge, 1990; Geus 1988) may also be used at this level.

\subsection{Global Diffusion Research and Models}

International diffusion studies span a variety of different product categories, such as cellular phones (Dekimpe, Parker and Sarvary, 1998; Dekimpe, Parker and Sarvary, 2000a), industrial products (Dekimpe, Parker and Sarvary, 2000b; Ganesh and Kumar, 1996; Mahajan and Peterson, 1979) and consumer durables (Ganesh, Kumar and Subramaniam, 1997; Gatignon, Eliashberg and Robertson, 1989). This research has also taken into account a variety of different dimensions, which include; population growth, number of population centers, GNP per capita, death rate, number of competitors, number of ethnic groups, mobility and cosmopolitanism. Most research studies have used the Bass model (Bass, 1969) or a modification of it (Mahajan and Peterson, 1979) in order to predict market size. Exceptions are Dekimpe et al., (2000a) and Dekimpe et al., 
(2000b) which used a hazard and coupled-hazard approach, respectively, in order to be able to examine the breadth of the diffusion stage ${ }^{3}$.

\subsubsection{Existing Generalizations in Global Diffusion}

Existing literature introduces a number of generalizations (Dekimpe et al., 2000c) which have set the stage for the current research.

The first generalization is that GNP per capita has a positive effect on the diffusion process. It reduces the time before a country tries the innovation as well as speeds the diffusion within the country (Dekimpe et al., 2000b).

A second finding is that there are cross-national learning effects (Dekimpe, Parker and Sarvary, 1998, 2000a, 2000b; Mahajan and Muller, 1994). Countries that introduce the innovation later than others appear to have faster within country adoption. This is especially important when studying regions of countries with similar social, cultural, political and economical backgrounds (Dekimpe et al., 2000c).

Third, social system heterogeneity seems to have a negative effect on both the timing of initial adoption as well as diffusion (Dekimpe et al., 1998, 2000a,

\footnotetext{
${ }^{3}$ Breadth examines adoption time across markets. This is in contrast to depth which only examines the adoption time within the market.
} 
$2000 \mathrm{~b}$ ). It is suggested that this is because of the speed it takes decision makers involved in the trial to reach a consensus.

\subsubsection{Existing Biases in Global Diffusion}

Although research in international diffusion is not abundant, there are some generalizations that can be used as a base for future research. In addition to these generalizations, some of the biases have also been identified (Dekimpe et al., 2000c).

First, the focus of existing research has left about 90 percent of the world's nations ignored. From a statistical point of view it is important to consider the developing nations in order to ensure the largest possible variation in terms of the dimensions used. It is reported that the sizes of the Bass parameters for developing nations are smaller than for developed ones (Dekimpe et al., 1998). There is also a lack of research when it comes to the cross-national learning effect among developing nations.

Second, existing research has focused mostly on consumer durables, there is very little research focused on services. Exceptions are Dekimpe et al., (1998) and Dekimpe et al., (2000a).

Third, the dimensions used across the studies vary greatly in nature and measurement. This may be due to the availability of proxies across multiple 
countries and to the product context that is being studied. Due to this inconsistency of variables and factors used, there is a proposal for a multi-item measure for international diffusion research (Dekimpe et al., 2000c). An exploratory factor analysis was used to investigate a set of dimensions that might be able to describe most nations. The results show that most countries can be described through eighteen factors. The authors of this list did not find the correlations among the factors to be severe.

\subsubsection{Diffusion Model Considerations}

Three different uses for diffusion models have been identified in existing literature: (i) forecasting; (ii) hypothesis testing; and (iii) formulating normative guidelines (Mahajan, Muller and Bass, 1990). Most studies focus on the hypothesis testing and very little research has been done in forecasting (Dekimpe et al., 2000c). Mahajan, Muller and Bass (1990) criticized that "parameter estimation for diffusion models is basically of historical interest; by the time sufficient observations have developed for reliable estimation, it is too late to use the estimates for forecasting purposes." There is also a need to study the nesting of country specific dimensions into the diffusion model; this is thought to improve long run forecasting performance (Dekimpe et al., 2000c).

The previous two sections identified some generalizations and biases in the current diffusion model literature. Dekimpe et al., (2000c) have also identified issues that should be considered when using diffusion models in a global 
context. When research is comparing two or more different samples of populations, there is a need to do sample matching. Sample matching requires the units of observation to be comparable across the samples (Dekimpe et al., 2000c). This means using relevant population as a dimension instead of total population. An example of this would be the study done by Dekimpe et al., (1998) that performed sample matching by reducing their relevant population to "the fraction of literate population living in urban areas having sufficient income to afford basic telephone service."

\subsubsection{Bass Model}

The basic construct of the Bass model (Bass, 1969) is to predict the likelihood that an individual will adopt a new product at time $\mathrm{T}$, given that he has not yet adopted. The model makes a distinction between two different kinds of adopters: (1) innovators and (2) imitators. Innovators are the individuals that decide to adopt independently of the decisions made by other individuals in their social system. Imitators are those individuals which are influenced by the adoption decisions made by other members of their social system. For the innovators, the pressure of adoption does not increase with the growth of the adoption process; this is not the case with the imitators. It can also be said that innovators are influenced by mass media communications or external influence, while imitators are influenced by word of mouth communications or internal influences (Mahajan, Muller and Bass, 1990). 
The likelihood of purchase at time $\mathrm{T}$, given than no purchase has yet been made is given by the following equation:

\section{Equation 1: Bass model}

$$
P(T)=p+q / m Y(T)
$$

- Where $P(T)$ is the probability that an initial purchase will be made at time $T$, given that no purchase has yet been made.

- $p$ is the coefficient of innovation.

- $q$ is the coefficient of imitation.

- $m$ is the total market potential.

- $Y(T)$ is the cumulative sales.

Since $Y(0)=0$, the constant $p$, is the probability of initial purchase at $T=0$, and its magnitude reflects the importance of innovators in the social system (Bass, 1969). The product $q / m Y(T)$ reflects the pressure operating on imitators as the number of previous buyers increases. For successful new products the coefficient of imitation, $p$, should be much larger than the coefficient of innovation, $q$, (Bass, 1969).

Mahajan et al., (1990) describes the modifications to the Bass model. For the most part these modifications have not been tested in the international context (Dekimpe et al., 2000c). Some of them limit the long-term forecasting ability of the Bass model. Other estimation considerations for when there is a lack of data 
use an algebraic estimation procedure with an initial estimation of $p, q$ and $m$ (Bass, 1969). If the goal was to calculate $m$ as a function of time, the following equation could be used (Kalish, 1985):

\section{Equation 2: Market over time}

$$
m(t)=m_{0} \exp \left[-d P(t)\left(\frac{a+1}{a+\frac{N(t)}{m_{0}}}\right)\right]
$$

- Where $a$ and $d$ are constants.

- $\mathrm{m}_{0}$ is the size of the market potential at the time of product introduction.

- $P(t)$ is the product price.

$\left(\frac{a+1}{a+\frac{N(t)}{m_{0}}}\right)$ represents the effect of market penetration in increasing the size of the market potential due to the word of mouth effect.

The Bass model assumes that the market potential is determined at the time of introduction and remains unchanged over time (Kalish 1985). Theoretically, there is no rationale for a static potential adopter population; Equation 2 was derived to address this Bass model assumption. This equation attempts to relax the model by specifying the market potential as a function of relevant exogenous and endogenous variables (Mahajan et al., 1990). Other applications have represented the market potential as a function of growth in the number of households, population growth, product profitability, growth in the number of 
retailers making the product available to consumers, and income distribution, price and product uncertainty (Mahajan et al., 1990) .

\subsubsection{Staged Estimation}

While several new product diffusion models have been documented, several authors have criticized their usefulness (Heeler and Hustad, 1980). Schmittlein and Mahajan (1982) note that diffusion models usually require ten or more observations to yield useful parameter estimates. Simon (1994) argues that the use of these models is "risky and potentially misleading." Dekimpe et al., (1998) pose that the models are not the root of the problem, but the way in which researchers operationalize them is what can lead to implausible results. Therefore Dekimpe et al., (1998) suggest a staged estimation procedure that will place external constraints on the parameter estimates.

There are four components to the diffusion pattern proposed by Dekimpe et al., (1998). These components should be seen as the four basic sources of global variations in new product diffusion patterns and all require a certain level of matching.

\footnotetext{
${ }^{4} \mathrm{~A}$ complete list of refinements and extensions to the Bass Model is outlined in Mahajan, Muller and Bass, 1990).
} 


\section{Component 1: Social System Size}

The social system size (S) is defined as the population within which the innovation diffuses. In the case of consumer products, $\mathrm{S}$ can be defined as the total population. For industrial products (e.g., CAT-scan machines) $\mathrm{S}$ can be defined as the number of hospitals. Social systems may vary. This is especially relevant for studies covering very long time horizons.

\section{Component 2: The Ceiling}

Sample matching on social system size is not enough, due to the fact that a certain percentage of the population will never find sufficient intrinsic utility for the innovation. Therefore it is necessary to define an exogenous ceiling, $\mathrm{C}$, which is independent of the size of the social system. In their study Dekimpe et al., (1998) define the ceiling as "the percentage of the population who is literate, lives in urban areas and has sufficient income to afford basic telephone service."

It is possible to multiply $\mathrm{C}$ and $\mathrm{S}$ and call it the total market potential, M. The authors of the staged estimation procedure decided to keep $\mathrm{C}$ and $\mathrm{S}$ separate so that the source of variation could be identified, $\mathrm{C}$ being an intensity parameter and $S$ being a scale parameter. Keeping the concepts separate also provides more details to the modeler from which tests of external validity can be performed. With the unmatched approach, a market potential can be estimated, but it is difficult to tell if this number has any external validity. With the matched 
approach, a study of growth dynamics can only take place after the acceptance of an externally valid and matched measure of social system and ceiling.

\section{Component 3: Time Origin Intercept}

In order to make cross country comparisons, it is necessary to adjust for the time origin intercept. It is important not to assume a fixed temporal window because this leads to a left hand truncation bias. Diffusion curves must be matched using the first year of within country penetration as a time origin that is comparable across countries. This intercept may be defined as:

\section{Equation 3: Time origin intercept}

$$
A=n / C S
$$

- Where $n$ is the number of first year adopters.

- $C$ is the ceiling.

- $S$ is the social system size.

The authors note that this figure, $A$, is similar, but not identical to the coefficient of innovation, $p$, in the Bass model.

\section{Component 4: Growth Rates}

The final component of the staged estimation model proposed by Dekimpe et al., (1998) is the growth rate, $B$, between the social system and the 
ceiling. Growth is defined only as occurring after the first year and the authors argue that growth rates may not be co-estimated with the time origin intercept. This is so that the growth rate may also be comparable across countries.

Using the four components, Dekimpe et al., (1998) derived the following model:

\section{Equation 4: Staged estimation model}

$$
n_{t}=\left[A+B^{*}\left(\frac{N_{t-1}}{C * S}\right)\right]\left[C * S-N_{t-1}\right]
$$

- Where $A, B$ and $C$ have been previously defined.

- $n$ is the number of adoptions at time period $t$.

- $N$ is the cumulative number of adoptions.

The proposed method for the model estimation consists of three stages that must occur in sequence: (i) external estimation and validation of the exogenous social system sizes and long-run adoption ceilings; (ii) calculation of the intercept term, A, which is exogenous to the subsequent growth process; and (iii) internal estimation of the growth parameter, B, which is endogenous to the social system, the ceiling and the time origin intercept. 


\subsubsection{Other Diffusion Models Considerations ${ }^{5}$}

Bass, Jain and Krishnan (2000) compiled a summary about the various published papers which include decision variables in diffusion models. When they evaluated the publications they provided a benchmark of desirable properties of diffusion models with marketing mix variables. They highlight that a major limitation of the early models of innovation diffusion such as the Bass model (1969) is that they do not explicitly incorporate marketing mix variables that are under the control of managers. These models therefore become less attractive for strategic planning with respect to policies for pricing and other variables under managerial control. Because of the growing importance in real world applications of diffusion models with decision variables, it is desirable to develop an understanding of the weaknesses and strengths of the available models. The following is a summary of desirable properties of diffusion models with decision variables:

1. It is desirable for extended diffusion models with decision variables to still be able to describe the empirical diffusion process. This means that even with the incorporation of decision variables, such as pricing and experience; the model should still reduce to or be approximately equivalent to the Bass model curve.

\footnotetext{
${ }^{5}$ The objective of this section is to aid the reader in the process of selecting a different diffusion model than the one illustrated in this research.
} 
2. The model should still posses the "carry-through" property of the Bass model, in which an event today carries through and has an impact on all future time periods. For example a price reduction today will not only increase adoptions today but have a positive impact in all future time periods.

3. The model should be capable of empirical estimation and it should yield plausible parameter estimates. In addition, the credibility of models is enhanced as the number of data sets for which empirical estimates of parameters increases.

4. In examining diffusion models with decision variables it is important to recognize that goodness of fit alone is an inadequate criterion for evaluating model validity.

5. Models with closed form solutions have nice properties, although they do not guarantee model validity they are usually special cases of more general models. This can aid in the understanding of the relationships among the variables and the time pattern of adoption.

6. It is desirable that the model is constructed in such a way that it is managerially useful. This means that the parameters of the model be 
expressed in such a way that allows for management interpretation either by intuition or with reference to comparisons to other products.

7. The model should be able to be implemented for new products without data. After all the period of greatest strategic importance is the period before the product is launched. The basic Bass model has been applied numerous times under this condition by "guessing by analogy"6.

\subsection{Lessons Learned from the Literature Review}

This section provides the most important lessons learned from the literature review:

\section{Empirical generalizations of existing studies}

The first consistent finding is that the wealth of a country, which is usually operationalized as GNP per capita, has a positive effect on the diffusion process. Second, countries that introduce the innovation later than others seem to have faster within country diffusion patterns suggesting the existence of cross-national learning effects. Countries which are culturally and economically similar have shown stronger learning effects. Third, social system heterogeneity has a negative effect on diffusion.

\footnotetext{
${ }^{6}$ For several examples of applications of the Bass model before product launch see www.utdallas.edu/ mzjb
} 


\section{Limited geographical scope and product context}

Current research has focused on a limited set of developed countries. 90 percent of the world's nations have been ignored and key countries like Brazil, Indonesia, China, India and Russia have been excluded. A study done by Dekimpe et al., (1998) found smaller coefficients of innovation and imitation than typically reported and this is attributed in part to the inclusion of developing nations in their sample.

There is also a limitation when it comes to the product context explored. The majority of the studies have focused on consumer durables and it is not clear to what extent these studies can be generalized to services and industrial innovations.

\section{Diffusion models have focused on descriptive uses}

Most of the currently available global diffusion studies are of a descriptive or hypotheses testing nature. There is a need to use diffusion models in a forecasting manner and examine countries that have not yet started the adoption process.

\section{Sample matching requirements}

Sample matching leads to better parameter estimates for the case in which a study is comparing two or more different samples or populations. It does so by requiring the units of observation to be comparable across samples. 


\section{Estimating by analogy}

The period of greatest strategic importance is before the product or service is launched, in which case there is no sales data available. In this case it is still possible to use diffusion models by estimating the parameters using analogies. A similar product, service or region can be used to build a forecast.

\section{High technology service success}

To succeed in high technology service innovation it is important to reduce the uncertainty of making investment decision by establishing an information infrastructure. The information gathering should be anchored around the customer requirements and not the technology or the competition. It is also important to keep in mind that experience is not always enough and that decision making tools will depend on the level of residual uncertainty. 


\section{Research Method}

The purpose of this research is to provide a method that can be used to estimate the size of new markets in developing nations for which abundant and convincing data are not available. A developing nation, as defined by the United Nations Educational, Scientific and Cultural Organization (UNESCO), is a low and middle income country in which most people have a lower standard of living with access to fewer goods and services than do most people in high-income countries ${ }^{7}$.

The method was developed using existing literature as a starting point and was then tested in a region for which adoption data are readily available. The results and insights of applying the method were then used to estimate the market size for mobile payments in South America. The overall results and lessons learned are then used to propose modifications to the method.

This research will be used to estimate the parameters in a diffusion model for countries that have not yet begun the adoption process, an area in which very little research has been done (Dekimpe et al., 2000c).

\footnotetext{
${ }^{7} \mathrm{~A}$ high income country is a country having an annual gross national product (GNP) per capita equivalent to $\$ 10,066$ or greater. Most high-income countries have an industrial economy. There are currently 24 high-income countries in the world and their combined population is about 0.9 billion, less than one-sixth of the world's population. (Source: The World Bank)
} 


\subsection{Research Model}

The literature review has shown that diffusion models need to be applicable to a variety of situations, especially when decisions need to be made before a product or service has been launched or in its very early stages of adoption.

In the context of Carlile and Christensen (2005), this research is an attempt to make diffusion model research more normative. While diffusion models are mathematically and statistically accurate, they are not practical. There is no clear relationship between the diffusion model inputs and the circumstances in which managers would use one set of inputs or models over another. This research tries not only to make the application of diffusion models more practical, but to link the results to decision making and the circumstances around those decisions. The contribution is not only methodological, but it also is a start in the direction of applicability. The results of this research will be shared with managers and decision makers, their feedback will contribute in establishing the kinds of decisions that can be made based on the forecast. We intend to accomplish this by moving away from using diffusion models solely for hypotheses testing and instead use them to build a forecast for a situation in which a service has yet to be launched. After all, a diffusion model is most useful in the early stages of adoption and current literature has overlooked this issue.

The method proposed in this research will use dimensions that capture theoretical perspectives. The intent is to provide for better estimates of the 
parameters in the diffusion model. The parameters and the model will then be used to provide estimates of the number of adoptions at time t. Estimates of the number of adoptions can also be calculated using dimensions extracted from the traditional literature as well as a set of control dimensions proposed by industry experts. Figure 1 shows a diagram of the proposed research model. The research method steps are developed in the sections to follow.

Figure 2: Research Model

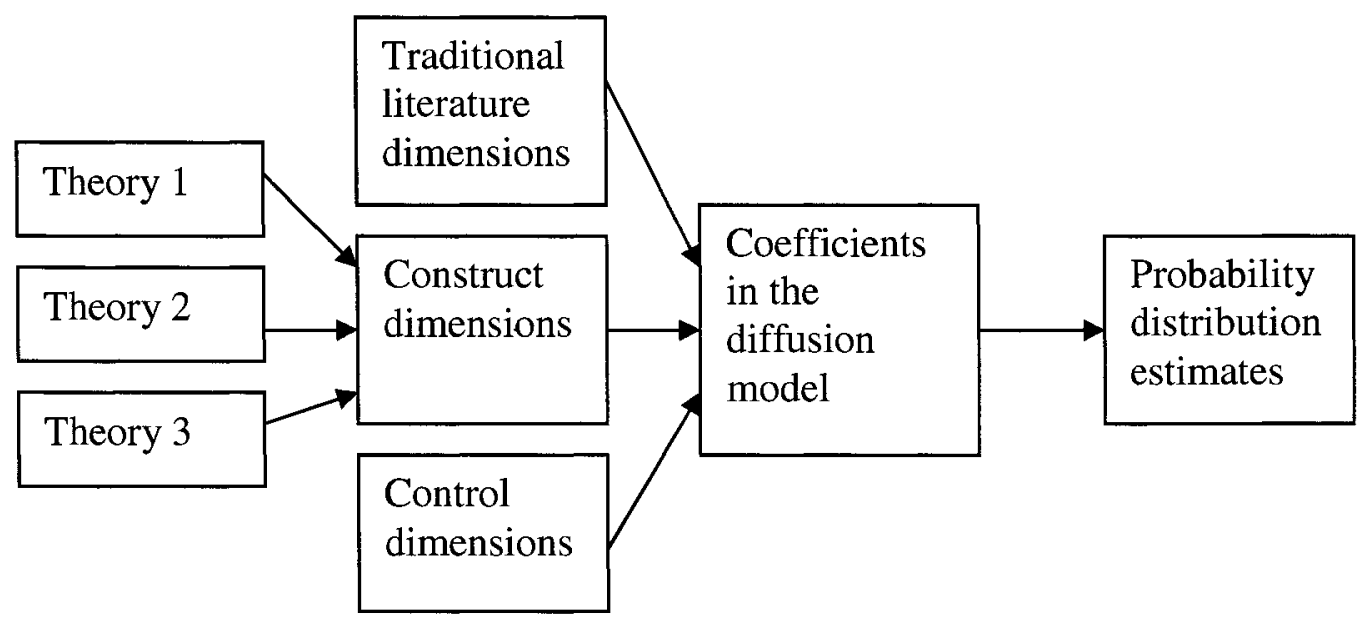

The research model is independent of the theoretical perspectives selected, the dimensions used and the diffusion model chosen.

There are ten steps in the proposed research method:

1. Identify research question or objective.

2. Select theoretical perspectives and cases. 
3. Identify literature, construct and control dimensions.

4. Operationalize dimensions.

5. Identify and operationalize regions to be addressed.

6. Select a diffusion model.

7. Use theoretical perspectives and dimensions developed in step three to define the inputs of the diffusion model.

8. Use historical data and/or theoretical insights to estimate the parameters of the diffusion model.

9. Use estimated parameters and model to predict the size of addressable markets.

10. Answer research question.

These steps will be described further in the sections to follow. While three specific theoretical perspectives, three sets of dimensions and a staged estimation procedure are explained, the intent of this section is also to provide guidance to the reader when applying the method in a different context.

\subsection{Selecting Theoretical Perspectives and Cases}

This research builds on the work done by Ashraf (2005) in which three theoretical perspectives and 17 cases were used to generate insights on the factors that influence the adoption of mobile payments. 


\subsubsection{Selecting Theoretical Perspectives}

Initially, the following seven theoretical perspectives were selected:

1. Theory of disruptive innovation (Christensen, 1997).

2. Theory of diffusion of innovations (Rogers, 1995).

3. Value chain evolution theory (Christensen et al., 2004).

4. Idea inspection (Goldenberg et al., 2001).

5. Profiting from technology (Gans and Stern, 2003).

6. Perspective for using business models to capture value from innovations (Chesbrough \& Rosenbloom, 2002).

7. Demand-based perspective on technology life cycles (Adner, 2002).

The seven theoretical perspectives were discussed with the industry partners in preliminary sessions. Three theoretical perspectives were chosen due to the following four reasons: (i) the cost of understanding, which was measured in terms of time and resources, (ii) the cost of acquiring the data, (iii) the expected complexity of data analysis, and (iv) perspective complementarity.

Data analysis was started with the following three theoretical perspectives:

1. Theory of disruptive innovation (Christensen, 1997).

2. Theory of diffusion of innovations (Rogers, 1995).

3. Value chain evolution theory (Christensen et al., 2004). 
After the analysis of the first wave of cases, Christensen's value chain evolution theory was replaced with Chesbrough's perspective of using business models to capture value from innovation. An overview of the three theoretical perspectives that were used is given below ${ }^{8}$ :

1. Diffusion of innovation theory states that the likelihood of adopting a new technology will be positively influenced by: the technology's relative advantage over other technologies, compatibility with existing technologies, trialability and observability. The adoption of the technology will be negatively influenced by the complexity (Rogers, 1983).

According to Rogers (1995), diffusion is the process by which an innovation is communicated through certain channels over time among the members of a social system. Diffusion is a special type of communication concerned with the spread of messages that are perceived as new ideas. The four main elements in the diffusion of new ideas are (i) the innovation, (ii) communication channels, (iii) time, and (iv) the social system.

An innovation is an idea, practice, or object that is perceived as new by an individual or other unit of adoption. The characteristics of an innovation, as perceived by the members of a social system, which determine an innovation's rate of adoption are: (i) relative advantage, (ii) compatibility, (iii) complexity, (iv) trialability, and (v) observability.

\footnotetext{
${ }^{8}$ Sections of this overview have been adapted from Ashraf (2005)
} 
Relative advantage is the degree to which an innovation is perceived as better than the idea it supersedes. The degree of relative advantage may be measured in economic terms, but social prestige, convenience, and satisfaction are also important factors. An innovation's objective or intended advantage is not important. What is important is whether an individual perceives the innovation as advantageous. The greater the perceived relative advantage of an innovation, the more rapid its rate of adoption will be.

Compatibility is the degree to which an innovation is perceived as being consistent with the existing values, past experiences, and needs of potential adopters. An idea that is incompatible with the values and norms of a social system will not be adopted as rapidly as one that is compatible. The adoption of an incompatible innovation often requires the prior adoption of a new value system, which is a relatively slow process.

Complexity is the degree to which an innovation is perceived as difficult to use and understand. Some innovations are readily understood by most members of a social system; others require the adopter to develop new skills and understanding. New ideas that are simpler to understand are adopted more rapidly. 
Trialability is the degree to which an innovation may be experimented with on a limited basis. New ideas that can be tried on an installment plan will generally be adopted more quickly than innovations that are not divisible. An innovation that is trialable represents less uncertainty to the individual who is considering it for adoption.

Observability is the degree to which the results of an innovation are visible to others. The easier it is for individuals to see the results of an innovation, the more likely they are to adopt it. Such visibility stimulates peer discussion of a new idea, as friends and neighbors of an adopter often request information about it.

In summary, innovations that are perceived by individuals as having greater relative advantage, compatibility, trialability, observability, and less complexity than existing systems will be adopted more rapidly than others (Rogers, 1995).

The second main element in the diffusion of new ideas is the communication channel. Communication is the process by which participants create and share information with one another in order to reach a mutual understanding. A communication channel is the means by which messages get from one individual to another. Mass media channels are more effective in creating knowledge of innovations, whereas 
interpersonal channels are more effective in forming and changing attitudes toward a new idea, and thus in influencing the decision to adopt or reject a new idea. Most individuals evaluate an innovation, not on the basis of scientific research by experts, but through the subjective evaluations of near-peers who have adopted the innovation.

The third main element in the diffusion of new ideas is time. The time dimension is involved in diffusion in three ways. First, time is involved in the innovation-decision process. The innovation-decision process is the mental process through which an individual passes from first knowledge of an innovation to forming an attitude toward the innovation, to a decision to adopt or reject, to implementation of the new idea, and to a confirmation of this decision. An individual seeks information at various stages in the innovation-decision process in order to decrease uncertainty about an innovation's expected consequences. The second way in which time is involved in diffusion is in the innovativeness of an individual or other unit of adoption. Innovativeness is the degree to which an individual or other unit of adoption is relatively earlier in adopting new ideas than other members of a social system. The third way in which time is involved in diffusion is in rate of adoption. The rate of adoption is the relative speed with which an innovation is adopted by members of a social system. The rate of adoption is usually measured as the number of members of the system that adopt the innovation in a given time period. 
The fourth main element in the diffusion of new ideas is the social system. A social system is defined as a set of interrelated units that are engaged in joint problem-solving to accomplish a common goal. The members or units of a social system may be individuals, informal groups, organizations, and/or subsystems. The social system constitutes a boundary within which an innovation diffuses. A change agent is an individual who attempts to influence clients' innovation-decisions in a direction that is deemed desirable by a change agency. A final crucial concept in understanding the nature of the diffusion process is the critical mass, which occurs at the point at which enough individuals have adopted an innovation that the innovation's further rate of adoption becomes self-sustaining. The concept of the critical mass implies that outreach activities should be concentrated on getting the use of the innovation to the point of critical mass. These efforts should be focused on the early adopters, as they are often opinion leaders and serve as role-models for many other members of the social system. Early adopters are instrumental in getting an innovation to the point of critical mass, and hence, in the successful diffusion of an innovation.

There are five adopter categories, or classifications of the members of a social system on the basis on their innovativeness: (i) innovators, (ii) early adopters, (iii) early majority, (iv) late majority, and (v) laggards. 
2. The theory of disruptive innovation segments the target market according to how demanding the customers are. It also classifies new products into two different types of innovations; sustaining and disruptive. Disruptive innovations create an entirely new market through the introduction of a new kind of product or service, one that's initially worse, as judged by the performance metrics of mainstream customers. Sustaining innovations are what move companies along established improvement trajectories. They are improvements to existing products on dimensions that have been historically valued by customers.

Disruptive innovations introduce a new value proposition. They either create new markets or reshape existing markets (Christensen, 1997). A new market disruption occurs when characteristics of a new product attract a large number of new users. Low-end disruptions occur when existing products and services are "too good" and therefore overpriced in relation to the value existing customers perceive.

There are two types of disruptive innovations:

- New-market disruptive innovations create new growth by making it easier for people to do something that has historically required deep expertise or great wealth (i.e. eBay online marketplace, Kodak's original personal camera). 
- Low-end disruptive innovations deliver a low-priced alternative to customers who are overshot by existing offerings (i.e. Dell's directto-customer business model) 
Figure 3: Disruptive innovations

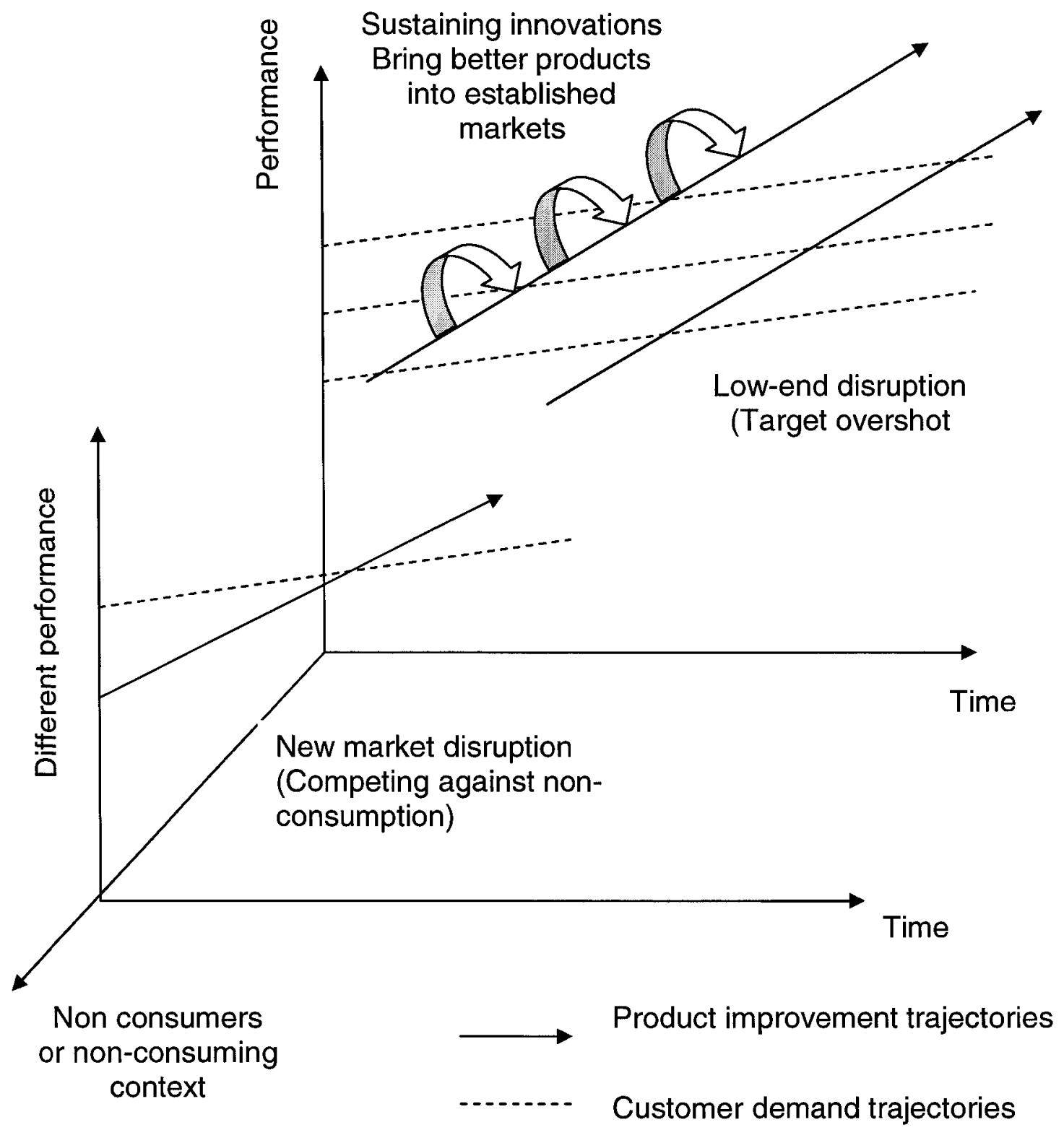

(Source: Christensen et al., 2004) 
Figure 4: Mobile Internet - a disruptive innovation

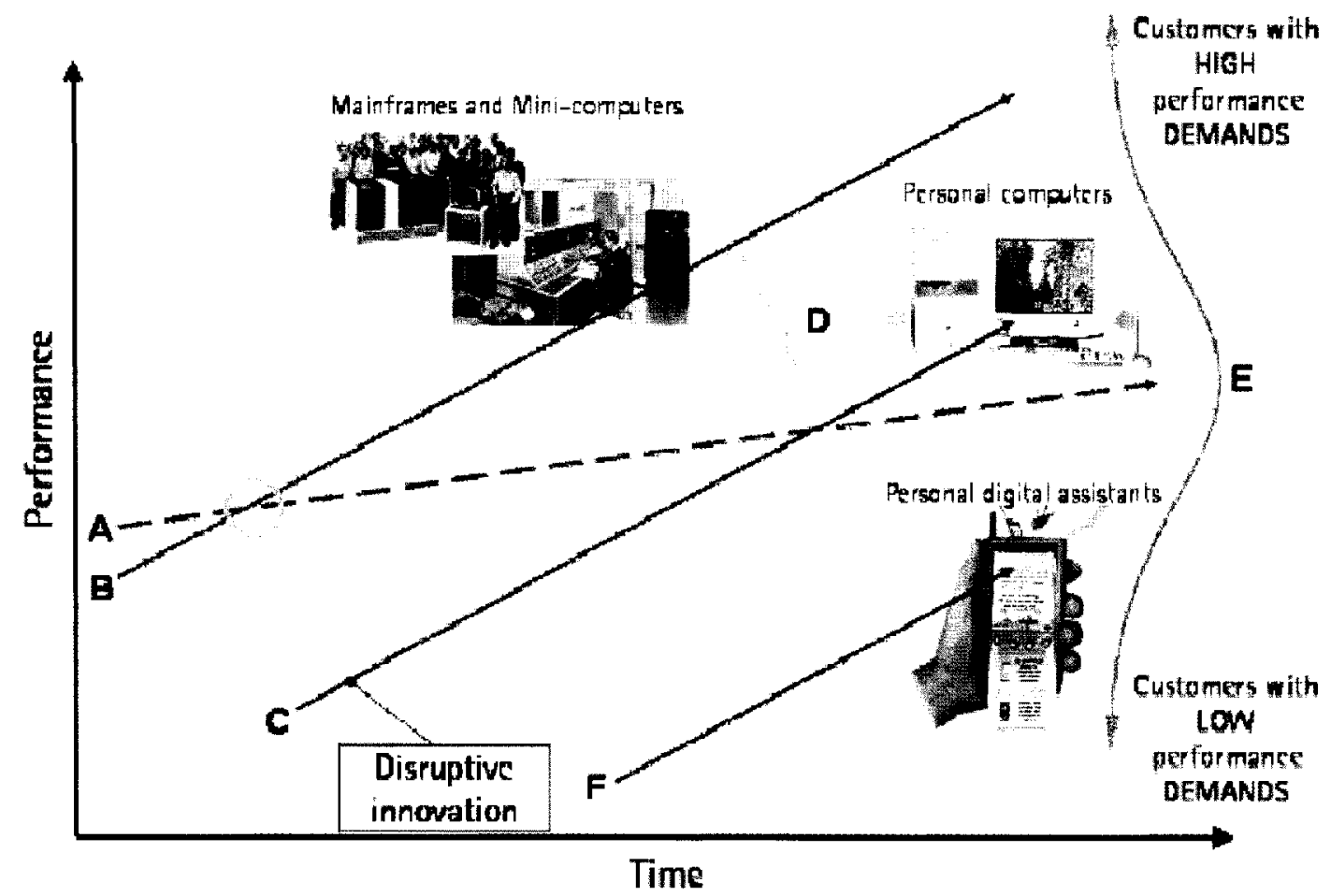

(Source: Ashraf, 2005)

3. Capturing value from innovation with business models states that a company's business model can be described using six different attributes; (i) value proposition, (ii) market segment, (iii) value chain composition, (iv) position in the value network, (v) cost/profit structure and (vi) competitive strategy.

A successful business model creates a heuristic logic that connects technical potential with the realization of economic value. The business model unlocks latent value from the technology (Chesbrough 
and Rosenbloom, 2002). The functions of a business model which capture the value from innovation include:

- Articulate the value proposition, i.e., the value created for users by the offering based on the technology.

- Identify a market segment, i.e., the users to whom the technology is useful and for what purpose; and specify the revenue generation mechanism for the firm.

- Define the structure of the value chain required to create and distribute the offering; and determine the complementary assets needed to support the firm's position in this chain.

- Estimate the cost structure and profit potential for producing the offering, given the value proposition and value chain chosen.

- Describe the position of the firm within the value network linking suppliers and customers, including identification of potential suppliers of complementary products and competitors.

- Formulate the competitive strategy by which the innovating firm will gain and hold advantage over rivals. 
The process begins with articulating a value proposition latent in the new technology, by defining what the product offering will be and in what form a customer may use it. The business model then specifies a group of customers or market segment to whom the proposition will be appealing and from whom resources will be received. A customer can value a technology according to its ability to reduce the cost of a solution to an existing problem. Identification of a market is also required to define the architecture of the revenues, i.e. how a customer will pay, how much to charge and how the value created will be appropriated between customers, the firm itself and its suppliers. Once the value chain needed to deliver the offering has been identified, it must then address how it will appropriate some portion of the value for itself. The value network created around a given business shapes the role that suppliers, customers and third parties play in influencing the value captured from commercialization of an innovation. The value network increases the supply of complementary goods on the supply side, and can increase the network effects among consumers on the demand side. Positive alignment with the value network can leverage the value of a technology and failure to align with the value network can dissipate potential value. The firm has to play a dominating role in the value chain to coordinate the incentives of all the elements of the value network. 
The research done by Ashraf (2005) was a joint effort with an industry partner. A number of theoretical perspectives were initially examined but the goal of the research was not to study and/or become theory experts, therefore the cost of understanding and implementing the theoretical perspectives needed to be low. The cost of acquiring the data also needed to be low. No proprietary data was used, therefore all data was public information that was gathered from press releases and company websites. The attributes and categories of the selected perspectives were all available as public information.

Finally, the three perspectives are not competing ones and their attributes complement each other. They examine the cases from the perspective of the technology, the market segment and the business model.

When applying this method, the reader needs to keep in mind that theory selection will depend on the product or service context being examined as well as the different costs involved in the development of the research.

\subsubsection{Selecting Cases}

Ashraf (2005) used theoretical sampling to select the cases. Given the limited number of available cases, random selection was not possible. Cases which were likely to replicate or extend theoretical abstractions and the cases which were of interest to the industry participants were selected for examination. The cases were selected from different regions of the world in order to maintain 
generalizability and to examine the adoption of different mobile Internet and mobile payments services.

The following search engines were used to identify mobile payment services that had been deployed worldwide:

1. Google (www.google.com).

2. Yahoo (www.yahoo.com).

3. Excite (www.excite.com).

4. Alta Vista (www.altavista.com).

5. Business Source Premier (www.library.carleton.ca).

The following phrases were entered into the search engines:

Mobile Internet, wireless application protocol, WAP, mobile data services, wireless applications, web phones, web enabled phones, mobile payments, wireless payments, micropayments, macropayments, contactless payments, proximity payments, remote payments, mobile commerce, and m-commerce.

The names of different mobile payment services were attained as a result of these searches. Ashraf (2005) then entered the name of each service in different search engines and collected all the news releases, white papers and online articles that were relevant to the service. For each service, the information in the 
website maintained by the operator that delivered the service was also examined.

The seventeen cases that were selected are listed below. Data was collected in four waves. For each case, the name of the service, the name of the operator and the country where the service was deployed is given.

1. i-mode (NTT DoCoMo, Japan).

2. m-mode (AT\&T Wireless, United States).

3. Mobipay (Mobipay International, Spain).

4. Smartpay (Smartpay, China).

5. Dexit (Dexit, Canada).

6. FeliCa i-mode (NTT DoCoMo, Japan).

7. Sonera Shopper (TeliaSonera, Finland).

8. Zoop (LG Telecom, South Korea).

9. Moneta (SK Telecom, South Korea).

10. Octopus (Octopus Cards Ltd., Hong Kong - China).

11. Vodafone Live (Vodafone Group, Europe).

12. Vivo Wap (Vivo, Brazil).

13. EZweb (KDDI, Japan).

14. Vodafone Live (Vodafone Group, Japan).

15. Nate (SK Telecom, South Korea).

16. EZi (LG Telecom, South Korea). 
17. Magic-N (Korea Telecom Freetel, South Korea).

Twelve more cases of wireless payments were identified but not included in the final sample. Preliminary data was gathered and the cases were discussed with industry participants in monthly meetings. These cases were not included in the research due to: (i) their limited scope and horizon, (ii) non availability of data (most of the cases were pilots and trials), and (iii) minimal incremental learning.

The twelve cases identified but not included in the sample are:

1. DirectBill (Cingular Wireless, United States).

2. M-parking (Mobilkom, Austria).

3. Paybox (Paybox, Germany).

4. PayMint (Mint Ab, Sweden).

5. SpeedPass (Exxon Mobil, United States).

6. Qpass (QPass, United States).

7. K-merce (Korea Telecom Freetel, South Korea).

8. PayPass (MasterCard International, United States).

9. M-pay bill (Vodafone Group, Europe).

10. Edy (BitWallet, Japan).

11. Payitmobile (Payitmobile, Germany).

12. Mondex (MasterCard International, United States). 


\subsection{Identify Traditional Literature, Construct and Control Dimensions}

Two sets of dimensions will be used to develop the forecasts in this research. The first set will be extracted from the literature, and the second set will be developed based on theory generated insights. In some cases it would be of value to identify an additional set of dimensions referred to as control dimensions, which are dimensions that provide a benchmark for the new forecasts. This is an initial view of how things are being done and can be used to show the value added of the changes. The following sections discuss these dimensions in further detail.

\subsubsection{Dimensions from the Literature}

The dimensions that have been traditionally used in the global diffusion literature vary greatly from one study to another. They vary both in their nature and in the method used to operationalize them. This is not surprising in view of the fact that global research requires the availability of proxies across all countries included in the study and at the same time different product contexts require the inclusion of different dimensions. The particular nature of the dimensions makes it harder to draw empirical generalizations, which in turn limits the scope of the theoretical conclusions that can be made based on the research (Dekimpe et al., 2000c).

In an attempt to encourage researchers to develop a consistent set of dimensions and their measurements Dekimpe et al., 2000c ran a preliminary analysis on sixty variables that can be used to describe over 200 countries along 
six key areas: socioeconomic development, political structure, demographics, culture, climate and geography. The data was extracted from multiple sources which included Euromonitor, The World Factbook (CIA), the International Telecommunications Union (ITU) and "Investing Licensing and Trade" (The Economist). The set of variables considered includes all variables that related to the six key areas describing a country and that were available for the 200 countries considered. Exploratory factor analysis (PCA with varimax rotation) was used to explore what constructs might describe the community of nations along these areas. As all sixty variables could not be simultaneously included in the analysis, they were analyzed by conceptually separate subsets. The variables were considered constant over time, and while most of them vary over time (e.g., GNP per capita changes from one year to the other); cross-country variations are orders of magnitude higher than the variation over time. As such, the factors showed remarkable stability. The partial results of their study are shown in Table 1 and reveal that most countries can be described through eighteen factors, although only sixteen are shown in the table ${ }^{9}$. Correlations among the factors resulting from the procedure were not found to be severe ${ }^{10}$. Most factors show strong face validity, and many relate to dimensions used in previous research (but then measured mainly through single-item scales).

\footnotetext{
${ }^{9}$ The excluded factors deal with Anglo-German and Asian populations.

${ }^{10}$ The highest correlation between any factors was 0.6 with only six significant correlation coefficients above 0.3 , for 153 possible coefficients.
} 
Table 1: Traditional literature dimensions

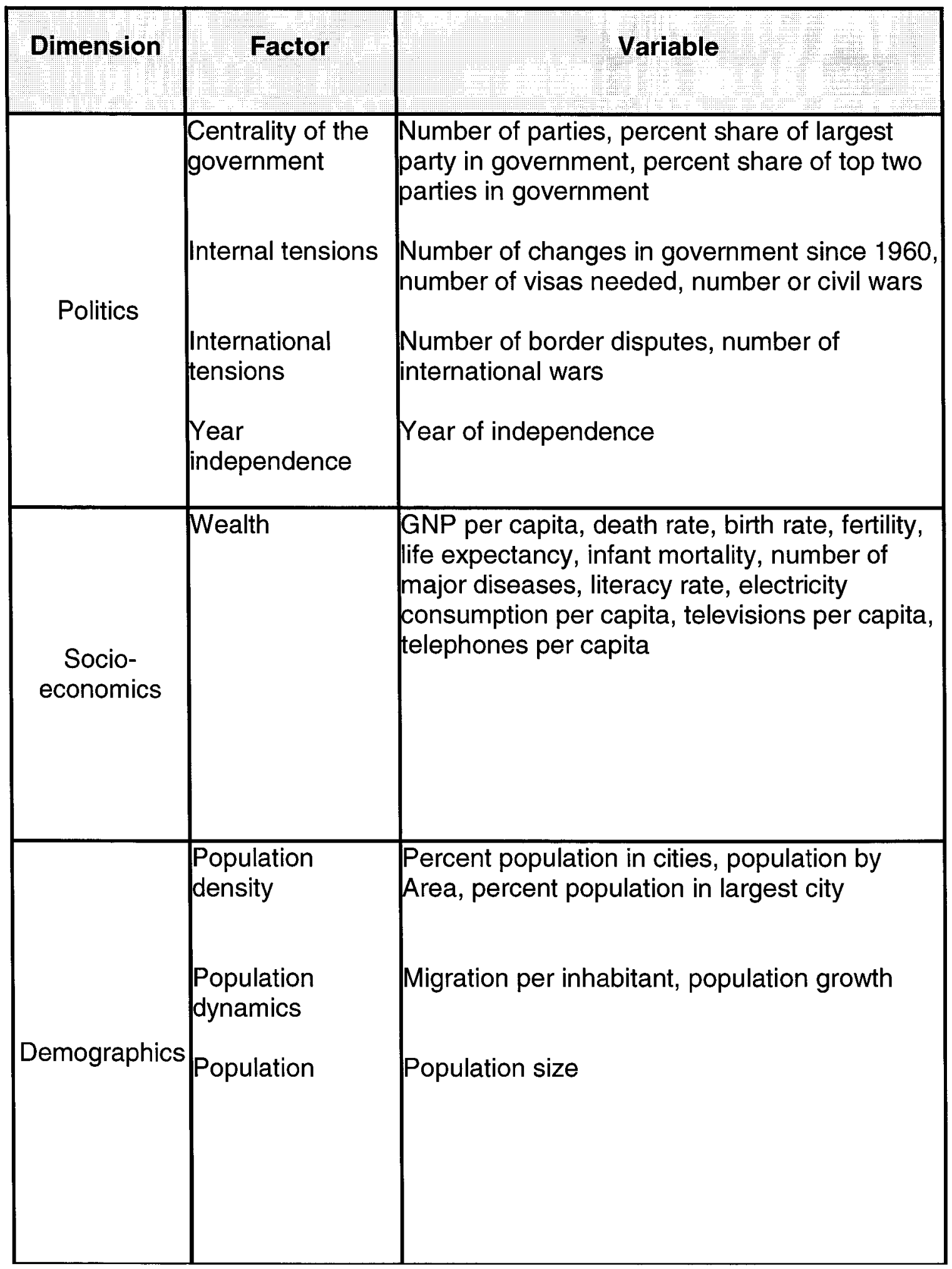




\begin{tabular}{|c|c|c|}
\hline Dimension & Factor & Variable \\
\hline Culture & $\begin{array}{l}\text { Social } \\
\text { heterogeneity }\end{array}$ & $\begin{array}{l}\text { Number of ethnic groups, percent of } \\
\text { population in largest ethnic group, number of } \\
\text { languages, percent of population in largest } \\
\text { language group } \\
\text { Percent Christian population, percent of } \\
\text { Roman Catholics }\end{array}$ \\
\hline Climate & $\begin{array}{l}\text { Temperature } \\
\text { Humidity } \\
\text { Rain }\end{array}$ & $\begin{array}{l}\text { Latitude, average temperature, monthly high } \\
\text { temperature, monthly low temperature, } \\
\text { monthly maximum rain } \\
\text { Morning minimum and maximum humidity, } \\
\text { afternoon maximum humidity } \\
\text { Afternoon minimum humidity, monthly } \\
\text { minimum rain, barometric pressure }\end{array}$ \\
\hline Geography & $\begin{array}{l}\text { Sea } \\
\text { Elevation }\end{array}$ & $\begin{array}{l}\text { Total area, inland waterways, number of } \\
\text { boundaries, length of boundary, number of } \\
\text { natural minerals } \\
\text { Length of coastline, water area, fishy supply } \\
\text { Elevation, sea territory }\end{array}$ \\
\hline
\end{tabular}

(Source: Dekimpe et al., 2000c)

\subsubsection{Construct Dimensions}

The data collected for each of the cases was examined using each of the three theoretical perspectives. The process allowed for the unique patterns of each 
case to emerge as well as enable comparison among cases for different patterns.

Ashraf (2005) discussed the insights generated from each wave of cases with industry participants and the thesis supervisor. Having multiple investigators had one key advantage. Convergent perceptions added to the sharpening of insights for empirical and theoretical grounding, while conflicting perceptions kept the group from premature closure. Multiple investigators enhanced the creative potential of the study due to their complementary insights as well as different perspectives which lead to the refinement of constructs. Convergence in the observations enhanced the confidence of the findings.

An essential feature of the research conducted by Ashraf (2005) was the comparison of the insights generated with the extant literature. A key to this process was to consider a broad range of literature. The literature discussing similar findings is important as it ties together literature streams normally not associated with each other. This results in an enhanced ability to generalize and a higher conceptual level.

Two important questions pertaining to the reach of closure needed to be answered: (i) when to stop adding cases, and (ii) when to stop iterating between theory and data. Adding to the number of cases was stopped when the industry participants suggested that the incremental learning was minimal. The iterations 
between theory and data were stopped when the supervisor decided that the incremental improvement and refinement to the insights were minimal.

As a result from the data collection and analysis process done by Ashraf (2005) a number of insights for each case were derived. These insights can be used to predict the outcomes of similar and future mobile payment systems. A proposition is defined as a statement about concepts that may be judged true or false if it refers to observable phenomena.

The rationale for the formulation of propositions lies in the data analysis by multiple investigators and a number of iterations between data and theoretical perspectives for within-case and cross-case comparison of patterns. In the research community, it is believed that humans are very poor processors of information and they may leap to premature or even false conclusions as a result of different information processing biases. The key to good cross case comparison is looking at the data in many divergent ways, with the help of multiple investigators.

From the study of the cases of mobile Internet and wireless payments as well as examining these cases through the lenses of various theoretical perspectives, the following propositions were generated to be used in future research on the adoption of mobile payments services. 


\section{Proposition 1}

The higher the number of young initial target users, the higher the number of users and the rate of adoption of mobile Internet service.

\section{Proposition 2}

The higher the number of professionals or business initial target users, the lower the number of users and the rate of adoption of mobile Internet service.

\section{Proposition 3}

The higher the number of high school or college student users, the higher the number of users and the rate of adoption of mobile Internet service.

\section{Proposition 4}

The lower the prices of handsets, the higher the number of young users and higher the rate of adoption of mobile Internet service.

\section{Proposition 5}

The lower the service usage charges for the mobile Internet service, the higher the number of young users and the rate of adoption of the mobile Internet service. 


\section{Proposition 6}

The higher the usefulness of the content, the higher the number of users and the rate of adoption of the mobile Internet service.

\section{Proposition 7}

The higher the number of content providers, the more innovative will be the content and the higher the number of users and the rate of adoption of mobile Internet service.

\section{Proposition 8}

The higher the number of simple content applications like ring tones, wallpapers, logos, melodies, songs and games, the higher the number of users and the rate of adoption of mobile Internet.

\section{Proposition 9}

The higher the number of users of existing data services like SMS, the higher the number of users and the rate of adoption of mobile Internet.

Proposition 10

The higher the availability of the complementary products and services, the higher the number of users and the rate of adoption of mobile Internet. 


\section{Proposition 11}

The higher the revenue share given by the mobile operators to the content providers, the more seeding of start-up firms (content providers) and higher the rate of adoption of mobile Internet.

\section{Proposition 12}

The higher the number of commuters using mass transit, the higher the number of users and the rate of adoption of mobile Internet and wireless payment services.

\section{Proposition 13}

The higher the number of compatible readers at point of sale and mass transit, the higher the number of users and rate of adoption of wireless payment services.

\section{Proposition 14}

The higher the number of credit card holders, the higher the number of users and the rate of adoption of wireless payment services.

\section{Proposition 15}

The greater the money spent by the operators to install POS terminals to seed the market, the higher the number of users and higher the rate of adoption of wireless payment services. 


\section{Proposition 16}

The greater the leveraging of large POS payments and mass transit ticketing networks, the higher the number of users and higher the rate of adoption of wireless payment services.

From these propositions a set of construct dimensions was derived:

1. Number of users; defined as the number of high school students, number of university and college students, number of users 15-34. This age range is the percentage of young, active and fun population that are more likely to adopt mobile payments. This dimension comes from theories (1) and (2). A study done by the National Internet Development Agency of Korea shows that the percentage of mobile Internet usage for each of these types of users is different (NIDA, 2004).

2. Number of professionals (lawyers, doctors, engineers, government employees); this dimension would be a measure of the importance attributed to status of waiting in line. It was also derived from theories (1) and (2). The study done by NIDA in (2004) shows the percentages of mobile Internet usage are different for each of these segments of the population. 
3. Price of handsets and price of service usage; this dimension comes from theory (1) and may actually be incorporated into the diffusion model by using the Generalized Bass Model (Bass, Krishnan, and Jain, 1994). This model could be a good fit for a product or service in which price will increase or decrease at a very fast rate, of course, the model is still subject to data availability.

4. Number of users that can afford the system; this dimension comes from theory (1) and can be measured in terms of the disposable income availability.

5. Percentage of commuters; this dimension comes from theory (1) and is part of the sample matching being incorporated into the diffusion model.

6. Technology compatibility, this dimension comes from theory (1) and can be measured by the number of SMS users or the amount of SMS traffic.

7. Availability of ancillary systems; this dimension comes from theory (1). Research also shows that this dimension has a positive effect on adoption (Gopalakrishnan, Wischnevsky, and Damanpour, 2003). This can be measured by the availability of $3 G$ and the number of broadband connections to homes. 
8. Number of point of sale terminals; this dimension comes from theory (1).

9. Number of competing systems; this dimension comes from theory (1) and can be measured by the number of credit card and debit card holders.

10. Position in the value network, this dimension comes from theoretical perspective (3) and may be measured as the number of content providers and handset manufacturers with exclusive agreements.

These ten construct dimensions have an impact on the adoption of mobile payment systems. This research will examine how these dimensions affect the parameters of diffusion models. The dimensions used will depend on the model chosen as well as the availability of information.

\subsection{Control Dimensions}

The industry participants were asked to provide the researchers with a view of their existing market assessment approach. They contributed the following observations:

1. Exploit both internal and external information sources; taking care to obtain multiple inputs: (i) refer to available literature, studies, market intelligence to assemble an understanding of the target market, (ii) solicit 
market-size insights from employees in that target market and (iii) include market insights from incumbent customers in the target market. Do not rely on sole sources of information.

2. Estimates benefit from application of the researcher's residual knowledge and experience, to interpret and calibrate the collected information. Statistical methods may be used but this varies with the practitioner's preferences and skills.

3. When building the actual forecast, first estimate the operators' market share; from that, estimate our company's market share.

4. Forecasting models are often updated on the basis of customer feedback.

When the industry participants were asked to provide a list of dimensions that they would consider relevant to the adoption of mobile payments they compiled the following list:

1. Service pricing for mobile payments.

2. Disposable income level.

3. Number of credit card users or number of debit card users. 
Due to unavailability of data we were unable to develop a forecast based on these dimensions. Although we are unable to show a quantitative comparison anchored around the control dimensions; based on the feedback provided by our industry participants and the results of the research, the use of theoretical perspectives does add value to their current market assessment approach.

\subsection{Identify and Operationalize Regions to be Addressed}

The region of interest is South America because; (i) there is a lack of diffusion research in this area; (ii) the countries in this region are interdependent with one another; and (iii) mobile payments in this area have not yet been launched.

It is important to define the regions to be addressed in a way that is practical for company managers. This is why it was decided to divide the regions according to the three major operators in the area: Telecom Italia, Telefónica Móviles and América Móvil. These three operators account for over $80 \%$ of the market share in South America ${ }^{11}$. The intent was to view the area from the perspective of an equipment supplier and determine which operator had the largest addressable market. Table 2 shows the countries in which each operator is present, as well as the percentage of market share they own.

\footnotetext{
${ }^{11}$ Source: 2004 Latin America Mobile Communications Market Report, Executive Summary and key highlights found at www.budde.com
} 
Table 2: Operator market share

\begin{tabular}{|l|l|}
\hline \multicolumn{1}{|c|}{ Operator } & \multicolumn{1}{|c|}{ Countries } \\
\hline Telecom Italia Mobile (TIM) & Brazil 22\% \\
\hline Telefónica Móviles (TEM) & $\begin{array}{l}\text { Argentina 42\%, Brazil 40\%, Chile } \\
50 \%, \text { Colombia 32\%, Ecuador 32\%, } \\
\text { Peru 69\%, Uruguay 36\%, Venezuela } \\
46 \%\end{array}$ \\
\hline América Móvil (AMX) & \\
& $\begin{array}{l}\text { Argentina 27\%, Brazil 21\%, Colombia } \\
55 \%, \text { Ecuador 66\%, Peru 29\%, } \\
\text { Uruguay 1\% }\end{array}$ \\
\hline
\end{tabular}

(Source: Operator websites and Telecom analyst reports)

The remaining percentage of market share is owned by a local provider in each country. The only country in which a local provider owns the majority of the market share is Uruguay.

Although the original intent was to group the forecast into three regions, we were unable to establish a robust method to do so. The main issue being that the resulting forecasts for Latin America did not give us an accurate estimate for the overall addressable market, but instead gave us an estimate of the expected performance of the operator who is first to market. A more detailed discussion on this issue will be given in Section 5. So the results are expressed at the level of each individual country.

\footnotetext{
${ }^{12}$ As of December 2005 America Móvil established operations in the countries of Paraguay and Chile, with 172,000 and 1.9 million subscriber respectively. A consistent number for market share was not obtained, so these numbers have been excluded from this research.
} 
One of the goals of the method proposed in this research is that it should be reusable across regions. So although the current region of interest is South America, the method should be applicable to any region specified.

\subsection{Select Diffusion Model}

When selecting a diffusion model, there are several considerations that need to be kept in mind (Dekimpe et al. 2000c) ${ }^{13}$ :

1. The model should be capable of empirical estimation and should yield reasonable and valid parameter estimates. The credibility of the model will be enhanced as the number of data sets used for the empirical estimation of the parameters increases.

2. The model should be managerially useful. This means that the parameters of the model can be expressed in such a way that management may be able to interpret them either by intuition or by comparisons with other products.

3. The model should be able to be implemented for new products without direct market data, since this is the period with greatest strategic importance.

${ }^{13}$ A complete list of these considerations is outlined in Section 2.3.6. 
One of the goals of the method proposed in this research is that it will be independent of the diffusion model selected. The objective is to make diffusion model estimates more reliable by introducing relevant theoretical perspectives and dimensions. The appropriate model will depend on the goal of the forecast and on the product context or service being studied. For example in the case of technology driven adoptions a Fisher-Pry model might be applicable, in contrast to a consumer driven adoption in which a Gompertz model would work best (Vanston and Hodges, 2004).

The model that was chosen for this research is a staged estimation procedure proposed by Dekimpe et al., (1998) to be modeled using Crystal Ball 7. Given the early stage market interest and the availability of data, this was the best diffusion model available for this research.

Using the four components that were described in section 2.3.5, Dekimpe et al., (1998) derived the following model in Equation 4:

$$
n_{t}=\left[A+B^{*}\left(\frac{N_{t-1}}{C * S}\right)\right]\left[C * S-N_{t-1}\right]
$$

The method for the model estimation consists of three stages that must occur in sequence: (i) external estimation and validation of the exogenous social system sizes and long-run adoption ceilings; (ii) calculation of the time origin intercept term, A, which is exogenous to the subsequent growth process; and (iii) internal 
estimation of the growth parameter, B, which is endogenous to the social system, the ceiling and the time origin intercept.

Crystal Ball ${ }^{14}$ is an analytical tool that conducts risk analysis by using stochastic assumptions and Monte Carlo simulation to create random outputs ${ }^{15}$. Our industry participants were already using Crystal Ball to perform simulations on spreadsheet models; this tool was decided to be used based on their recommendations and interest. The forecasts that result from the simulations help quantify areas of risk so decision makers can have as much information as possible to support their decisions. A basic model was built in Crystal Ball that consisted of assumptions and forecast statistics. Assumptions represent uncertainties and are entered into spreadsheets as probability distributions; these distributions are selected to represent the variability faced in real world decisions. The forecast statistic is a summary of the values of a forecast distribution such as the mean, standard deviation and variance. While a more complicated model that includes decisions and optimizations can be built, it was decided to keep the model simple and focus on the use of theoretical perspectives to improve the inputs. The following is an overview of the major steps to follow when modeling with Crystal Ball:

\footnotetext{
${ }^{14}$ For more information on this software visit the manufacturer website www.decisioneering.com

${ }^{15}$ Monte Carlo simulation can only approximate a real world situation. When a model is built it is important to carefully examine the nature of the problem and continually refine the model until it is as close to the actual scenario as possible.
} 
1. Identify the problem in such a way that it can be modeled using a spreadsheet.

2. Quantify the uncertainty in the model's variables and any statistical relationship between them (i.e. any correlations between the assumptions).

3. Model the uncertain variables in the smallest component for which you have historical data collected.

4. Make sure each assumption has only been included once in the model.

5. Choose the distribution that best fits the assumption.

6. Enter the requirements for the distribution (i.e. for a normal distribution enter the mean and the standard deviation).

7. Define the forecast; forecast cells contain formulas that refer to one or more of the assumption cells.

8. Run a single step simulation initially to examine the plausibility of the results.

9. Run the complete simulation.

10. Analyze the forecasts.

11. Perform a sensitivity analysis; these are used to evaluate the impact of the assumptions on the forecast.

12. Make decisions based on the analysis. 
Using Crystal Ball overcomes the main limitations of spreadsheet models, which are: (i) single point estimates explain what is possible, not probable and (ii) spreadsheets are unable to explore the entire range of possible outcomes.

The combination of a staged estimation procedure and Crystal Ball is the best combination available for this research. The use of the staged estimation will allow us to overcome operationalization issues that face the Bass model, while the use of Crystal Ball will allow us to view our inputs as distributions instead of single point estimates. This is important since a forecast for a region in which mobile payments have not been adopted is being constructed.

\subsection{Use Theoretical Perspectives and Dimensions to Define the Inputs of the Diffusion Model}

This step will depend on the diffusion model selected, since each model requires a different set of inputs. In the case of the Dekimpe et al., (1998) model, the inputs are; the social system (S); the ceiling (C); the time origin intercept (A); and the growth rate $(B)$. Theoretical perspectives were used to help define the social system and the ceiling. The time origin intercept and the growth rate will be calculated using existing mobile phone, mobile Internet and mobile payment data as analogies.

The social system size (S) is defined as the population within which the innovation diffuses. In the case of consumer products, the traditional definition of $S$ is the total population. 
In order to use theoretical perspectives to define $S$ we need to consider the groups of the population who are likely to adopt mobile payments. From the dimensions that were developed in the third step of the research method $S$ is defined as: (i) the number of user types, which include the young, active, fun population (ages 15-34) and the number of university and college students enrolled in engineering and science; (ii) number of commuters; and (iii) the number of professionals (including lawyers, doctors and engineers).

Due to the availability of data across the countries involved in our study it was necessary to limit the definition of social system. Tables 3 shows the definition of social system for developed nations and Table 4 shows the definition of social system for developing nations. The data sources for these dimensions were kept consistent across countries in order not to introduce unnecessary variance.

It is important to highlight that traditional literature assumes one definition of social system across countries. In some cases it is important to be consistent (e.g. when building a model), but if the intent of the forecast is to aid managers in making decisions, the market needs to be examined from an individual point of view. This research illustrates that the relevant social system and ceiling will vary from one country to the next; since the drivers for adoption also vary from country to country. 
The definition of $S$ for developed nations used in this research is the number of commuters plus the population between the ages of 15-34. The number of professionals and students was unable to be used due to inconsistent reporting across countries. The number of university and college students is a very small percentage of the population (e.g. .004 for Japan, even smaller for the United States), so this omission should not affect the results significantly. The exclusion of the number of professionals could have a bigger impact on the results, but the main goal of this research is to illustrate the use of theoretical perspectives and show how it can aid managers by providing them with the best possible forecast available to them.

To avoid counting members of the social system twice, the number of commuters age 15-34 was first calculated ${ }^{16}$. This number was then subtracted from the total number of commuters and the result was added to the population between the ages of 15 to 34 .

\footnotetext{
${ }^{16}$ It was assumed that commuters are indicative of a random sample of the population. The percentage of the population who is of ages 15-34 was used to calculate the percentage of commuters ages 15-34.
} 
Table 3: Definition of social system and ceiling for developed nations

\begin{tabular}{|c|c|c|}
\hline $\begin{array}{c}\text { Japan, South } \\
\text { Korea and } \\
\text { Europe }\end{array}$ & $\begin{array}{c}\text { Traditional } \\
\text { Literature }\end{array}$ & Construct \\
\hline $\mathbf{S}$ & Total population & Commuters + Young, Active, Fun population \\
\hline $\mathbf{C}$ & $\begin{array}{l}\text { \% of pop who is } \\
\text { literate, lives in } \\
\text { urban areas and } \\
\text { can afford the } \\
\text { service }\end{array}$ \\
\hline
\end{tabular}

The number of commuters is taken into account for developed nations, but not for developing nations. While certain cities in Latin America are going through some major changes in their transport systems, the majority of the people using it are people of limited financial resources who use it out of necessity. A topic review paper prepared by Prointec Inocsa Stereocarto of Spain for the World Bank Group highlights some of the shared characteristics of the transport systems in Latin America. Among these issues are the lack of availability, planning, regulation and integration. Mass transit rail systems are barely available; underground rail transit is found in just a few cities and suburban railways were never built or have gradually been discontinued and are currently used for hauling goods. In Latin America only twelve cities have underground transit facilities, six of them are in Brazil; while tramcars or narrow gauge railways are only operated in fifteen cities. Rail systems amount to slightly over $300 \mathrm{~km}$; while over 100 million people live in Latin America. Wherever mass transit services are not available, different types of vehicles take care of the demand. 
Some buses accommodate 50 to 60 passengers and some mini buses can transport 18 to 30 . In some countries taxicabs, tricycles, and pickups complete the transport means available. In addition to the vehicles with more or less preset routes and schedules, there are also informal transport operations which service specific origin destination running and departing when the vehicles are full. Informal transportation services are often a cover up for illegal routes, stops and, even, the vehicles' repair. As a consequence there is an overall lack of safety, service quality and unfair competition implied for scheduled runs. Any possible coordination of transport services is rather limited. Passengers have to walk long distances to access the bus lines, which makes transfers hard and leads to passengers paying more than one fare. Colectivos are the medium-sized buses of Buenos Aires, Bogotá or Lima which are some times convenient for passengers because of their somewhat unscheduled routes and stops, but the speed and even some stops are often rearranged as they look for additional passengers. The routes are also established by the operators based on their convenience. In some cases the average travel distance is much longer than the distance between the actual start and destination. This is an example of operators resorting to zigzagging routes to obtain more passengers.

Overall the transport systems in Latin America are lagging and there are political, financial and legal obstacles that stand in the way of its development. In contrast, commuters in developed nations have access to a multitude of safe and reliable public transport vehicles. 
Passengers in developed nations use public transport as a form of convenience for reasons such as avoiding traffic and parking fees; it is not a reflection on their income level. Unlike Latin America where the passengers of the public system have to use it because most of them don't own private vehicles.

Since the commuters had to be excluded for developing nations, we defined the social system as the population ages $15-34$ who is literate. It is important to note that the literacy rate was used as a proxy for income, which we found to be useful in the case of South America; this is because according to UNESCO there is a correlation between income and literacy. Statistics that support this correlation include; (i) per capita income in countries with a literacy rate less than 55 percent averages about $\$ 600$; (ii) per capita income in countries with a literacy rate between 85 and 95 percent is $\$ 3,700$; and (iii) per capita income in countries with a literacy rate above 96 percent is $\$ 12,600$. Based on this correlation we are assuming that, in South America, someone that is able to read and write is more likely to posses the income required to afford a mobile phone.

Our definition of $S$, for Latin America, excludes the number of professionals above the age of 34 , which could play a role in the end result. We decided not to include this number to due to inconsistent reporting across countries. While it is possible to obtain the breakdown by profession that is needed to be included, this information is not available as public data. 
Table 4: Definition of social system and ceiling for developing nations

\begin{tabular}{|c|c|c|}
\hline Latin America & Traditional & \multicolumn{1}{c|}{ Construct } \\
\hline S & Total population & $\begin{array}{l}\text { Young, Active, Fun population + Literate } \\
\text { population }\end{array}$ \\
\hline C & $\begin{array}{l}\text { \%of pop who are } \\
\text { iterate, lives in } \\
\text { urban areas and } \\
\text { can afford the } \\
\text { service }\end{array}$ \\
\hline
\end{tabular}

Certain percentage of the population will never find sufficient intrinsic utility for the innovation. Therefore it is necessary to define an exogenous ceiling, $\mathrm{C}$, which is independent of the size of the social system. The definitions of ceiling used in this study are shown in Tables 3 and 4 . In their study Dekimpe et al., (1998) define the ceiling as "the percentage of the population who is literate, lives in urban areas and has sufficient income to afford basic telephone service", this will be used as the traditional way of defining $C$.

For developed nations, the ceiling was defined as the percentage of the population who already owns cell phones. In developed countries, the cellular market is mature and is relatively saturated and stable, with almost anyone who might want a mobile phone owning one.

For developing nations, the cellular market is emerging and mobile phone penetration is increasing. Moreover, the social system for the developing 
markets include groups for whom existing cell phone value propositions may not apply, but may see value in the mobile payments services. Consequently, our final definition of $C$ for developing nations is the percentage of the population who lives in urban areas, since in these countries this is the percentage of the population with access to mobile coverage.

When using theoretical perspectives to define the inputs of a diffusion model it is important to examine the available list of dimensions and use the ones that are most relevant for the specific input. Once the determination of relevancy has been established, examine the availability of data. Whether the data is public or obtained from private sources, it is important to keep the measurement consistent. For the case in which there are no construct dimensions available that would help with the definition of the inputs, the available theoretical perspectives and cases would have to be reexamined

\subsection{Use Historical Data and Theoretical Insights to Estimate the Parameters of the Diffusion Model}

When little data is available, data from similar cases can be used to estimate the parameters of the diffusion model (Bass, 1969). For this research, it was necessary to use adoption data from mobile payments, mobile Internet and mobile phones in other regions to estimate the parameters of the diffusion model. The list of available cases in Section 3.2.2 was examined and searches were performed in order to find the number of adopters since the service was 
launched. The data was found on the operator websites, their annual and quarterly reports, monthly fact sheets and telecommunication reports.

Some of the available cases were not applicable to the type of mobile payment that our industry participant was interested in for South America. For this reason, the following cases were removed from the list:

1. Mobipay (Mobipay International, Spain).

2. Smartpay (Smartpay, China).

3. Dexit (Dexit, Canada).

4. Octopus (Octopus Cards Ltd., Hong Kong - China).

The following cases were also removed from the list due to inconsistent or lack of reporting for adoption data:

1. m-mode (AT\&T Wireless, United States).

2. FeliCa i-mode (NTT DoCoMo, Japan).

3. Sonera Shopper (TeliaSonera, Finland).

4. Zoop (LG Telecom, South Korea).

5. EZi (LG Telecom, South Korea). 
With the addition of a new case, the final list of historical cases available is the following:

1. i-mode (NTT DoCoMo, Japan).

2. Moneta (SK Telecom, South Korea).

3. Vodafone Live! (Vodafone Group, Europe). ${ }^{17}$

4. Vivo Wap (Vivo, Brazil).

5. EZweb (KDDI, Japan).

6. Vodafone Live! (Vodafone Group, Japan).

7. Nate (SK Telecom, South Korea).

8. Magic-N (Korea Telecom Freetel, South Korea).

9. BankON (LG Telecom, South Korea).

Year by year adoption data was collected for each case, starting one year after the application was launched. The source was kept consistent when examining each individual case, in order to minimize any reporting error. From the yearly adoption data the value for the time origin intercept, $A$, can be calculated as well as the growth rate, B. Some applications had more degrees of freedom than others, depending on their launch date. $A$ is defined as the number of first year adopters divided by the market potential (i.e. $A=n / C^{*} S$ ). By using the number of first year adopters of a specific operator in the calculation of A, we are making

\footnotetext{
${ }^{17}$ Vodafone Live! Europe was split into 9 cases, the numbers for the Vodafone Live! application were not obtained, so cell phone adoption was examined in the countries of UK, Spain, France, Australia and Portugal. Growth rates were used for all countries, but due to availability of data the time origin intercept, A, was only calculated for the UK.
} 
innovation operator dependant (i.e. it is not just technology and country dependant).

B was obtained by using the following formula:

\section{Equation 5: Growth rate}

$$
a(t)-a(t-1) / a(t-1)
$$

- Where $a$ is the number of adoptions for a given time, $t$.

Growth only occurs after the first year of adoption. The growth rate is also operator and not just technology specific, meaning that this calculation of growth rate accounts for mergers and acquisitions that the operator was involved in ${ }^{18}$.

\subsubsection{The Case of the Japanese Operators}

For each case a forecast was built using the model given in Equation 4. Two forecasts were done for the traditional definition of $\mathrm{S}$ and $\mathrm{C}$. The first traditional forecast would assume a constant growth rate and the second would use the growth rate derived from actual adoptions ${ }^{19}$.

The construct forecast used the definitions of $S$ and $C$ illustrated in Tables 3 and 4. The results for the Japanese operators are given in Figures 5, 6 and 7.

\footnotetext{
${ }^{18}$ The growth rate could also be calculated using each operator's adoption data by keeping the parameters C, S and A fixed (Dekimpe et al., 1998).

${ }^{19}$ The values for the traditional definitions of $S$ and $C$ where obtained from the appendix of Dekimpe et al., (1998).
} 
Figure 5: i-mode forecast

\section{i-mode}

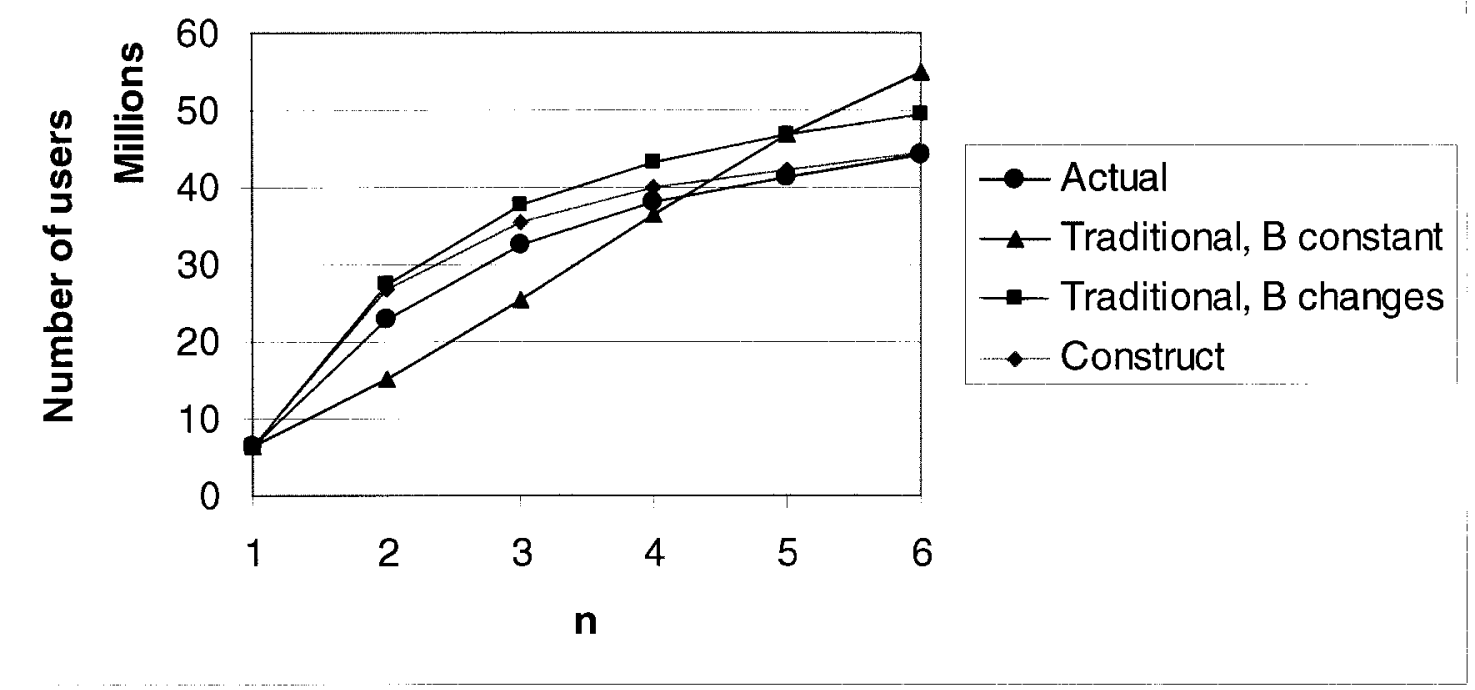

Figure 6: EZWeb forecast

\section{EZWeb}

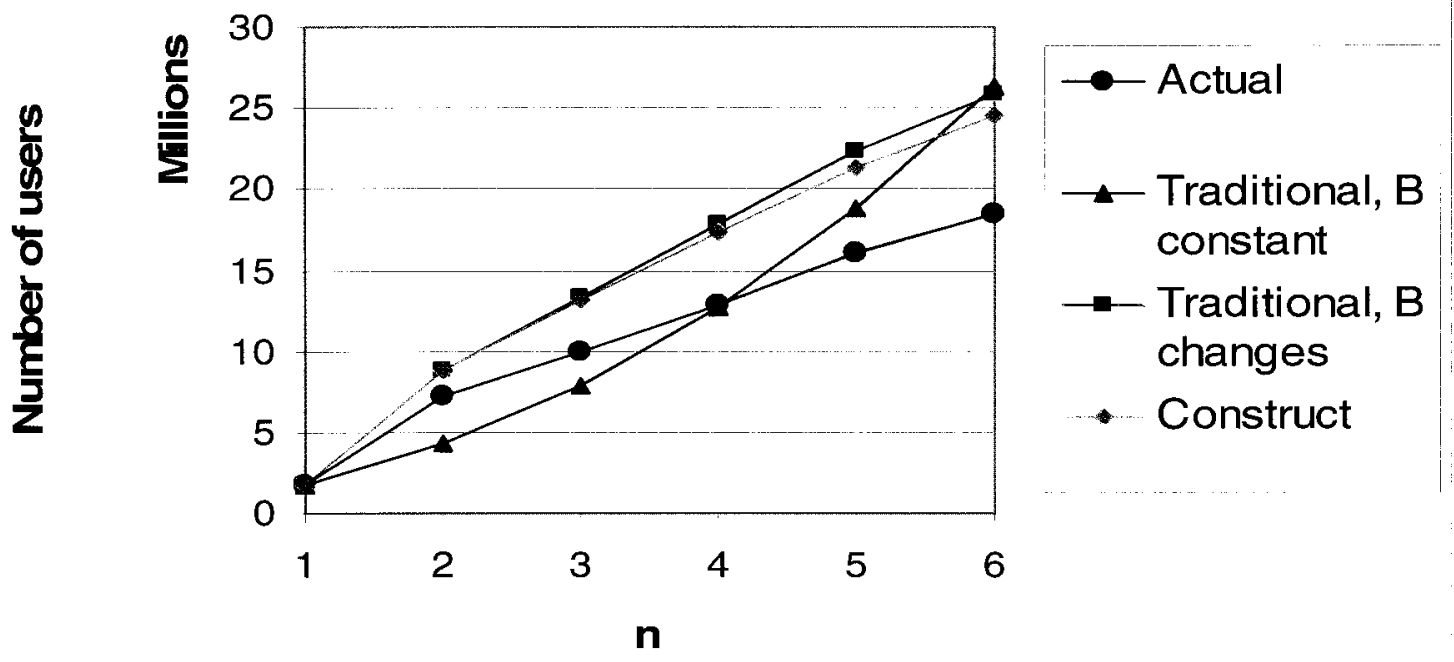


Figure 7: Vodafone Live! forecast

\section{Vodafone Live!}

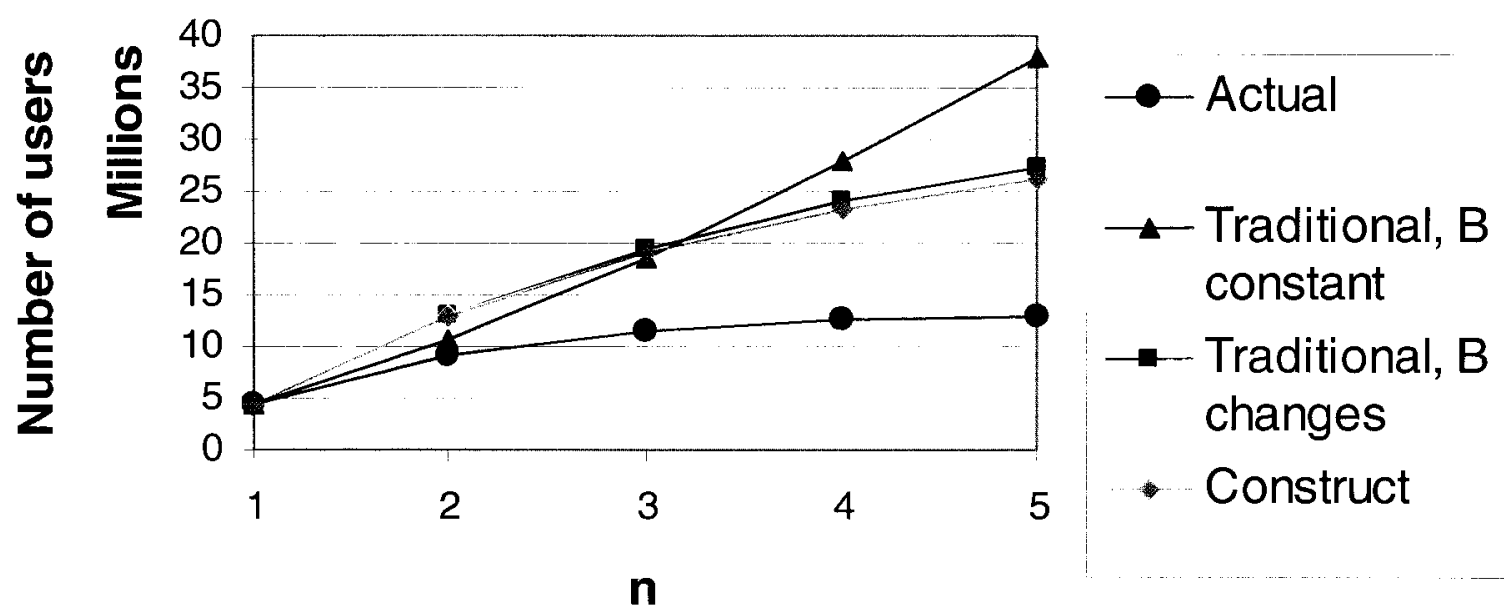

In all of these three cases the construct based forecast is closest to the actual number of adoptions. In the case of $\mathrm{i}$-mode, for $\mathrm{t}=6$, the construct forecast differs from actual adoptions by less than 100 thousand. Table 5 shows the difference between the forecasts and the actual number of adoptions for i-mode. 
Table 5: Difference between forecast and actual adoptions for the case of i-mode

\begin{tabular}{|c|c|c|c|}
\hline $\mathbf{n}$ & Traditional, B constant & Traditional, B changes & Construct \\
\hline $\mathbf{2}$ & $-7,959,285$ & & \\
\hline $\mathbf{3}$ & $-7,190,566$ & $4,221,200$ & $3,717,179$ \\
\hline $\mathbf{4}$ & $-1,505,327$ & $5,091,631$ & $3,005,738$ \\
\hline & & $5,085,716$ & \\
$\mathbf{5}$ & $5,590,167$ & $5,314,429$ & $1,745,854$ \\
\hline & & & $1,063,227$ \\
\hline $\mathbf{6}$ & $10,576,222$ & $5,170,886$ & \\
\hline
\end{tabular}

From Figures 5, 6 and 7 we note that the construct forecast is most accurate for the operator with the largest percentage of the market share (i.e. i-mode). By following the steps of the staged estimation procedure the traditional and construct methods estimate the addressable market for Japan to be approximately 65 million and 53 million respectively. In the case of Vodafone Live!, the operator which is third in the market place, while the construct forecast is still closer to actual adoptions, it differs from actual adoptions by 13 million. This is because the diffusion model chosen is not taking into consideration that there is more than one player reaching for the addressable market. While this is a practical limitation of the diffusion model selected, the method still produces better results than traditional ones and it is the first step towards normative theory building. 
To estimate the number of adoptions at time $t$, the model uses all the previous time periods' data. A growth rate can be calculated for all the previous years and the last available growth rate will be the one used to forecast the remaining time periods of interest. The idea is that as the number of observations increases, the forecast becomes more accurate. The following tables are used to illustrate this point for the case of $i$-mode.

From Table 6 we observe that when only two years of adoption data are available both, the traditional and construct, forecasts are not very accurate in estimating subsequent years. This is due to the high growth rate that $\mathrm{i}$-mode experienced in the first year (i.e. 254\%). Maintaining the first year's growth rate is unlikely for any operator, and using the model alone does not provide a plausible forecast. Existing literature suggests that traditional methods require more than ten observations for useful parameter estimates.

Table 6: i-mode forecast with two years of adoption data

\begin{tabular}{|c|c|c|c|c|}
\hline $\mathbf{n}$ & $\begin{array}{c}\text { Traditional B } \\
\text { changes }\end{array}$ & $\begin{array}{c}\text { Difference from } \\
\text { actual adoptions }\end{array}$ & Construct & $\begin{array}{c}\text { Difference from } \\
\text { actual adoptions }\end{array}$ \\
\hline $\mathbf{2}$ & $\mathbf{2 7 , 2 6 0 , 2 0 0}$ & $4,221,200$ & $26,756,179$ & $3,717,179$ \\
\hline $\mathbf{3}$ & $71,419,471$ & $38,781,471$ & $64,049,270$ & $31,411,270$ \\
\hline $\mathbf{4}$ & $54,013,446$ & $15,905,446$ & $31,047,754$ & $-7,060,246$ \\
\hline $\mathbf{5}$ & $78,969,555$ & $37,651,455$ & $66,963,622$ & $25,645,522$ \\
\hline $\mathbf{6}$ & $35,866,619$ & $-8,422,881$ & $22,915,439$ & $-21,374,061$ \\
\hline
\end{tabular}


In Table 7 we see that with three years of adoption data the traditional forecast is overestimating adoptions by $15-34 \%$, as the time period increases so does the overestimation. The construct based forecast is overestimating adoptions by 9$15 \%$, and the overestimation is not proportional to the increase in time period (i.e. the overestimation from year 5 to year 6 actually decreases by $1 \%$ ).

Table 7: i-mode forecast with three years of adoption data

\begin{tabular}{|c|c|c|c|c|}
\hline $\mathbf{n}$ & $\begin{array}{c}\text { Traditional B } \\
\text { changes }\end{array}$ & $\begin{array}{c}\text { Difference from } \\
\text { actual adoptions }\end{array}$ & Construct & $\begin{array}{c}\text { Difference from } \\
\text { actual adoptions }\end{array}$ \\
\hline $\mathbf{2}$ & $27,260,200$ & $4,221,200$ & $26,756,179$ & $3,717,179$ \\
\hline $\mathbf{3}$ & $37,729,631$ & $5,091,631$ & $35,643,738$ & $3,005,738$ \\
\hline $\mathbf{4}$ & $\mathbf{4 7 , 1 8 1 , 5 9 4}$ & $9,073,594$ & $42,838,560$ & $4,730,560$ \\
\hline $\mathbf{5}$ & $\mathbf{5 4 , 5 0 5 , 0 8 1}$ & $13,186,981$ & $47,756,288$ & $6,438,188$ \\
\hline $\mathbf{6}$ & $59,390,002$ & $15,100,502$ & $50,650,812$ & $6,361,312$ \\
\hline
\end{tabular}

Table 8 shows that with four years of adoption data the traditional forecast is still overestimating sales by $13-17 \%$, while the overestimation of the construct forecast has reduced to less than $4.7 \%$ for subsequent years. 
Table 8: i-mode forecast with four years of adoption data

\begin{tabular}{|c|c|c|c|c|}
\hline $\mathbf{n}$ & $\begin{array}{c}\text { Traditional B } \\
\text { changes }\end{array}$ & $\begin{array}{c}\text { Difference from } \\
\text { actual adoptions }\end{array}$ & Construct & $\begin{array}{c}\text { Difference from } \\
\text { actual adoptions }\end{array}$ \\
\hline $\mathbf{2}$ & $27,260,200$ & $4,221,200$ & $26,756,179$ & $3,717,179$ \\
\hline $\mathbf{3}$ & $37,729,631$ & $5,091,631$ & $35,643,738$ & $3,005,738$ \\
\hline $\mathbf{4}$ & $43,193,716$ & $5,085,716$ & $39,853,854$ & $1,745,854$ \\
\hline $\mathbf{5}$ & $47,892,509$ & $6,574,409$ & $43,260,103$ & $1,942,003$ \\
\hline $\mathbf{6}$ & $51,808,998$ & $7,519,498$ & $45,933,684$ & $1,644,184$ \\
\hline
\end{tabular}

Tables 9 and 10 show that while the traditional forecast is still giving an overestimation of above $10 \%$, the construct forecast gets as close as $0.2 \%$ to actual adoptions.

Table 9: i-mode forecast with five years of adoption data

\begin{tabular}{|c|c|c|c|c|}
\hline & $\begin{array}{c}\text { Traditional B } \\
\text { changes }\end{array}$ & $\begin{array}{c}\text { Difference from } \\
\text { actual adoptions }\end{array}$ & Construct & $\begin{array}{c}\text { Difference from } \\
\text { actual adoptions }\end{array}$ \\
\hline $\mathbf{2}$ & $27,260,200$ & $4,221,200$ & $26,756,179$ & $3,717,179$ \\
\hline $\mathbf{3}$ & $37,729,631$ & $5,091,631$ & $35,643,738$ & $3,005,738$ \\
\hline $\mathbf{4}$ & $43,193,716$ & $5,085,716$ & $39,853,854$ & $1,745,854$ \\
\hline $\mathbf{5}$ & $46,632,529$ & $5,314,429$ & $42,381,327$ & $1,063,227$ \\
\hline $\mathbf{6}$ & $49,620,755$ & $5,331,255$ & $44,488,348$ & 198,848 \\
\hline
\end{tabular}


Table 10: i-mode forecast with six years of sales data

\begin{tabular}{|c|c|c|c|c|}
\hline & $\begin{array}{c}\text { Traditional B } \\
\text { changes }\end{array}$ & $\begin{array}{c}\text { Difference from } \\
\text { actual sales }\end{array}$ & Construct & $\begin{array}{c}\text { Difference from } \\
\text { actual sales }\end{array}$ \\
\hline $\mathbf{2}$ & $27,260,200$ & $4,221,200$ & $26,756,179$ & $3,717,179$ \\
\hline $\mathbf{3}$ & $37,729,631$ & $5,091,631$ & $35,643,738$ & $3,005,738$ \\
\hline $\mathbf{4}$ & $43,193,716$ & $5,085,716$ & $39,853,854$ & $1,745,854$ \\
\hline $\mathbf{5}$ & $46,632,529$ & $5,314,429$ & $42,381,327$ & $1,063,227$ \\
\hline $\mathbf{6}$ & $49,460,386$ & $5,170,886$ & $44,381,935$ & 92,435 \\
\hline
\end{tabular}

A similar comparison was done for all the cases being examined and from this we derive that our proposed method, of incorporating theoretical perspectives into the inputs of prediction models, gives us much better estimations than traditional definitions of the inputs. In all other cases, except one in South Korea, using the construct dimensions showed improvements to the traditional forecasts.

From the cases of the Japanese operators we also obtain three different values for A. As expected, i-mode has the highest value with 0.121 . The value for Vodafone Live! $(0.085)$ is 1.5 times higher than the value for EZWeb $(0.033)$. Although EZWeb has a lower value for A, five years after their introduction, EZWeb has over 2 million more adopters than Vodafone Live!. 


\subsubsection{The Case of the South Korean Operators}

Other cases that are worth highlighting are the ones of two operators in South Korea. The traditional definitions of social system and ceiling underestimate the total addressable market for South Korea (i.e. the traditional forecast estimates the market to be 7.2 million, while the construct forecasts estimates the market to be 18.3 million - actual number of adoptions for South Korea Telecom alone are above 17 million). The result of this underestimation is that after year three the incremental growth of adoptions, for the traditional forecast, is minimal. Figure 8 shows the results of the forecast for South Korea Telecom.

\section{Figure 8: SKT forecast}

\section{SKT}

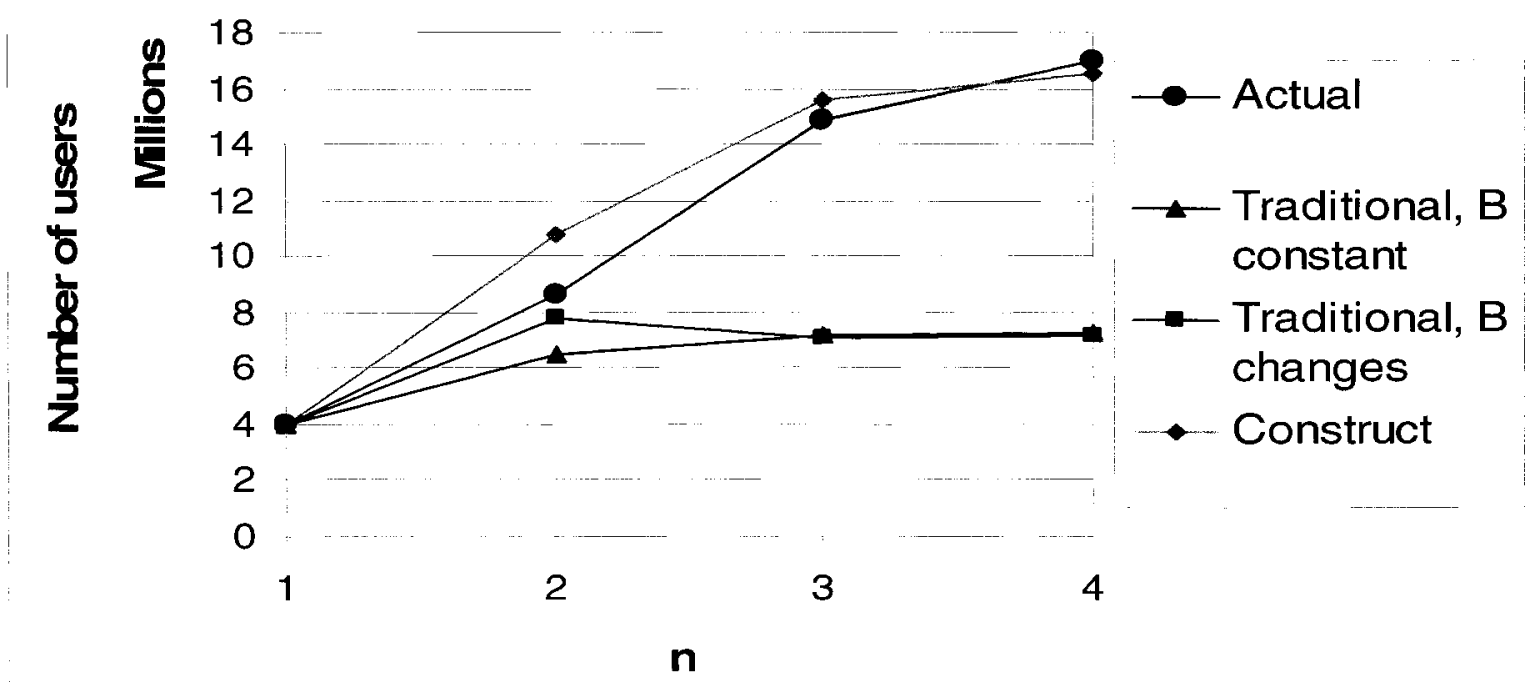

Magic@ is the only case examined in which the construct based forecast does not yield the most accurate estimation. Figure 8 shows the actual forecast and 
Table 11 shows the difference between the forecasts and actual number of adoptions. While a more detailed analysis based on the circumstances that surrounded the adoption of the Magic@ service are required; a preliminary analysis leads us to believe that this is due to the high number of first year adopters of the service. Magic@ holds a record for most adoptions in the shortest period of time, with over $52 \%$ of their total number of users adopting the service in the first year. This high number of initial adopters leads to an overestimation of the time origin intercept $A$ (i.e. an overestimation of the coefficient of innovation) and therefore and overall overestimation of the total number of adoptions. Since the traditional market is much smaller than the construct derived one, after year two the incremental number of adoptions is minimal and therefore closer to the actual adoptions of the Magic@ service. Table 11 show a breakdown of the difference between each of the forecasts and the total number of adoptions. 
Figure 9: Magic@ forecast

\section{Magic@}

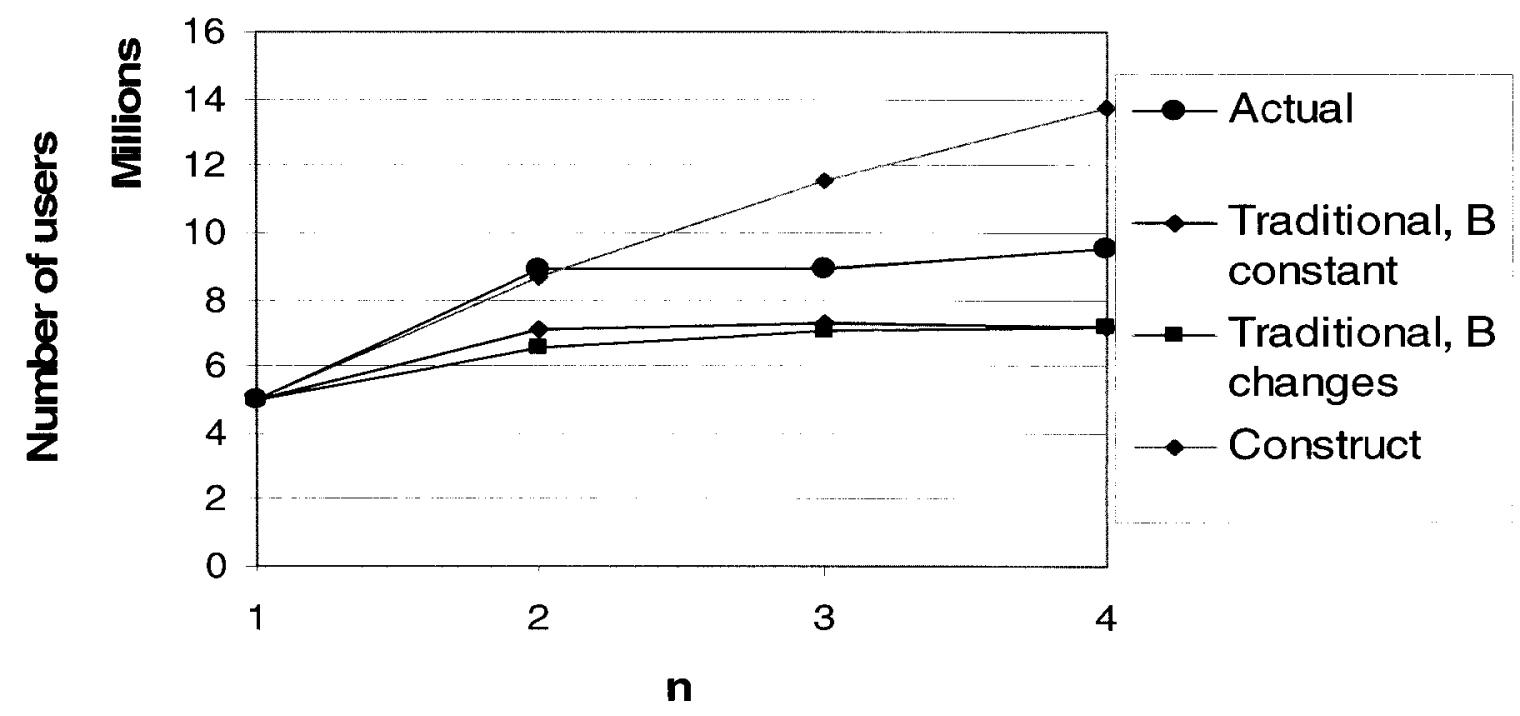

Table 11: Difference between forecast and actual adoptions for the case of Magic@

\begin{tabular}{|l|c|c|c|}
\hline & Traditional, B constant & Traditional, B changes & Construct \\
\hline $\mathbf{2}$ & $-1,775,837$ & $-2,380,145$ & $-284,563$ \\
\hline $\mathbf{3}$ & $-1,665,667$ & $-1,839,382$ & $2,701,187$ \\
\hline $\mathbf{4}$ & $-2,284,562$ & $-2,324,140$ & $4,222,136$ \\
\hline
\end{tabular}

\subsubsection{The Case of Vodafone UK}

In the case of Vodafone in the UK, the traditional forecast is more accurate for the first half of the time period examined. As time elapses the construct forecast gets closer and closer to actual adoption. Mathematically, this can be explained, because the estimated market for the construct forecast is almost half the size of the traditional estimate, $\mathbf{1 8 . 1}$ million and $\mathbf{3 1 . 6}$ million respectively. It is necessary 
to note that the data collected for Vodafone UK is of mobile phone adoption and not mobile payments or mobile Internet. The definitions of social system and ceiling $^{20}$ used for the forecasts were derived from a study done on mobile payment and mobile Internet adoption. These dimensions were also derived from data collected in the previous five years, which could mean that the drivers for mobile phone adoption have changed over time.

Figure 10: Vodafone UK forecast

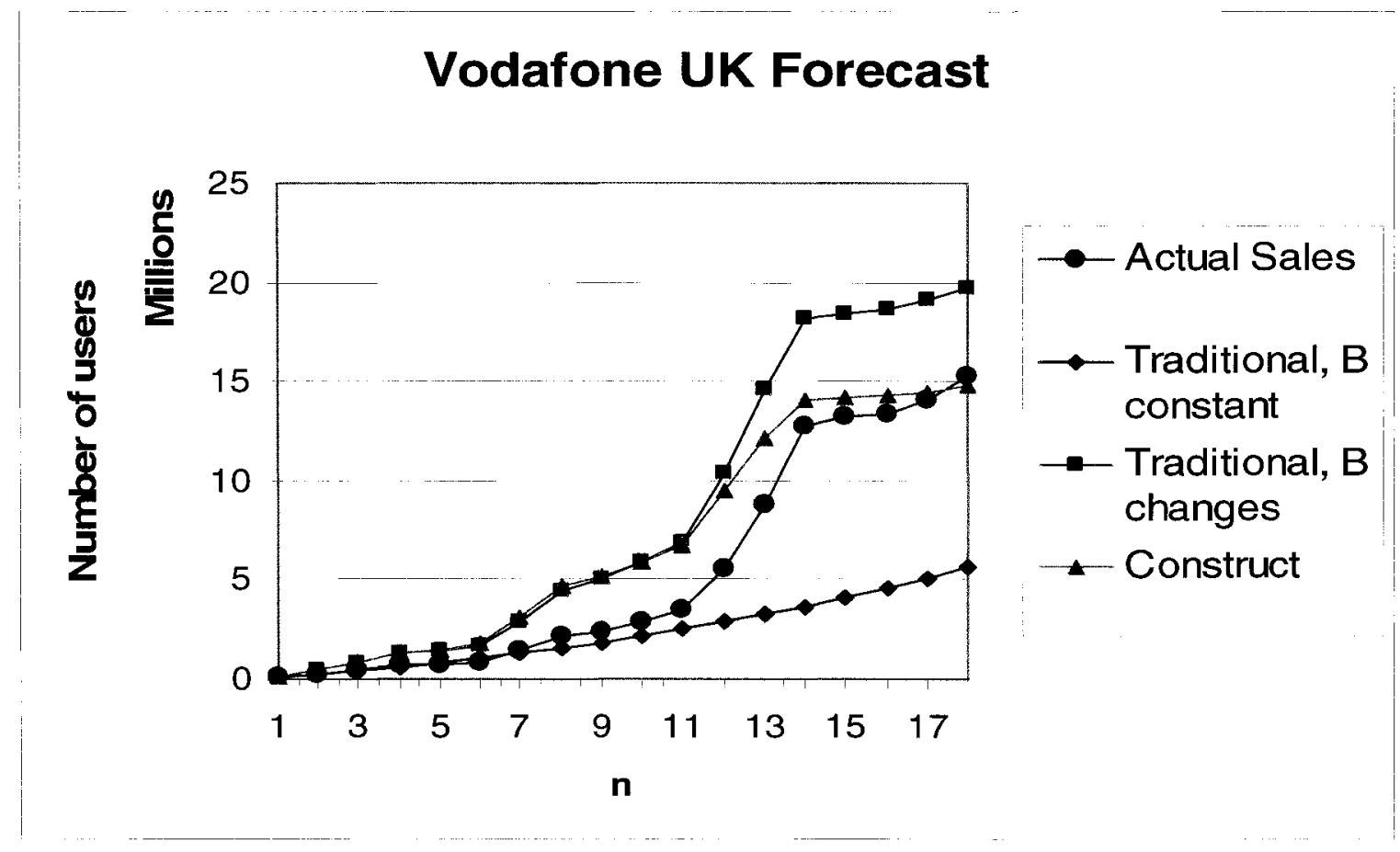

\footnotetext{
${ }^{20}$ The ceiling definition that was used, was the percentage of the population living in urban areas. This was a practical consideration, since the difference between the urban population percentage and the cell phone penetration percentage is only 0.051 , in contrast the difference in a country like Brazil is 0.553 .
} 


\subsubsection{The case of Vivo in Brazil}

The case of Vivo in Brazil is another example of how the proposed method is very accurate when it is forecasting adoptions for the number one player in the market. Figure 11 shows the forecast for Vivo (mobile phone adoption) and Table 12 shows the difference between the forecasts and actual number of adoptions.

\section{Figure 11: Vivo forecast}

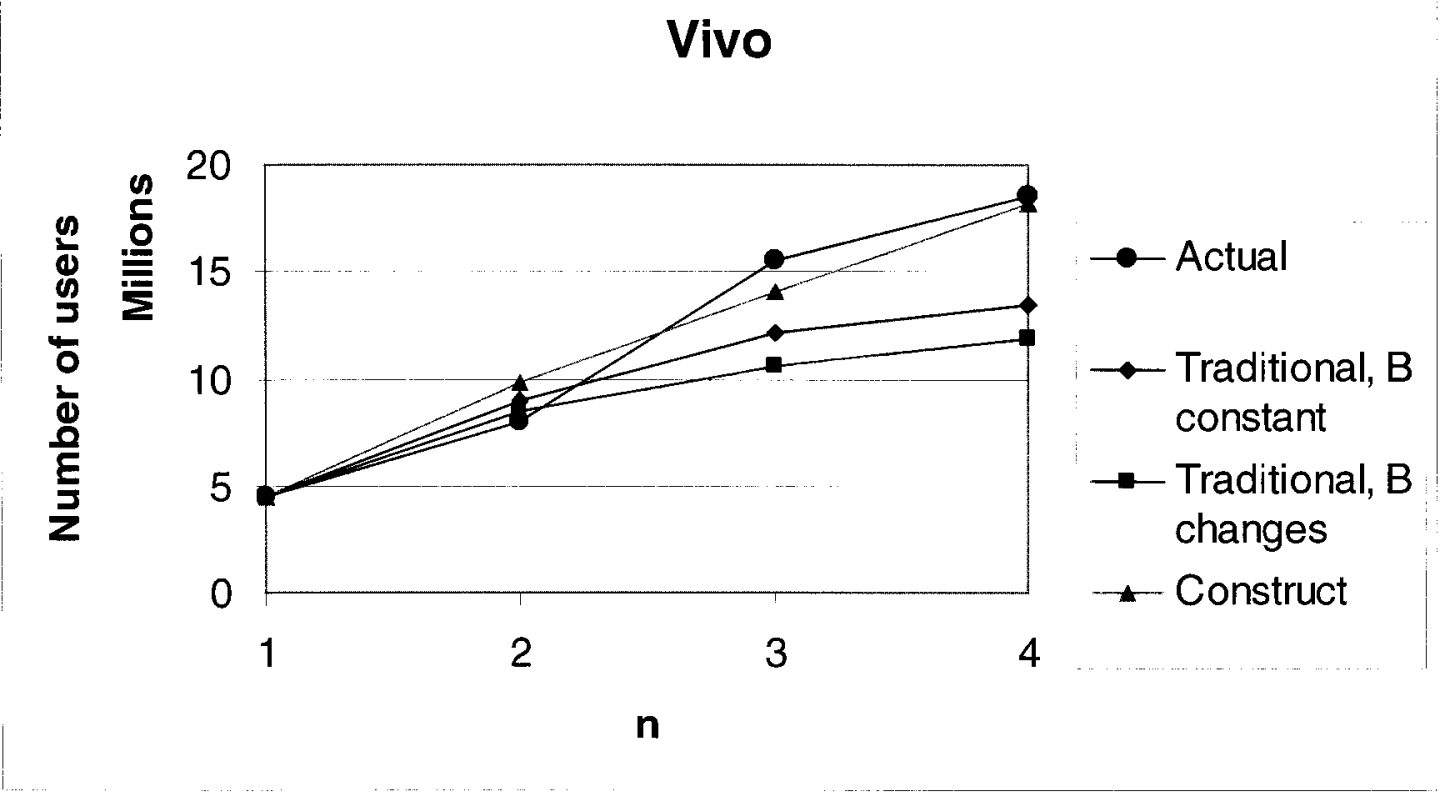

The results of this forecast support the idea that the drivers for adoption change considerably over extended periods of time. The data on Vivo, like the one for Vodafone UK, is for mobile phones; yet in this case the construct based forecast gives the most accurate estimation. We believe this is due to two main reasons; (i) the traditional definitions underestimate the addressable market for Latin 
America considerably; and (ii) this forecast only goes back 4 years, unlike the Vodafone UK case which goes back 17 years.

Table 12: Difference between forecast and actual adoptions for the case of Vivo

\begin{tabular}{|l|c|c|c|}
\hline & Traditional, B constant & Traditional, B changes & Construct \\
\hline $\mathbf{2}$ & 996,063 & 522,893 & $1,849,519$ \\
\hline $\mathbf{3}$ & $-3,493,382$ & $-4,988,817$ & $-1,459,075$ \\
\hline $\mathbf{4}$ & $-5,147,547$ & $-6,685,534$ & $-426,236$ \\
\hline
\end{tabular}

\subsection{Use Estimated Parameters and Model to Predict Size of Addressable Markets}

The addressable market was calculated with the two sets of dimensions (traditional and construct) for the regions of South America that have been previously defined.

In order to calibrate the new set of dimensions, the model was tested for regions in which mobile payments, mobile Internet or mobile phones have already been adopted and sales data are available. The result of this historical analysis is a range for each of the inputs of the diffusion model. With the use of Crystal Ball it is possible to define the inputs as assumptions and assign distributions to them. The number of first year adopters, as a percentage of the total population, and the growth rate were entered into Crystal Ball as assumptions (i.e. A and B were defined as assumptions). Both assumptions were given triangular distributions defined by the minimum, maximum and likeliest value for each. The likeliest 
value was defined as the mean for each assumption. Figure 12 shows how $A$ was defined as an assumption in Crystal Ball. The parameters for the triangular distributions for the growth rate are given in Appendix A (note that historical data is available for time periods two through six).

Figure 12: Assumption 1- Time origin intercept, A

Triangular Distribution

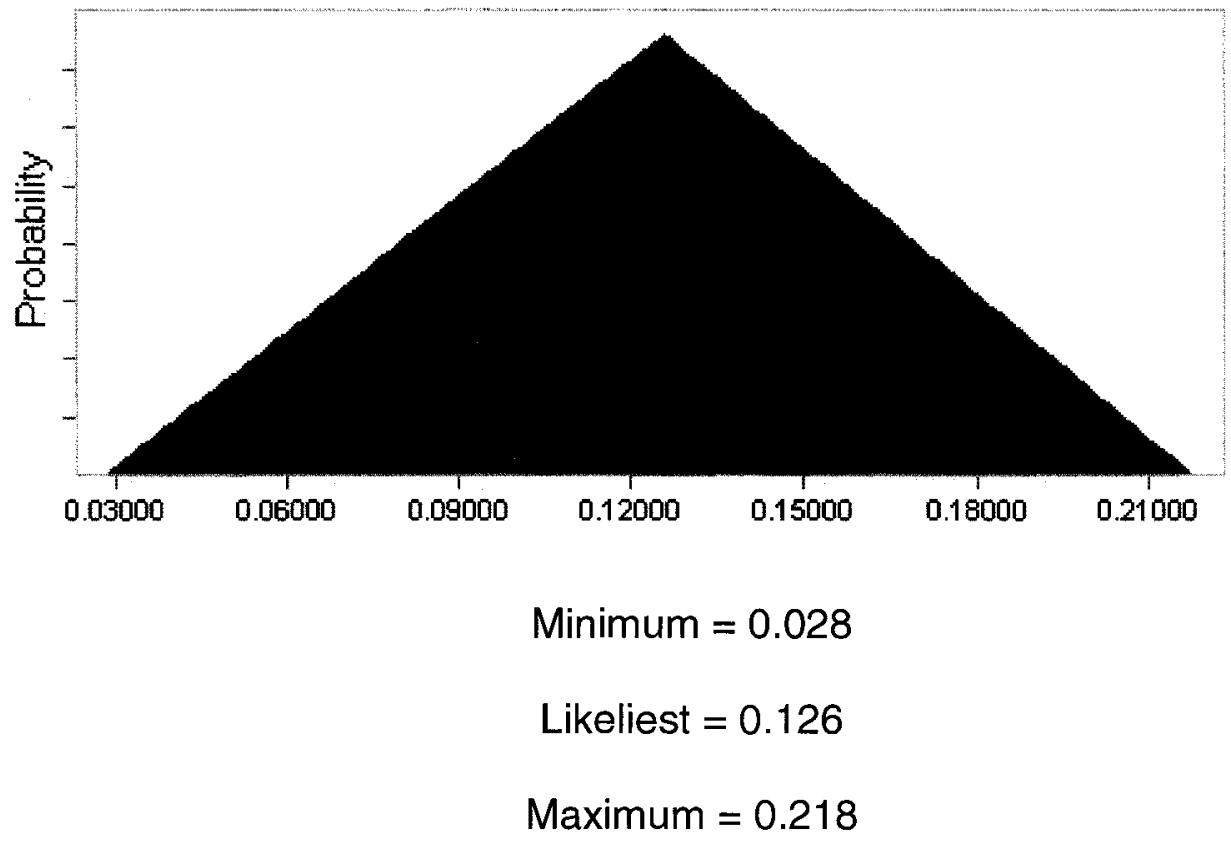

The diffusion model used in this research requires the number of first year adopters as one of its inputs. Although the value for $A$, which depends on the first year adopters, was defined as an assumption; an actual value for the number of first year adopters, $\mathrm{n}$, was still needed. This value was obtained by taking the average number of first year adopters from the available cases. The result was that 0.04 of the population is likely to adopt mobile payments, mobile Internet or mobile phones in the first year of service. The total population of each 
South American country was multiplied by 0.04 , and the resulting value was used as the starting estimate of first year adopters. ${ }^{21}$

There are two plots for the traditional method, one in which the growth rate, $B$, was kept constant (which will be referred to as first traditional forecast) and another in which the growth rate was defined as a Crystal Ball assumption (the same way in which it was defined for the construct forecast). For both cases, the value for A was obtained from the Appendix of Dekimpe et al., (1998).

The forecasts were defined by the model given in Equation 4. Crystal Ball was used to run 1000 trials of the simulation and descriptive statistics were obtained for each country. The mean was plotted over time and the results are given in the following section. It is not only important to consider the mean, but also the standard deviation, since this will give managers a better understanding of how close the values for each trial are. For illustration purposes, Appendix B contains some of the results of the Crystal Ball simulation for the construct forecast in the country of Argentina.

\footnotetext{
${ }^{21}$ It was not possible to use the mean value of $A$ and multiply it by the market size because that would require the nesting a forecast within another forecast, which is something Crystal Ball does not allow.
} 


\section{Research Outcomes}

The existing research has contributed the following two research outcomes:

1. Estimates of the total number of adoptions for each of the South American countries using:

- Dimensions from traditional literature.

- Construct dimensions from theoretical perspectives.

2. Method to incorporate theoretical constructs into the parameters of diffusion models.

\subsection{Estimates of the Total Number of Adoptions}

The following figures and tables are the results of the Crystal Ball simulations. The figures show the mean plotted over time and the tables contain the mean plus the standard deviation for each time period. The result is our view of the expected performance of the operator that is first to market. This is because the forecasts are operator dependant since the time origin intercept, $A(n / C S)$, is dependant on the number of first year adopters, $n$. The number of first year adopters was calculated for each of the services in the case studies and not for a technology or country as a whole. The coefficient of innovation $(A)$ is measuring the operator's innovativeness and not just the country's and the technology's (i.e. 
for the Japanese operators we have 3 different A's even though we are examining similar services in the same country).

Figure 13: Argentina forecast (mean values from 1000 trials)

\section{Argentina}

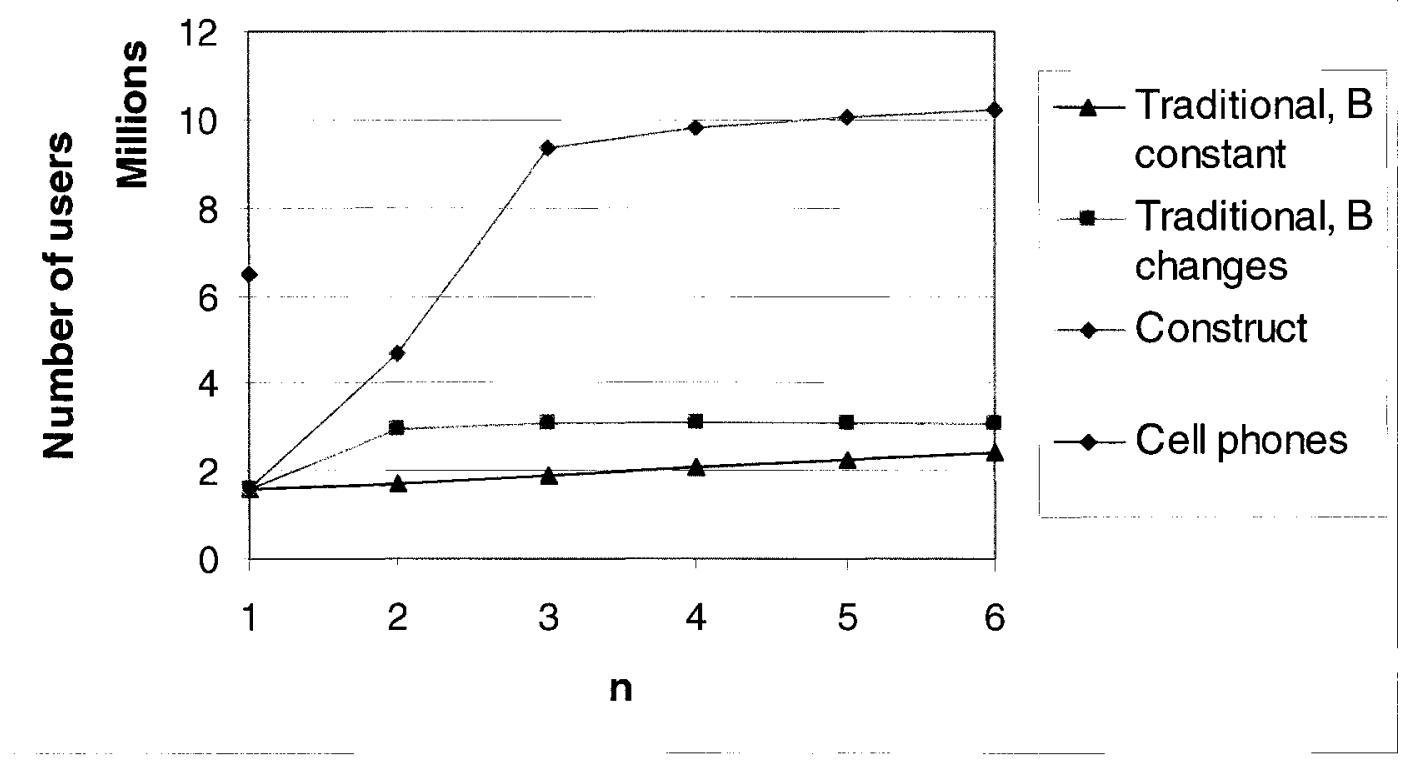

For Argentina (Figure 13) we note that all three forecasts yield plausible results, and that varying the growth rate in the traditional model does not play a significant role. The purple diamond is the total number of cell phones that are currently in use (source: CIA Factbook), and the estimated number of first year adopters is about $24 \%$ of the current cell phone users. The incremental number of adoptions for the traditional forecast is small; due to a small estimation of market size (i.e. traditional estimate is 4 million, compared to almost 11 million for the construct estimate). 
Table 13 shows the means for the three forecasts along with the standard deviations. The first traditional forecast does not have a standard deviation because no assumptions were used in it. The coefficient of variability for the second traditional forecast is 0.44 and 0.30 for the construct forecast in the second year. In the third year the coefficient goes up by 0.26 for the traditional forecast and by 0.16 for the construct forecast. While the coefficients are still high for both forecasts, we can see from Appendix A that the range of the assumptions is also quite high. With a more in depth study, we could reduce the standard deviation, by using the most relevant case studies to the actual type of mobile payment that is being launched in the country.

Table 13: Means and standard deviations for Argentina

\begin{tabular}{|c|c|c|c|c|c|c|}
\hline $\mathbf{n}$ & $\begin{array}{c}\text { Traditional, B } \\
\text { constant }\end{array}$ & $\begin{array}{c}\text { Standard } \\
\text { deviation }\end{array}$ & $\begin{array}{c}\text { Traditional, B } \\
\text { changes }\end{array}$ & $\begin{array}{c}\text { Standard } \\
\text { deviation }\end{array}$ & Construct & $\begin{array}{c}\text { Standard } \\
\text { deviation }\end{array}$ \\
\hline $\mathbf{2}$ & 161,590 & 0 & $1,396,281$ & 613,929 & $3,081,827$ & 937,724 \\
\hline $\mathbf{3}$ & 166,803 & 0 & 119,648 & 786,815 & $4,668,357$ & $2,141,109$ \\
\hline $\mathbf{4}$ & 170,021 & 0 & $-21,285$ & 265,334 & 473,052 & $1,046,740$ \\
\hline & 171,039 & 0 & 3,704 & 80,761 & 267,904 & 383,968 \\
\hline $\mathbf{5}$ & & & & & & \\
\hline & 169,758 & 0 & 3,642 & 34,270 & 152,784 & 205,910 \\
\hline
\end{tabular}


Figure 14: Bolivia forecast (mean values from 1000 trials)

\section{Bolivia}

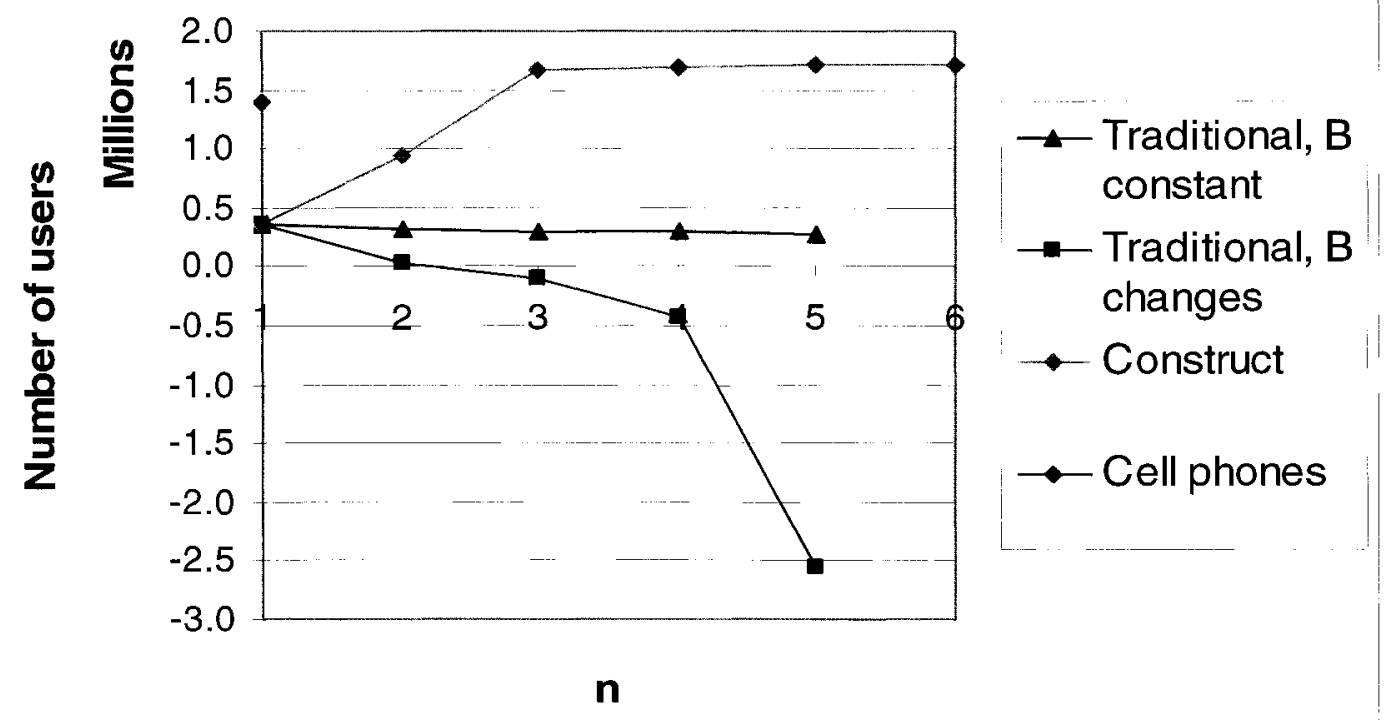

Figure 14 shows that the traditional forecasts underestimate market size and the number of first year adopters that the model used was actually higher than the traditional estimate of addressable market, resulting in negative values. These negative values increase quite rapidly and therefore have not been plotted beyond year five.

As far as the number of first year adopters and the coefficients of variability, the results are consistent with the ones for the country of Argentina. 
Table 14: Means and standard deviations for Bolivia

\begin{tabular}{|c|c|c|c|c|c|c|}
\hline n & $\begin{array}{c}\text { Traditional, B } \\
\text { constant }\end{array}$ & $\begin{array}{l}\text { Standard } \\
\text { deviation }\end{array}$ & $\begin{array}{c}\text { Traditional, B } \\
\text { changes }\end{array}$ & $\begin{array}{l}\text { Standard } \\
\text { deviation }\end{array}$ & Construct & $\begin{array}{l}\text { Standard } \\
\text { deviation }\end{array}$ \\
\hline 2 & $-27,864$ & 0 & $-331,997$ & 149,737 & 574,490 & 185,525 \\
\hline 3 & $-20,729$ & 0 & $-120,922$ & 309,184 & 732,652 & 341,004 \\
\hline 4 & $-15,947$ & 0 & $-343,925$ & $1,295,337$ & 23,650 & 177,913 \\
\hline 5 & $-12,574$ & 0 & $-2,123,468$ & $17,386,510$ & 19,489 & 57,812 \\
\hline 6 & & & & & 12,016 & 30,355 \\
\hline
\end{tabular}

Figure 15: Brazil forecast (mean values from 1000 trials)

\section{Brazil}

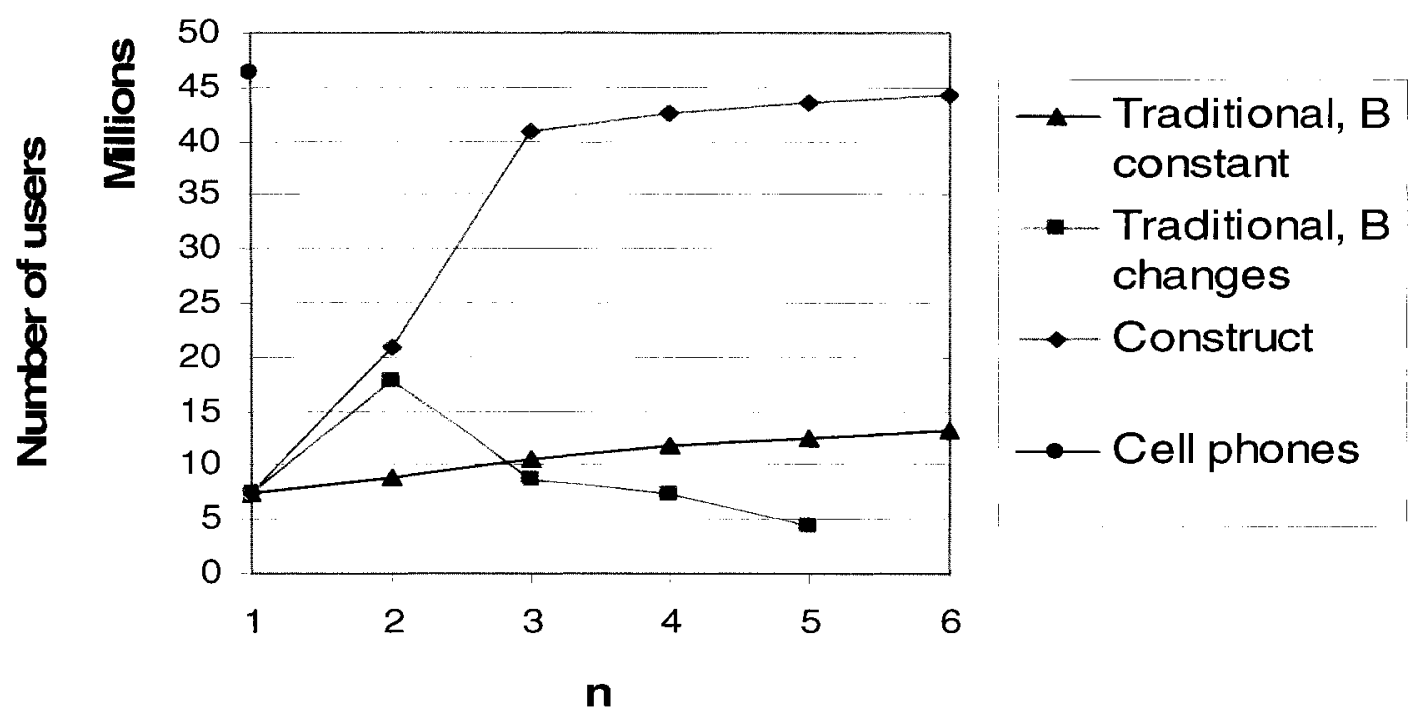


For Brazil our estimate of the first year adopters is $15 \%$ of the people whole already own cell phones. Brazil has a higher cell phone penetration rate than Argentina and Bolivia, so we assume that this is why this number is lower. We see from Figure 15 that the second traditional forecast reaches the addressable market in the second year and is forced to yield negative values after that.

Although the coefficient of variability for the construct forecast is higher in the second year than for the previous two countries, 0.31 , it is still lower than the coefficient for the second traditional forecast, 0.44 .

Table 15: Means and standard deviations for Brazil

\begin{tabular}{|c|c|c|c|c|c|c|}
\hline $\mathbf{n}$ & $\begin{array}{c}\text { Traditional, B } \\
\text { constant }\end{array}$ & $\begin{array}{c}\text { Standard } \\
\text { deviation }\end{array}$ & $\begin{array}{c}\text { Traditional, B } \\
\text { changes }\end{array}$ & $\begin{array}{c}\text { Standard } \\
\text { deviation }\end{array}$ & Construct & $\begin{array}{c}\text { Standard } \\
\text { deviation }\end{array}$ \\
\hline $\mathbf{2}$ & $1,618,190$ & 0 & $10,424,350$ & $4,626,049$ & $13,665,738$ & $4,179,577$ \\
\hline $\mathbf{3}$ & $1,490,761$ & 0 & $-9,168,746$ & $13,797,656$ & $19,805,467$ & $9,091,694$ \\
\hline $\mathbf{4}$ & $\mathbf{1 , 2 2 0 , 3 3 0}$ & 0 & $-1,437,406$ & $7,947,446$ & $1,782,203$ & $4,269,288$ \\
\hline $\mathbf{5}$ & 889,714 & 0 & $-2,846,227$ & $20,883,589$ & 983,353 & $1,606,248$ \\
\hline $\mathbf{6}$ & 586,681 & 0 & & & 562,231 & 847,265 \\
\hline
\end{tabular}


Figure 16: Chile forecast (mean values from 1000 trials)

Chile

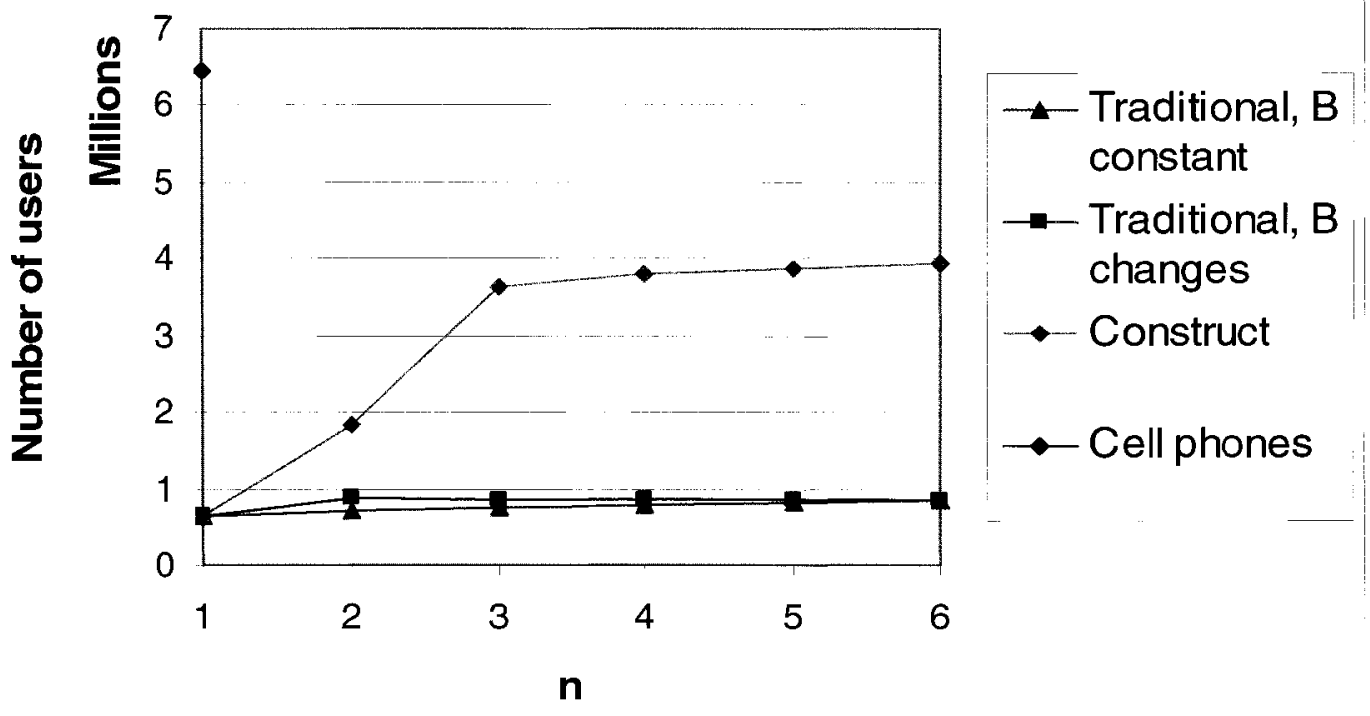

Chile has the highest cell phone penetration rate in Latin America; this is why our estimated first year adopters are only $9.9 \%$ of the current cell phone users. As in previous examples, the traditional forecasts have underestimated the market size and are unable to give reasonable estimates for adoption.

The coefficient of variability in this case is lower for the construct forecast by 0.13 than for the second traditional forecast. 
Table 16: Means and standard deviations for Chile

\begin{tabular}{|c|c|c|c|c|c|c|}
\hline $\mathbf{n}$ & $\begin{array}{c}\text { Traditional, B } \\
\text { constant }\end{array}$ & $\begin{array}{c}\text { Standard } \\
\text { deviation }\end{array}$ & $\begin{array}{c}\text { Traditional, B } \\
\text { changes }\end{array}$ & $\begin{array}{c}\text { Standard } \\
\text { deviation }\end{array}$ & Construct & $\begin{array}{c}\text { Standard } \\
\text { deviation }\end{array}$ \\
\hline $\mathbf{2}$ & 66,236 & 0 & 235,294 & 101,593 & $1,211,758$ & 363,581 \\
\hline $\mathbf{3}$ & 51,329 & 0 & $-33,446$ & 177,937 & $1,773,645$ & 834,177 \\
\hline $\mathbf{4}$ & 37,057 & 0 & 2,818 & 31,174 & 168,189 & 397,064 \\
\hline $\mathbf{5}$ & 25,277 & 0 & 2,141 & 11,149 & 97,059 & 150,303 \\
\hline $\mathbf{6}$ & 16,532 & 0 & 1,043 & 5,134 & 55,223 & 79,920 \\
\hline
\end{tabular}

Figure 17: Colombia forecast (mean values from 1000 trials)

\section{Colombia}

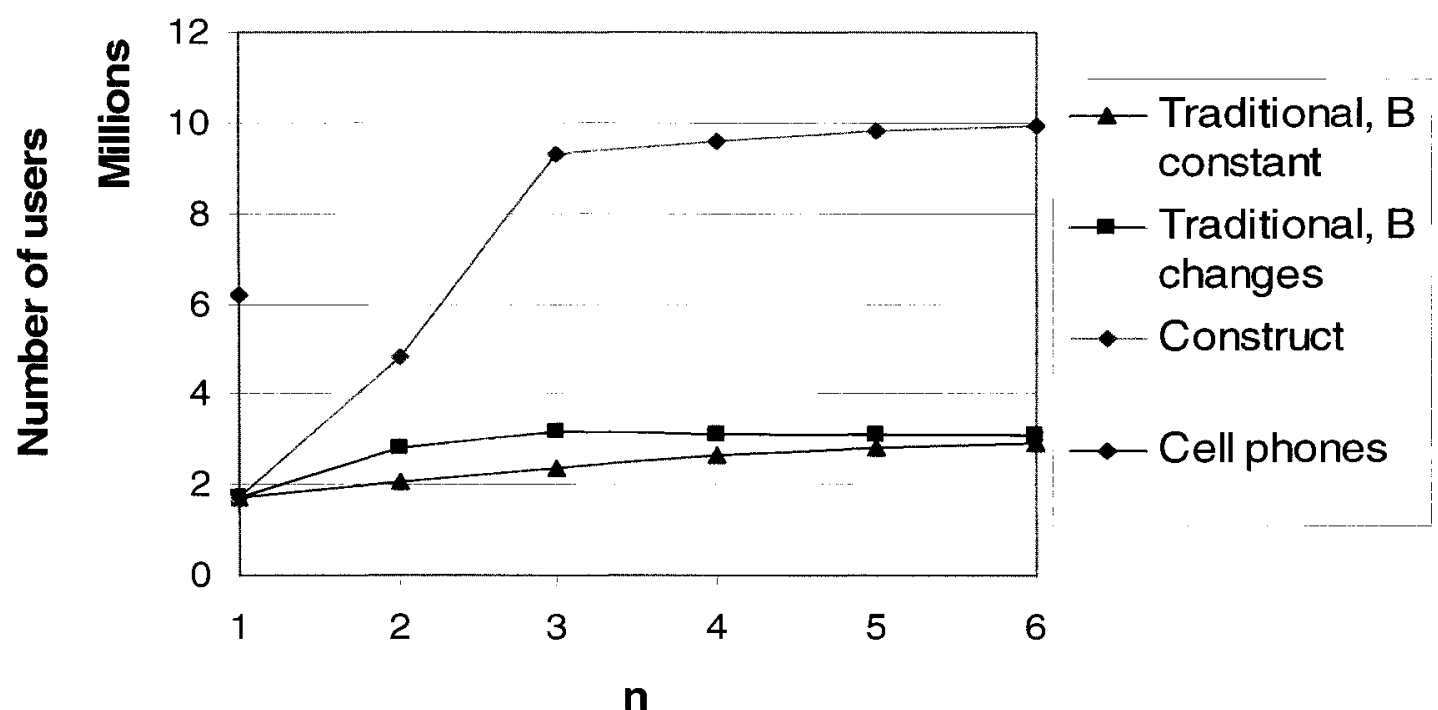


The results for Colombia are consistent with previous countries, including a lower coefficient of variability for the construct forecast.

Table 17: Means and standard deviations for Colombia

\begin{tabular}{|c|c|c|c|c|c|c|}
\hline $\mathbf{n}$ & $\begin{array}{c}\text { Traditional, B } \\
\text { constant }\end{array}$ & $\begin{array}{l}\text { Standard } \\
\text { deviation }\end{array}$ & $\begin{array}{c}\text { Traditional, B } \\
\text { changes }\end{array}$ & $\begin{array}{l}\text { Standard } \\
\text { deviation }\end{array}$ & Construct & $\begin{array}{l}\text { Standard } \\
\text { deviation }\end{array}$ \\
\hline 2 & 347,549 & 0 & $1,075,536$ & 485,598 & $3,090,878$ & 931,625 \\
\hline 3 & 314,988 & 0 & 356,777 & 709,910 & $4,516,585$ & $2,040,397$ \\
\hline 4 & 255,927 & 0 & $-23,614$ & 157,964 & 289,714 & $1,040,420$ \\
\hline 5 & 187,251 & 0 & $-2,524$ & 47,728 & 188,589 & 360,879 \\
\hline 6 & 125,253 & 0 & -756 & 21,392 & 105,488 & 190,756 \\
\hline
\end{tabular}

Figure 18: Ecuador forecast (mean values from 1000 trials)

\section{Ecuador}

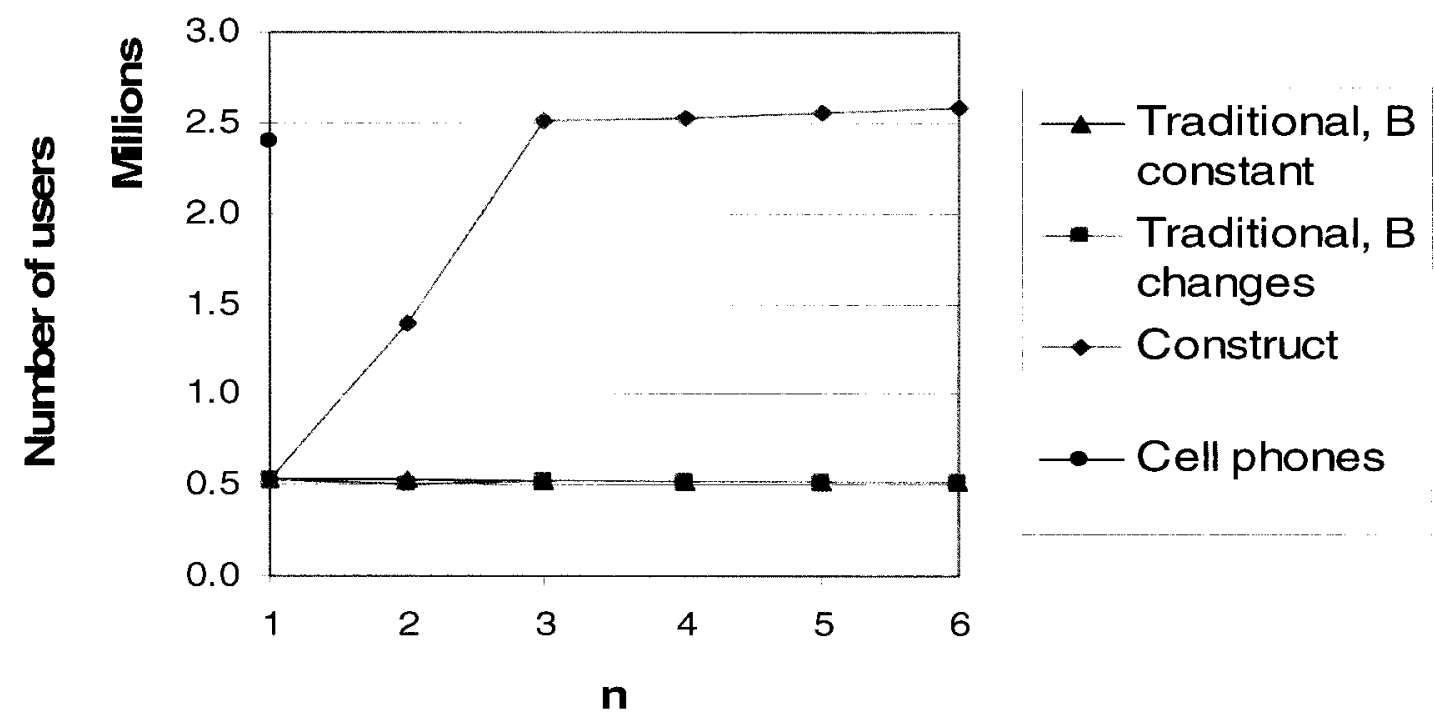


Table 18: Means and standard deviations for Ecuador

\begin{tabular}{|c|c|c|c|c|c|c|}
\hline $\mathbf{n}$ & $\begin{array}{c}\text { Traditional, B } \\
\text { constant }\end{array}$ & $\begin{array}{c}\text { Standard } \\
\text { deviation }\end{array}$ & $\begin{array}{c}\text { Traditional, B } \\
\text { changes }\end{array}$ & $\begin{array}{c}\text { Standard } \\
\text { deviation }\end{array}$ & Construct & $\begin{array}{c}\text { Standard } \\
\text { deviation }\end{array}$ \\
\hline $\mathbf{2}$ & $-7,924$ & 0 & $-38,892$ & 18,253 & 852,484 & 293,310 \\
\hline $\mathbf{3}$ & $-5,493$ & 0 & 16,972 & 31,503 & $1,131,036$ & 540,042 \\
\hline $\mathbf{4}$ & $-3,848$ & 0 & $-1,922$ & 7,720 & 14,927 & 277,344 \\
\hline $\mathbf{5}$ & $-2,716$ & 0 & -564 & 12,390 & 27,253 & 93,692 \\
\hline & $-1,926$ & 0 & -222 & 1,053 & 16,465 & 47,200 \\
\hline 6 & & & & & & \\
\hline
\end{tabular}

Ecuador has one of the highest coefficients of variability, 0.34 , yet its construct forecast is the only one that provides us with reasonable estimates (i.e. the traditional forecasts for Ecuador yield implausible estimates.) 
Figure 19: Paraguay forecast (mean values from 1000 trials)

\section{Paraguay}

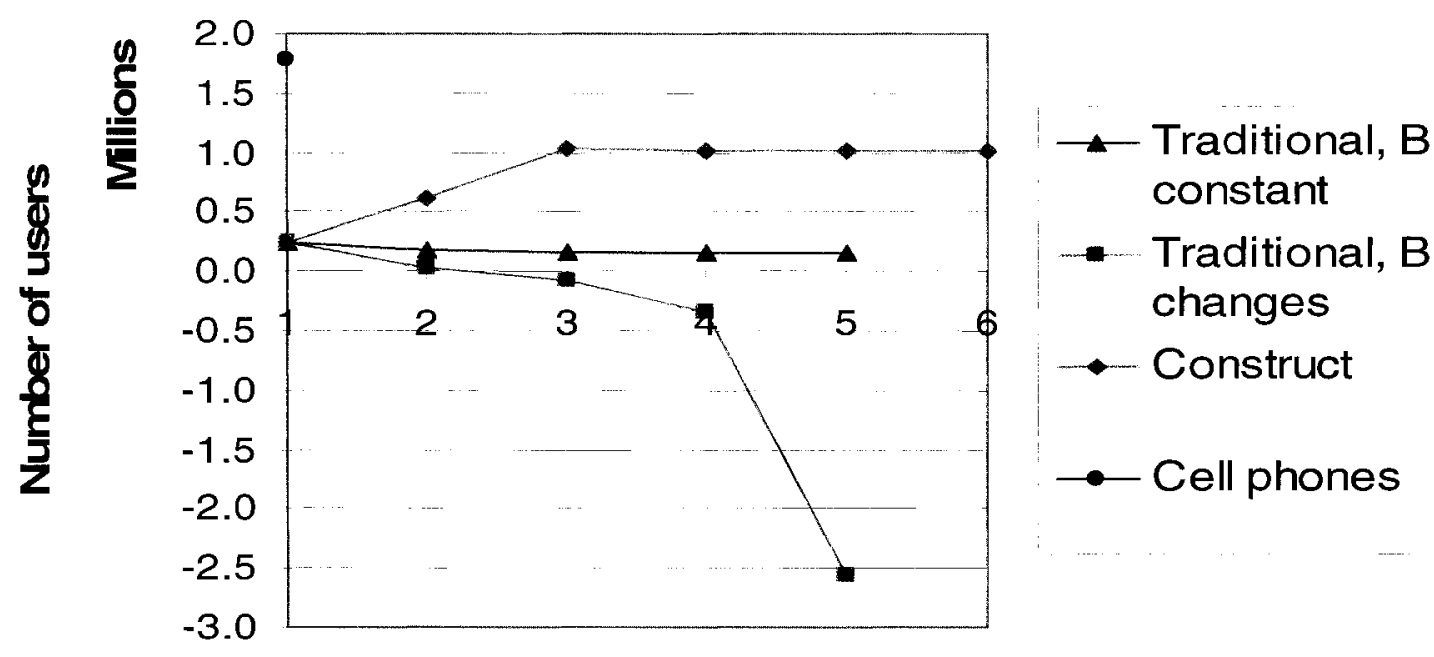

n

The construct forecast for Paraguay reaches the estimated market potential by the third year, so any results beyond that point are unreliable. On the other hand, both traditional methods are unable to provide plausible estimates for even the second year. 
Table 19: Means and standard deviations for Paraguay

\begin{tabular}{|c|c|c|c|c|c|c|}
\hline $\mathbf{n}$ & $\begin{array}{c}\text { Traditional, B } \\
\text { constant }\end{array}$ & $\begin{array}{l}\text { Standard } \\
\text { deviation }\end{array}$ & $\begin{array}{c}\text { Traditional, } \mathrm{B} \\
\text { changes }\end{array}$ & $\begin{array}{l}\text { Standard } \\
\text { deviation }\end{array}$ & Construct & $\begin{array}{l}\text { Standard } \\
\text { deviation }\end{array}$ \\
\hline 2 & $\begin{array}{l}-73,999 \\
\end{array}$ & 0 & $-236,981$ & 106,335 & 363,385 & 124,345 \\
\hline 3 & $-14,288$ & 0 & $-92,198$ & 242,336 & 408,502 & 201,927 \\
\hline 4 & $-6,344$ & 0 & $-269,503$ & 995,579 & $-12,698$ & 110,655 \\
\hline 5 & $-3,189$ & 0 & $-2,211,355$ & $19,901,461$ & 3,021 & 32,236 \\
\hline 6 & & 0 & & & 2,656 & 16,109 \\
\hline
\end{tabular}

Figure 20: Peru forecast (mean values from 1000 trials)

\section{Peru}

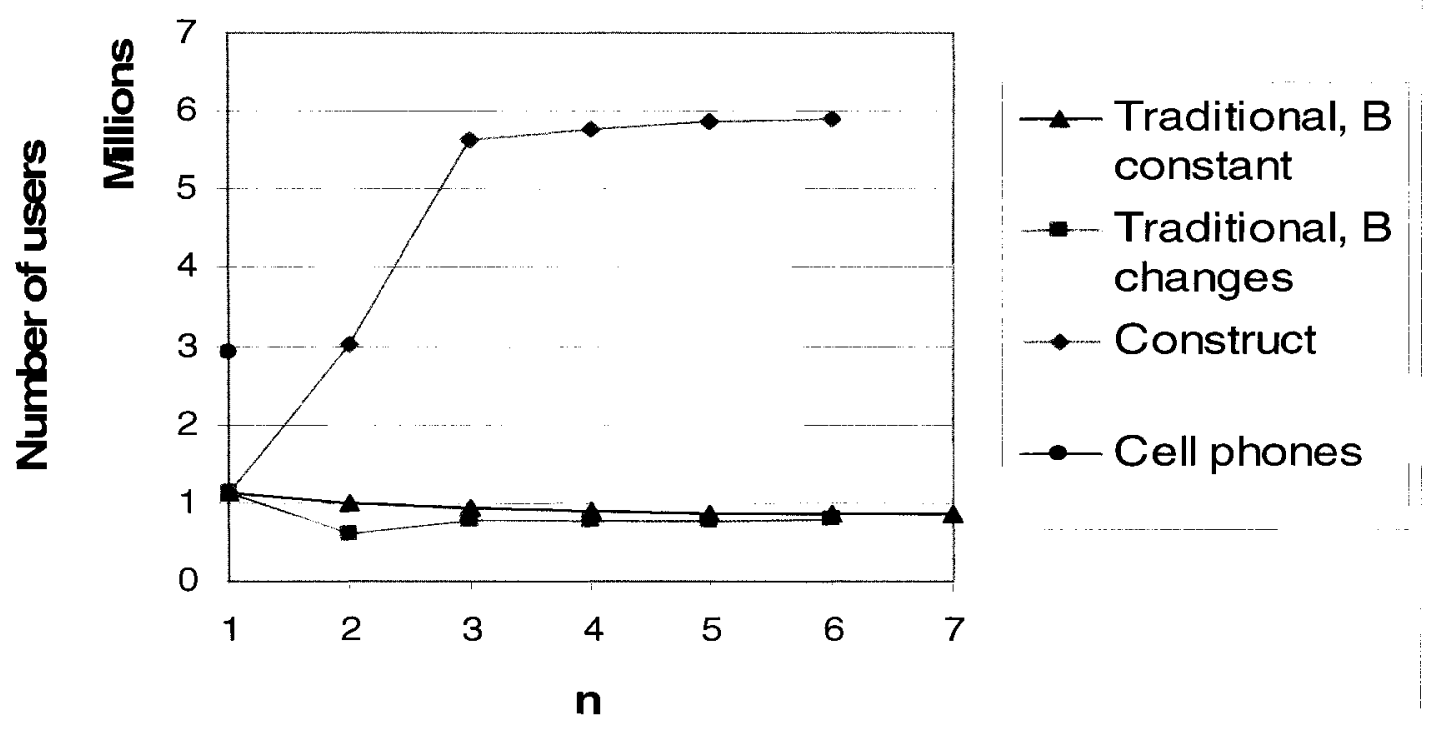


Peru is another example for which the traditional forecasts fail to provide any useful information. This is again due to an underestimation of market size. It is also important to note that Peru is the country with the lowest mobile phone penetration for South America; our estimate is that $30 \%$ of current users will adopt mobile payments in the first year of service.

As with the other countries, we continue to see a very high growth rate between time periods two and three. This is because the growth rate for one of the case studies, Vodafone Spain, observed a growth rate of 3.772 for that time period. A deeper case study analysis would reveal the circumstances around this observation and provide insights as to whether it should be included in the parameters of the distribution or not.

Table 20: Means and standard deviations for Peru

\begin{tabular}{|c|c|c|c|c|c|c|}
\hline $\mathbf{n}$ & $\begin{array}{c}\text { Traditional, B } \\
\text { constant }\end{array}$ & $\begin{array}{c}\text { Standard } \\
\text { deviation }\end{array}$ & $\begin{array}{c}\text { Traditional, B } \\
\text { changes }\end{array}$ & $\begin{array}{c}\text { Standard } \\
\text { deviation }\end{array}$ & Construct & $\begin{array}{c}\text { Standard } \\
\text { deviation }\end{array}$ \\
\hline $\mathbf{2}$ & $-120,985$ & 0 & $-527,958$ & 231,513 & $1,908,099$ & 596,336 \\
\hline $\mathbf{3}$ & $-61,347$ & 0 & 176,331 & 200,030 & $2,609,843$ & $1,196,016$ \\
\hline $\mathbf{4}$ & $-35,326$ & 0 & 7,195 & 53,078 & 130,027 & 610,985 \\
\hline $\mathbf{5}$ & $-21,630$ & 0 & 5,722 & 19,868 & 90,526 & 211,644 \\
\hline & $-13,709$ & 0 & 3,150 & 9,313 & 52,663 & 108,594 \\
\hline 6 & & & & & & \\
\hline
\end{tabular}


Figure 21: Uruguay forecast (mean values from 1000 trials)

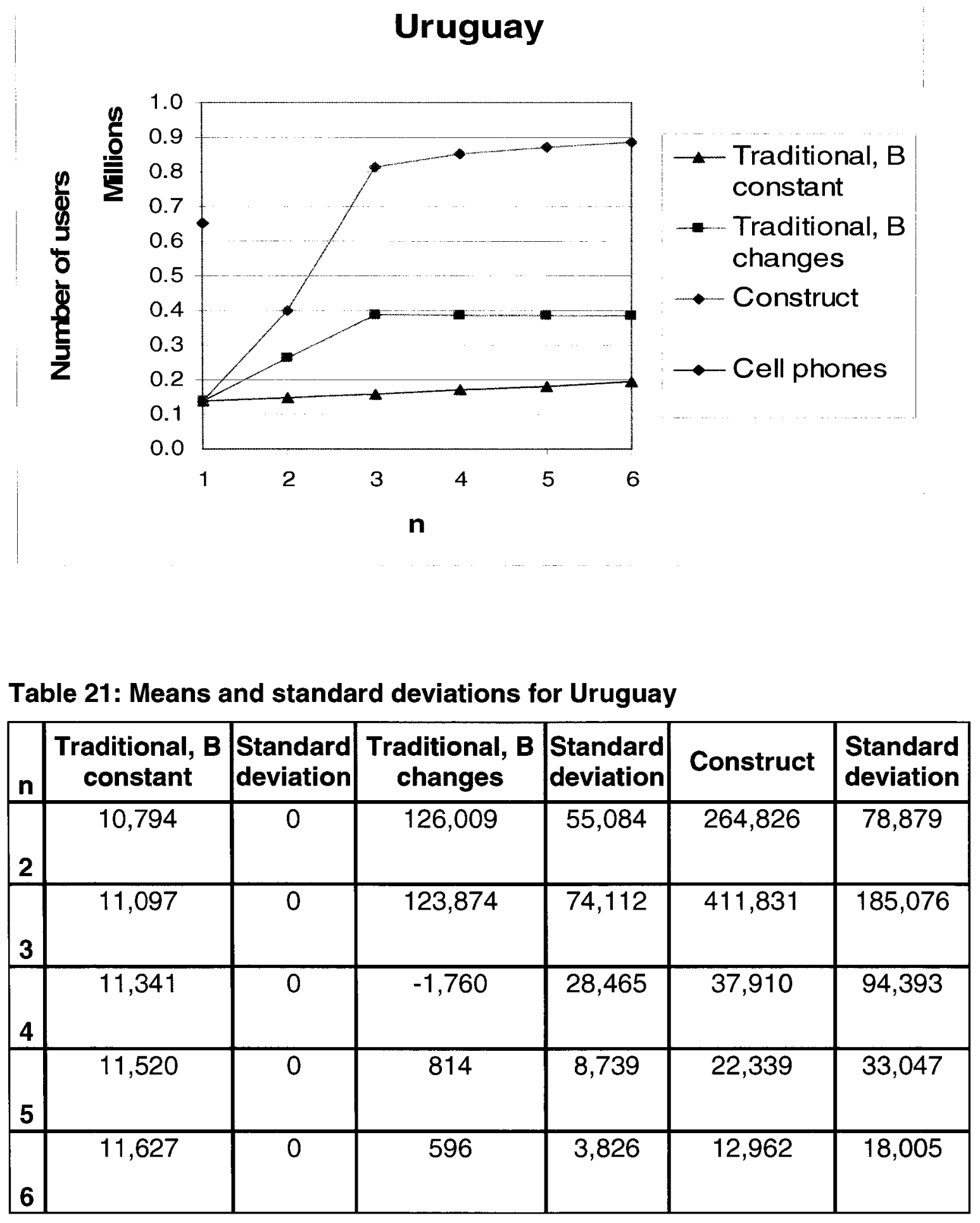


Figure 22: Venezuela forecast (mean values from 1000 trials)

\section{Venezuela}

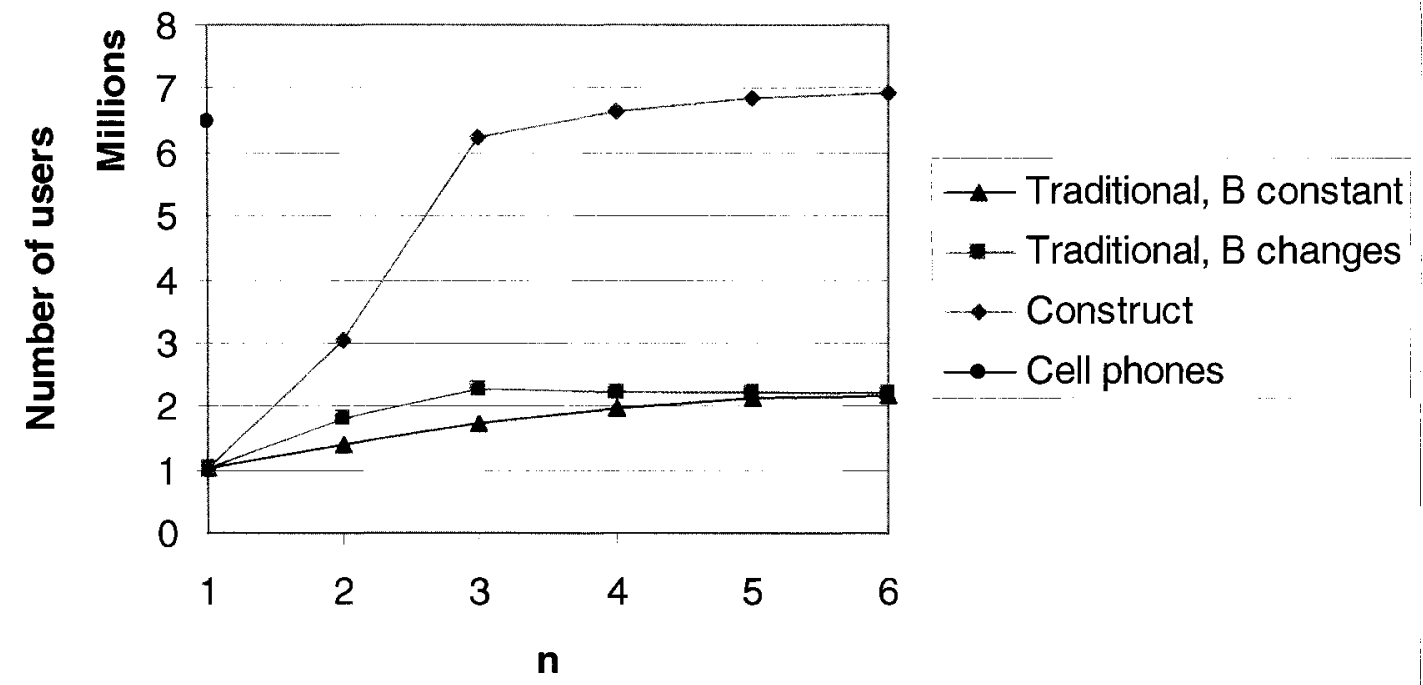

Table 22: Means and standard deviations for Venezuela

\begin{tabular}{|c|c|c|c|c|c|c|}
\hline $\mathbf{n}$ & $\begin{array}{l}\text { Traditional, B } \\
\text { constant }\end{array}$ & \begin{tabular}{|l|} 
Standard \\
deviation
\end{tabular} & $\begin{array}{c}\text { Traditional, B } \\
\text { changes }\end{array}$ & $\begin{array}{l}\text { Standard } \\
\text { deviation }\end{array}$ & Construct & \begin{tabular}{|l|} 
Standard \\
deviation
\end{tabular} \\
\hline 2 & 361,702 & 0 & 775,778 & 339,148 & $2,033,503$ & 611,499 \\
\hline 3 & 344,724 & 0 & 464,831 & 461,898 & $3,184,339$ & $1,460,293$ \\
\hline 4 & 257,439 & 0 & $-23,225$ & 129,161 & 396,421 & 663,780 \\
\hline 5 & 146,991 & $\overline{0}$ & $-3,345$ & 40,566 & 205,341 & 266,214 \\
\hline 6 & 66,570 & 0 & -784 & 16,553 & 117,602 & 142,854 \\
\hline
\end{tabular}


The forecasts for Uruguay and Venezuela, again show, that the construct forecast is the only one able to show reasonable estimates. The coefficient of variability remains lower than the one for the second traditional forecast, and the traditional forecast reaches the addressable market by the fourth year in both countries.

\subsection{Method to Incorporate Theoretical Constructs}

The contribution of this research is in part methodological. Previous sections illustrated that using theoretical perspectives to define the inputs of diffusion models can provide decision makers with more accurate forecasts. In some cases it provides them with the only plausible forecast. The following ten steps are the suggested method that can be used to incorporate theoretical perspectives into the parameters of diffusion models:

1. Identify research question or objective.

2. Select theoretical perspectives and cases.

3. Identify literature, construct and control dimensions.

4. Operationalize dimensions.

5. Identify and operationalize regions to be addressed.

6. Select a diffusion model.

7. Use theoretical perspectives and dimensions developed in step three to define the inputs of the prediction model. 
8. Use historical data and/or theoretical insights to estimate the parameters of the prediction model.

9. Use estimated parameters and model to predict the size of addressable markets.

10. Answer research question.

The method is independent of the product context or service being studied, as well as the region of interest and the diffusion model selected. It is up to the researcher to determine the most appropriate theoretical perspectives and cases as well as the most appropriate model. The value added of using this research method is that incorporating different insights from theories and available cases will yield a better forecast and understanding of the addressable market than traditional definitions alone. 


\section{Discussion of Results}

Section 3.7.1 examines adoption for the cases of the Japanese operators (i.e. the cases of i-mode, EZWeb and Vodafone Live!), and Table 23 shows a summary of the results for the available cases. Japan is the only country for which we were able to compare three similar services in the same country ${ }^{22}$. The proposed method was able to provide better estimates for the case of i-mode; and while it was the closest to actual adoptions, it was less accurate for the second and third players in the market. The construct based forecast was off by less than 100,000 for the case of $i$-mode, but differed by 13 million for the case of Vodafone Live! (third player in the market).

From the cases of the Japanese operators we also obtain three different values for A. As expected, i-mode has the highest value with 0.121 . The value for Vodafone Live! (0.085) is 1.5 times higher than the value for EZWeb $(0.033)$. Although EZWeb has a lower value for A, five years after their introduction, EZWeb has over 2 million more adopters than Vodafone Live!. Further research could provide valuable insights on why the growth rate for Vodafone Live! has slowed down faster than the one for EZWeb.

From our available cases we see that varying the definition of $C$ proves to be helpful when examining developed and developing nations. This is consistent with the suggestion by Dekimpe et al., (1998) that greater research efforts should

\footnotetext{
${ }^{22}$ South Korea also has more than one operator offering the same service, but we did not have access to all the data required for the forecasts.
} 
be made to anticipate variances of $S$ and $C$ across countries. To compare and test results, the definitions of $\mathrm{C}$ and $\mathrm{S}$ we used for developing nations were tested in developed nations; for example, in the case of Japan, the market goes from 53 million to 21 million. This drop in market size increases our confidence, in that we have selected the most accurate definitions available.

Table 23: Summary of the results for available cases

\begin{tabular}{|c|c|}
\hline Insight & Instances \\
\hline Construct forecast is closer to actual adoptions & 13 \\
\hline Traditional ceiling too low to make viable predictions & 3 \\
\hline Coefficient of innovation, A, is operator dependant & 14 \\
\hline Most accurate for operator with highest market share & 3 \\
\hline Accuracy of traditional forecast is dependant on a & 14 \\
larger number of observations & 14 \\
\hline Traditional literature assumes one definition of ceiling & \\
and social system & 14 \\
\hline Total number of cases & \\
\hline
\end{tabular}

From the available cases and the Latin America forecasts we see that the definitions used in traditional literature for $\mathrm{C}$ and $\mathrm{S}$, sometimes underestimate the size of the market, causing negative results and implausible forecasts. The forecasts for Latin America give us some more insight into the value added of the construct dimensions; Table 24 shows a summary of these insights. Traditional 
dimensions underestimate the market size by their definition of ceiling, which is the percentage of the population who is literate, lives in urban areas and has enough money to afford cell phone services. Out of the nine countries studied, the traditional forecast is able to give positive values in only one country, while the construct forecast does it for eight of them. The traditional forecasts either underestimate market size from the very beginning, or fails after the third year. The construct forecast provides a negative value, only for Paraguay, and this is only after the fourth year since the adoption process began.

The forecast and estimations can be adjusted as data becomes available; this process will continually change the remaining time periods' estimations and yield better results as more data become available. The cases studied, indicate that the likely value added of this method is that there is a significant improvement after only three years of available data, as opposed to ten years as some of the traditional methods. 
Table 24: Summary of results for Latin American forecast

\begin{tabular}{|c|c|}
\hline \multicolumn{1}{|c|}{ Insight } & Instances \\
\hline Traditional method yields implausible results & 8 \\
\hline Construct method yields implausible results $^{23}$ & 1 \\
\hline $\begin{array}{c}\text { Construct method consistent with the number of } \\
\text { current cell phones in use }\end{array}$ & 7 \\
\hline Total number of countries & 9 \\
\hline
\end{tabular}

\subsection{Validity}

This section discusses the extent in which the dimensions and forecasts were correctly operationalized (construct validity) as well as the circumstances in which the proposed method is applicable (external validity).

\subsubsection{Construct Validity}

The forecasts in this research are built on an initial set of assumptions or practical considerations. A recurring issue in all global diffusion literature is the difference in the operationalization, both in their definitions and the data sources, of the dimensions used. The source for all but one of the dimensions was kept consistent throughout the countries and operators examined. If a consistent source and measurement was not found, it was removed from the study (e.g. the

\footnotetext{
${ }^{23}$ The construct forecast failed after four years, while the traditional forecasts where unable to even predict the second year of adoption.
} 
number of professionals). For example, all the information on the percentage of the population that lives in urban areas was gathered from a report on urbanization developed by the United Nations. Similarly, the information on literacy rate and mobile phone penetration was found in the World Factbook (CIA). The only dimension that had to be gathered from different sources was the number of commuters in each country. This dimension was obtained from the census and statistic bureau of each individual country. While the source was not the same, the manner in which each number was reported and operationalized by each country was very similar. For example South Korea reported the number as "passengers using railway, subway, road, shipping and aviation transport"; while Japan reported population over age 15 using public transport.

One potential issue to construct validity is the way in which the number of commuters was added to the population who is 15 to 34 . While an attempt was made to not count the members of the social system twice, this is only an estimate and could be operationalized differently by another researcher.

A second issue deals with the data used from available cases. Some of the cases, for which the data was not relevant, were initially removed from the study and furthermore other cases in which the data was not complete were also excluded. All other cases with available data were used to define the distribution of the two assumptions, A and B. It is possible that some extreme cases could 
be further excluded based on the circumstances that surrounded their adoption. An example could be the case of Vodafone Spain, which observed a much higher than average growth rate in the third year. Another case that could be excluded is Magic@, which observed a negative growth rate in the first year. This can have an impact on the estimates of each forecast (i.e. change the actual number of adoptions and reduce the standard deviation), but it is expected that the overall conclusions and certainly the method would remain the same.

Finally, Crystal Ball could also allow us to define a correlation between each year's growth rates. Binding the growth rates by using a correlation would also change the results of the Latin American forecasts. This was not done because there were not enough cases that could be used to develop a meaningful correlation. This creates a potential issue that could be fixed as more cases become available.

\subsubsection{External Validity}

Due to the fact that the Latin American forecasts are based on a nonprobability sampling ${ }^{24}$ of the case studies, there is a potential threat to the generalizations that can be made. The main issue is that most of the case studies are from services in developed nations. It is possible that there are other dimensions that could be relevant for developing countries, but our case studies do not reflect that. To overcome part of this issue, the social system and ceiling were

\footnotetext{
${ }^{24}$ The cases were initially selected using theoretical sampling, but had to be narrowed down to a convenient sample due to availability of data.
} 
redefined for Latin America; leaving $A$ and $B$ as the only assumptions based on the case study adoption numbers.

While the Latin American forecasts could vary depending on the initial set of assumptions, the use of theoretical constructs and analogies to define the inputs of a diffusion model can still be generalized in different contexts. First, the method proposed in this research is applicable to both products and services. The dimensions used can vary depending on the product context, but the overall method will remain the same. Second, the method is independent of the regions or countries of interest. We illustrated how the definitions of the inputs can change depending on the market being studied, and how this adds value to traditional methods which assume only one definition. Third, the method is applicable to a variety of diffusion models; whether it's the Bass model, Generalized Bass model or a more informal drawing of an S-curve. The proposed method can add value by providing the researcher with an objective way of using theoretical perspectives and analogies. Finally the method is also independent of the theoretical perspectives used. Different perspectives could result in different dimensions, but the method of using the insights and translating them into inputs of a diffusion model will remain the same.

The method can also be generalized one step further by saying it is an illustration of how theoretical perspectives and analogies can be used to solve real world problems. Once the relevant theoretical perspectives and case studies have 
been the selected; (i) the first step is to categorize the problem based on the set of attributes described in the perspective, (ii) use the attributes to generate insights and possible dimensions from the available cases, (iii) find a model or simulation that can help you address the problem and (iv) incorporate the dimensions and insights into the model or simulation. By following these general recommendations an objective and quantitative solution to the problem may be obtained.

\subsection{Applicability of the Results}

The value captured in this research was examined and contributed to by our industry participants. Updates in the method and results were discussed in monthly meetings which constantly shaped the direction of the research.

When examining the results of the research and how these results impacted their daily decision making process they contributed the following:

- The proposed method has shown the importance of investing in market understanding; resources should be focused on a clear view of the social system and ceiling.

- Market research firms are skeptical about using diffusion models, but when making an investment decision, it is always necessary to have a quantitative analysis. This method allows for the combination of the objective mathematical analysis and the use of the relevant dimensions. 
- Using theoretical perspectives and available cases also provides accountability for the use of one set of inputs over another. The logic used to derive the forecast can become traceable and is not solely dependant on the experience of the researcher.

This study has made an academic contribution by providing a methodology that can be used to estimate market size when there is little or no available data. Existing literature has emphasized the use of analogies when there is a lack of data, but the proposed method takes it one step further by incorporating the use of theoretical perspectives. The results show that the use of theory can add significant value to traditional diffusion models. It has also contributed in establishing a specific set of circumstances for which this method is applicable; early stage markets for service deployment in developing nations.

This study has also made a contribution to existing business practices by providing a formal (i.e. traceable) methodology that can be used in early stage markets. When there is a lack of data, analysts rely heavily on previous experience and qualitative research. This study shows that a diffusion model can still be used to provide an objective and quantitative measure of market size. 


\section{Conclusions}

The objective of this research is to propose a method that can be used to estimate the size of early stage markets. The use of theoretical perspectives and available cases has been examined in order to add value to traditional literature methods of estimating market size. Incorporating theoretically generated dimensions into the inputs of a diffusion model has been shown to yield better results than the use of traditional dimensions alone. The method offers a repeatable and traceable approach to selecting the market dimensions, which makes any results more defensible.

The results and lessons learned from the proposed method are applicable to different diffusion models; since the method is not dependant on the diffusion model chosen. The key is that no matter what the model chosen is, the estimates will be enhanced by incorporating theoretical perspectives and available cases into its inputs. In some cases the construct dimensions not only enhanced the results, but they proved to be critical in yielding credible results. The proposed method can be used when abundant or convincing data are not available, as is the case of emerging markets. The method is also reusable across domains and regions and has been shown to be especially useful in the case of services in developing nations; since existing literature has focused on consumer durables in developed countries and has defined diffusion models and their inputs based on these findings. 
This research shows that by incorporating theoretical perspectives and examining available cases (i.e. using available cases as analogies), insights can be generated that lead to better definitions of the inputs of diffusion models. These definitions will depend on the availability of data and can be refined to produce a better understanding of the market being studied. When studying specific inputs, such as social system and ceiling, traditional literature has defined them the same way for developed and developing nations. The studies conducted in this research have shown that doing so can lead to a misrepresentation of the addressable market. The use of the construct dimensions allowed us to use the relevant definitions of the inputs and examine the drivers of adoption independently (i.e. traditional literature has defined a very low ceiling for Latin America, this yields an underestimation of market size, which leads to implausible forecasts). The use of the traditional ceiling, proposed for cell phone diffusion, may reject opportunities that may be accepted under the proposed method.

The construct dimensions provide a frame of reference, which is required to compare product adoption parameters. Since sample matching was performed; we can study the inputs to the model, both from the available cases and the ones derived for Latin America, and compare them. Countries can be ranked by their market potential and operators can be ranked by their coefficient of innovation. 
Although we are unable to show a quantitative comparison anchored around the control dimensions; based on the feedback provided by our industry participants and the results of the research, the use of theoretical perspectives does add value to their current market assessment approach.

By examining the cases of the available operators, instead of a country or technology as a whole, we have taken the first step in making the coefficient of innovation a function of the operator and the number of operators already in the market. For Japan, we have the same addressable market estimate, 3 similar services and three different coefficients of innovations. This could be a reflection of many things, including the operator's business model. Further research can make some important determinations on placing a value on an operator's innovativeness.

The cases of the Japanese operators lead us to believe that the method is most accurate for the operator with the highest percentage of market share. This is because the diffusion model used was developed to model technology adoption as a whole, so it does not acknowledge competition. The social system and ceiling give an estimate of market potential and then the model assumes one operator meeting the market demands. The result is an overestimation of actual adoptions for the second and third players in the market. 
Incorporating Crystal Ball allowed for the use of distributions, instead of single point estimates. The variance in the available cases was used to produce estimates of the parameters of the model with the potential to examine sensitivities.

The method proposed in this research is a top-down model, start out with the total population and divide it into segments (Day, 1980). An alternative model would be a bottom-up approach, in which you start out with a single customer and build on that profile. This type of model is applicable for highly segmented markets and has been used in "segment of one marketing" to achieve mass customization (Pine, 1993).

For the case in which the market is completely new and there are no cases available from which to derive insights. Theoretical perspectives can still be used to add value to the market analysis. Even in the most uncertain scenarios, it is still possible to identify the relevant variables that will determine how the market will evolve over time (Courtney et al., 1999). Favorable and unfavorable indicators can be identified and adapted as information becomes available. Tools such as pattern recognition and non linear dynamic models can be used to derive insights in these cases (Courtney et al., 1999). Analogous markets can be studied and the key attributes of the winners and losers can be identified (Senge, 1990). Mahajan, Muller and Bass, 1990 state that when there is no information available, one can still derive estimates by using management judgment and the 
diffusion of analogous products. The proposed method provides a traceable and objective view, instead of relying solely on previous experience. 


\section{Limitations and Future Research}

The following section outlines the limitations of the current research as well as suggestions for future research in the areas of early stage market involvement and global diffusion.

\subsection{Limitations}

The forecasts in this study were done for developing nations, although the majority of the case study data was for adoption in developed nations. There is potential to have excluded dimension that are only relevant for developing nations or to have included dimensions which are only applicable for developed nations. Since there are no cases of mobile payments in Latin America, a case study analysis of a similar service in the region could be relevant (e.g. ATM machines, debit cards).

This study focuses only on the depth of adoption and not on the breadth. Breadth is important when examining adoption in regions with similar social, cultural, political and economic values. Cross country learning effects is anticipated to play an important role in adoption for a region like Latin America. 


\subsection{Proposed Changes to the Method}

The following is a list of suggestions that could be used to improve the method used in this research:

- Provide additional documentation, which would include additional examples of how to apply the method in different contexts and regions.

- Split the initial sample into two different sub-samples, this would allow for the validation of the parameters obtained with a sub-sample using a different sub-sample.

- Exploit the functionality of Crystal Ball, include a sensitivity analysis of the dimensions, decision points and optimization of circumstances.

\subsection{Suggestions for Future Research}

Suggestions for future research anchored around the areas of early stage market involvement and diffusion model research include:

- Perform a coalition analysis in early stage strategic planning. This analysis would include the composition of the coalition that would create the most value for a player, when assessing early stage investment decisions, as well as the factors that affect value created versus value captured by a player. 
- Manipulate the existing analysis so that it can continue to accurately track the market life cycle (i.e. modify the method to better capture the experience of the subsequent entrants to the market).

- Create a categorization around the circumstances in which decision makers find themselves in when using diffusion models; this would contribute to normative theory building.

- Compare the results and lessons learned of this research when applying different diffusion models.

- Explore the dynamics of the dimensions used, such as the changes of the social system, S, and ceiling, C, over the study period. 


\section{References}

Adner, R. (2002). "When are Technologies Disruptive? A Demand-based View of the Emergence of Competition." Strategic Management Journal 23, 667-688.

Ashraf, M. (2005). "Using Theoretical Perspectives to Examine the Adoption of Mobile Internet and Wireless Payment Services." A Thesis Submitted to the Faculty of Graduate Studies and Research, Department of Systems and Computer Engineering, Carleton University, Ottawa.

Barney, J. B. (1991). "Firm Resources and Sustained Competitive Advantage." Journal of Management 17, 99-120.

Bogner, W.C. and P. Barr. (2000). "Making Sense in Hypercompetitive Environments: A Cognitive Explanation for the Persistence of High-Velocity Competition." Organization Science 11, 212-226.

Bass, F.M. (1969). "A New-Product-Growth Model for Consumer Durables." Management Science 15, 215-227.

Bass, F.M., and J. Wind. (1995). "Introduction to the Special Issue: Empirical Generalizations in Marketing." Marketing Science 14, G1-G5.

Bass, F.M., D.C. Jain, and T.V. Krishnan. (2000). "Modeling the Marketing-Mix Influence in New-Product Diffusion." In New Product Diffusion Models. Mahajan, V., E. Muller, Y. Wind, Kluwer Academic Publishers, 99-122.

Bass, F.M., T.V. Krishnan, and D.C. Jain. (1994). "Why the Bass Model Fits Without Decision Variables." Marketing Science 13, 203-223.

Black, F. and M. Scholes. (1973). "The Pricing of Options and Corporate Liabilities." Journal of Political Economy 81, 637-654.

Boyle, P.P. (1977). "Options: A Monte Carlo Approach." Journal of Financial Economics 4, 323-338.

Brandenburger, A.M., and B.J. Nalebuff. (1995). "The Right Game: Use Game Theory to Shape Strategy." Harvard Business Review 73, 57-71.

Broadie, M., and P. Glasserman. (1997). "Pricing American-Style Securities Using Simulation." Journal of Economic Dynamics and Control 21, 1323-1352.

Carlile, P.R., and C.M. Christensen (2005). "The Cycles of Theory Building in Management Research." January 6, version 6.0 http://www.innosight.com/documents/Theory\%20Building.pdf. 
Charnes, J.M., and B.R. Cobb (2003). "Documentation for Sprint/Nortel Networks Real Options Valuation Tool." A document submitted to the industry participant.

Chesbrough, H., and R.S. Rosenbloom. (2002). "The Role of the Business Model in Capturing Value from Innovation: Evidence from Xerox's Corporation Technology Spin-off Companies." Industrial and Corporate Challenge 11, 529-555.

Christensen, C.M. (1997). "The Innovator's Dilemma: When New Technologies Cause Great Firms to Fail." Boston: Harvard Business School Press.

Christensen, C. M., D. A, Scott, and A. R. Erik. (2004). "Seeing What's Next: Using Theories of Innovation to Predict Industry Change." Boston: Harvard Business School Press.

Cooper, R.G. and Edgett, S.J. (1996). "Critical Success Factors for New Financial Services: A Stage-Gate Approach Streamlines the New Product Development Process." Marketing Management 5, 26-37.

Courtney, H., J. Kirkland, and P. Viguerie. (1999). "Strategy Under Uncertainty." In Harvard Business Review on Managing Uncertainty. Harvard Business Review Paperback Series, Boston Harvard Business School Press, 1-31.

Cox, J.C., S.A. Ross, and M. Rubinstein. (1979). "Option Pricing: A Simplified Approach." Journal of Financial Economics 7, 229-263.

D'Aveni, R.A. (1994). "Hypercompetition: Managing the Dynamics of Strategic Maneuvering." New York: Free Press.

D'Aveni, R.A. (1995). "Coping with Hypercompetition: Utilizing the New 7s Framework." Academy of Management Executive 9, 45-57.

De Brentani, U., and E. Ragot. (1996). "Developing New Business-to-Business Professional Services: What Factors Impact Performance?" Industrial Marketing Management 25, 517-531.

Dekimpe, M.G., P.M. Parker, and M. Sarvary. (1998). "Staged Estimation of International Diffusion Models: An Application to Global Cellular Telephone Adoption." Technological Forecasting and Social Change 57, 105-32.

Dekimpe, M.G., P.M. Parker, and M. Sarvary. (2000a). "Globalization: Modeling Technology Adoption Timing Across Countries." Technological Forecasting and Social Change 63, 25-42. 
Dekimpe, M.G., P.M. Parker, and M. Sarvary. (2000b). "Global Diffusion of Technological Innovations: A Coupled-Hazard Approach." Journal of Marketing Research 37, 47-59.

Dekimpe, M.G., Parker, P.M., and M. Sarvary. (2000c) "Multimarket and Global Diffusion." In New Product Diffusion Models. V. Mahajan, E. Muller, and Y. Wind, Kluwer Academic Publishers, 49-73.

Dixit, A.K., and B.J. Nalebuff. (1991). "Thinking Strategically: The Competitive Edge in Business, Politics and Everyday Life." New York: W.W. Norton.

Dixit, A.K., and R.S. Pyndick. (1995). "The Options Approach to Capital Investment." Harvard Business Review 73, 105-115.

Dutta, S., Narasimhan, O. and Rajiv, S. (1999). "Success in High-Technology Markets: Is Marketing Capability Critical?" Marketing Science 18, 547-568.

Edvardsson, B., Haglund, L., and Mattsson, J. (1995). "Analysis, Planning, Improvisation, and Control in the Development of New Services." International Journal of Service Industry Management 6, 24-35.

Galbraith, J. (1973). "Designing Complex Organizations." Reading, MA: AddisonWesley.

Galbraith, J. (1974). "Organization Design: An Information Processing View." In: Organizational Psychology, David A. Kolb (ed.). Englewood Cliffs, NJ: Prentice Hall, 313-322.

Ganesh, J., and V. Kumar. (1996). "Capturing the Cross-National Learning Effect: An Analysis of an Industrial Technology Diffusion." Journal of the Academy of Marketing Science 24, 328-337.

Ganesh, J., V. Kumar, and V. Subramanian. (1997). "Learning Effect in Multinational Diffusion of Consumer Durables: An Exploratory Investigation." Journal of the Academy of Marketing Science 25, 214-228.

Gans, J. S., and S. Stern. (2003). "The Product Market and the Market of Ideas: Commercialization Strategies for Technology Entrepreneurs." Research Policy 32, 333-350.

Gatignon, H., J. Eliashberg, and T.S. Robertson. (1989). "Modeling Multinational Diffusion Patterns: An Efficient Methodology." Marketing Science 8, 231-247.

Geus, de A. (1988). "Planning as Learning." Harvard Business Review 66, 7074. 
Goldenberg, J., D. R. Lehman, and D. Mazursky. (2001). "The Idea Itself and the Circumstances of its Emergence as Predictors of New Product Success." Management Science 47, 69-84.

Gopalakrishnan, S., J.D. Wischnevsky, and F. Damanpour. (2003). "A Multilevel Analysis of Factors Influencing the Adoption of Internet Banking." IEEE Transactions on Engineering Management 50, 413-425.

Heeler, R.M., and T.P. Hustad. (1980). "Problems in Predicting New Product Growth for Consumer Durables." Management Science 26, 1007-1020.

Kalish, S. (1985). "A New Product Adoption Model with Pricing, Advertising and Uncertainty." Management Science 31, 1569-85.

Lievens, A. and Moenaert, R.K. (2000). "New Service Teams as InformationProcessing Systems: Reducing Innovative Uncertainty." Journal of Service Research 3, 46-65.

Luehrman, T.A. (1997). "What it's Worth." Harvard Business Review 75, 132143.

Mahajan, V., and E. Muller. (1994). "Innovation Diffusion in a Borderless Global Market: Will the 1992 Unification of the European Community Accelerate Diffusions of New ideas, Products and Technologies?" Technological Forecasting and Social Change 45, 221-237.

Mahajan, V., E. Muller, and F.M. Bass. (1990). "New-Product Diffusion Models in Marketing: A Review and Directions for Research." Journal of Marketing 54, 1-26.

Mahajan, V., and R. Peterson. (1979). "Integrating Time and Space in Technological Substitution Model." Technological Forecasting and Social Change 14, 231-241.

March, J.G. (1991). "Exploration and Exploitation in Organizational Learning." Organization Science 2, 71-87.

Merton, R.C. (1973). "The Theory of Rational Option Pricing." Bell Journal of Economics and Management Science 4, 141-183.

Moore, G. (1991). "Crossing the Chasm." New York: Harper Business.

National Internet Development Agency of Korea. (2004) "2004 Survey on the Wireless Internet Usage." Executive Summary 1-15. 
Parkinson, M. (1977). "Option Pricing: The American Put." Journal of Business $50,21-36$.

Rogers, E.M. (1983). "Diffusion of Innovations." New York: Free Press.

Rogers, E.M. (1995). "Diffusion of Innovation." 4th edition. New York: Free Press.

Schmittlein, D.C., and V. Mahajan. (1982). "Maximum Likelihood Estimation for an Innovation Diffusion Model of New Product Acceptance." Marketing Science 1, 57-78.

Schwartz, E.S. (1977). "Valuation of Warrants Implementing a New Approach." Journal of Financial Economics 4, 79-93.

Senge, P.N. (1990). "Fifth Discipline: The Art and Practice of the Learning Organization." New York: Doubleday.

Shapira, Z. (1997). "Introduction and Overview." In: Organizational Decision Making. Cambridge, UK: Cambridge University Press, 3-8.

Simon, H. (1994). "Marketing Science's Pilgrimage to the Ivory Tower." In Research Traditions in Marketing. G. Laurent, G. Lilien, and B. Pras, Kluwer Academic Publishers, 27-43.

Simon, H. (1997). "Administrative Behavior: A Study of Decision-Making Processes in Administrative Organizations." New York: Free Press.

Storey, C. and C. Easingwood. (1993). "The Impact of the New Product Development Project on the Success of Financial Services." Services Industry Journal, 13, 40-54.

Vanston, L., and R.L. Hodges. (2004). "Technology Forecasting for Telecommunications." Telektronikk 4, 32-42.

van Riel, A.C.R., J. Lemmink, and H. Ouwersloot. (2004). "High-Technology Service Innovation Success: A Decision-Making Perspective." The Journal of Product Innovation Management 21. 348-359. 


\section{Appendix A: Growth Rate Distributions}

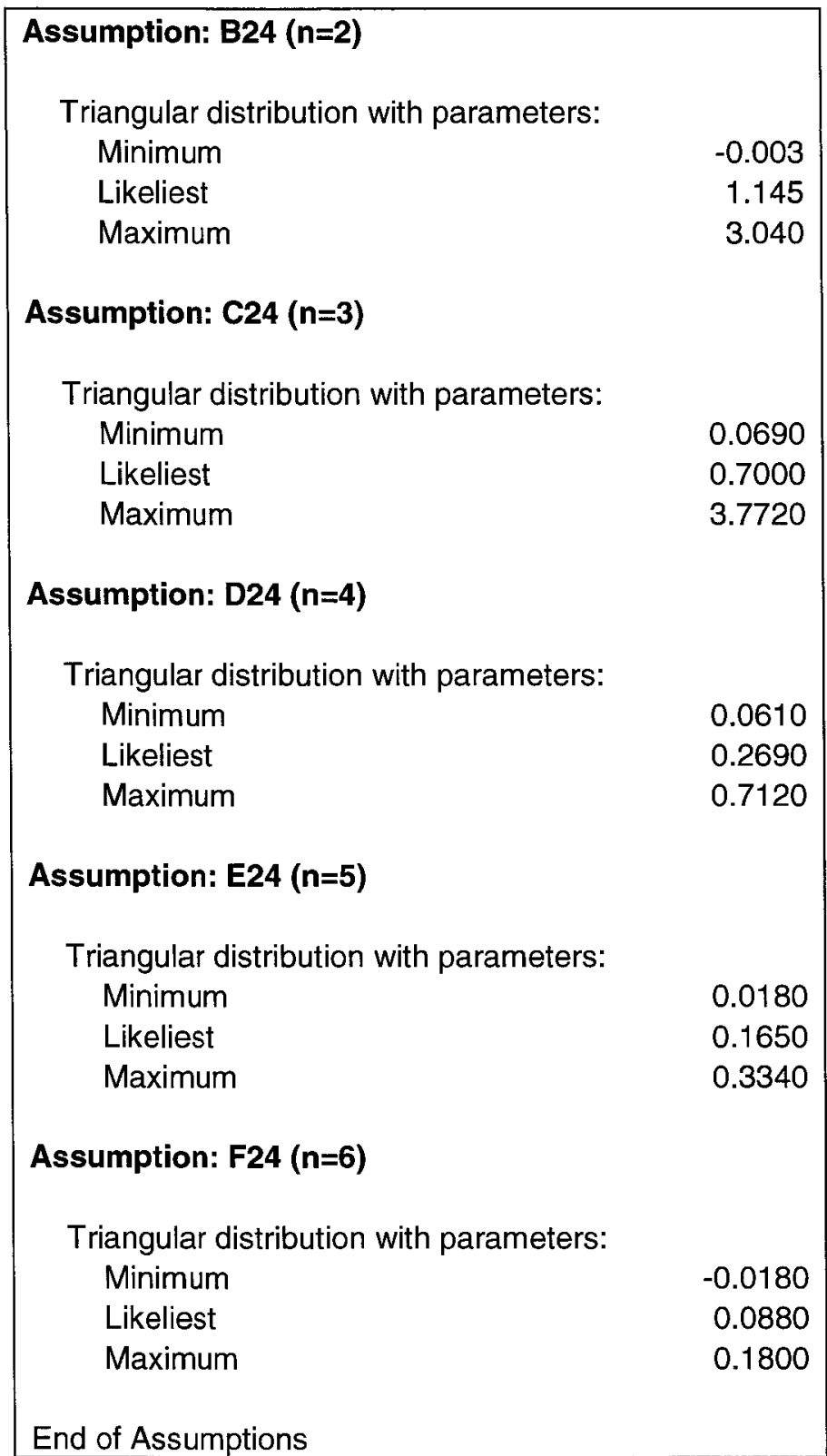


Appendix B: Example of Crystal Ball Results

Run preferences:

Number of trials run $\quad 1,000$

Extreme speed

Monte Carlo

Random seed

Precision control on

Confidence level $\quad 95.00 \%$

Run statistics:

Total running time (sec)

26.16

Trials/second (average)

38

Random numbers per sec

459

Crystal Ball data:

Assumptions

12

Correlations

0

Correlated groups

Crystal Ball Report - Full

Decision variables

Forecasts

0

0

54

Forecast: Construct

Forecasts

Summary:

Entire range is from 756,316 to $5,853,235$

Base case is 4,505,094

Statistics:

Trials

Forecast values

Mean

1,000

Median

$3,081,827$

Mode

Standard Deviation

$3,017,711$

$--$

Variance

937,724

$879,325,998,873$

Skewness

0.19

Kurtosis

2.66

Coeff. of Variability

0.30

Minimum

756,316

Maximum

$5,853,235$

Range Width

$5,096,919$

Mean Std. Error

29,653 


\begin{tabular}{|cl|}
\hline Forecast: Construct (cont'd) & \\
Percentiles: & \\
$0 \%$ & Forecast values \\
$10 \%$ & 756,316 \\
$20 \%$ & $1,900,819$ \\
$30 \%$ & $2,249,951$ \\
$40 \%$ & $2,529,742$ \\
$50 \%$ & $2,815,969$ \\
$60 \%$ & $3,017,711$ \\
$70 \%$ & $3,257,620$ \\
$80 \%$ & $3,586,605$ \\
$90 \%$ & $3,897,386$ \\
$100 \%$ & $4,337,450$ \\
& $5,853,235$ \\
\hline
\end{tabular}

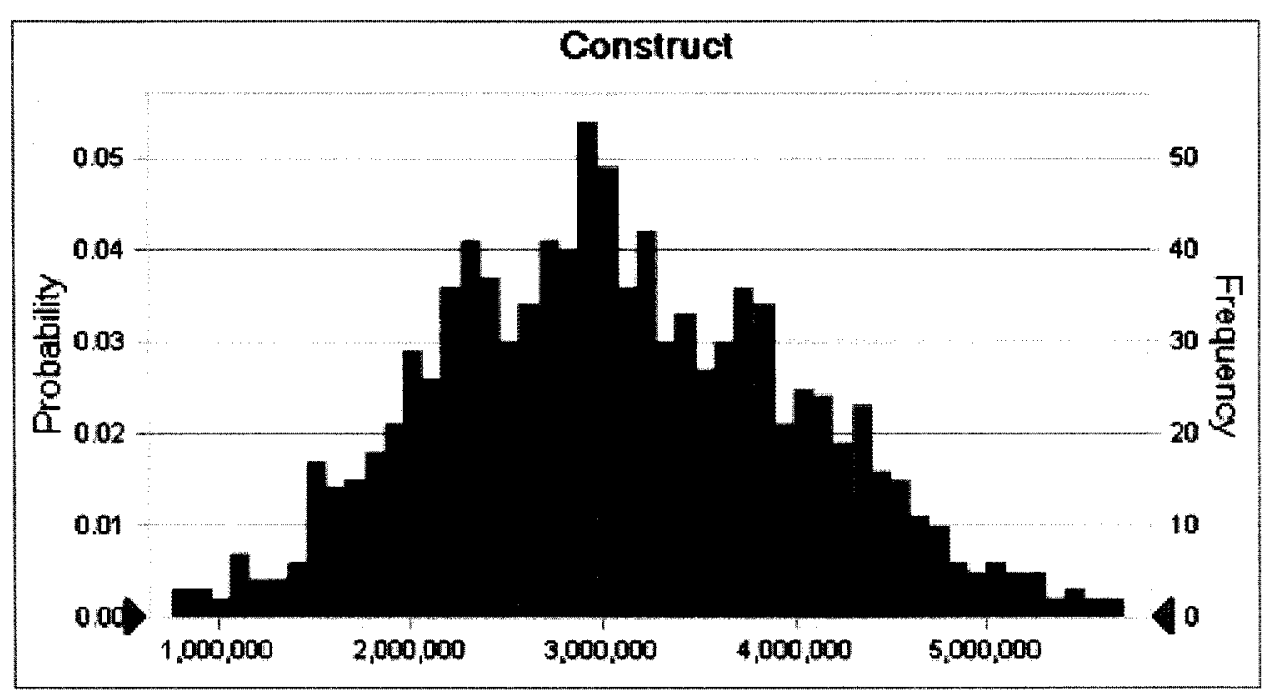

